UNIVERSIDADE DE SÃO PAULO

ESCOLA DE ENFERMAGEM

RODRIGO MARQUES DA SILVA

ALTERAÇÕES DE SAÚDE, RESILIÊNCIA E QUALIDADE DE VIDA DE DISCENTES DE GRADUAÇÃO EM ENFERMAGEM NO PRIMEIRO ANO LETIVO

SÃO PAULO

2017 


\title{
ALTERAÇÕES DE SAÚDE, RESILIÊNCIA E QUALIDADE DE VIDA DE DISCENTES DE GRADUAÇÃO EM ENFERMAGEM NO PRIMEI- RO ANO LETIVO
}

\begin{abstract}
Tese apresentada ao Programa de Pós-Graduação em Enfermagem na Saúde do Adulto (PROESA) da Escola de Enfermagem da Universidade de São Paulo (EEUSP-SP), como requisito parcial à obtenção do título de Doutor em Ciências.
\end{abstract}

Área de concentração: Enfermagem na Saúde do Adulto

Orientadora: Prof ${ }^{a}$. Dr ${ }^{\mathrm{a}}$. Ana Lucia Siqueira Costa

\section{VERSÃO CORRIGIDA}

A versão original encontra-se disponível na Biblioteca da Escola de Enfermagem da Universidade de São Paulo e na Biblioteca Digital de Teses e Dissertações da Universidade de São Paulo. 
AUTORIZO A REPRODUÇÃO E DIVULGAÇÃO TOTAL OU PARCIAL DESTE TRABALHO, POR QUALQUER MEIO CONVENCIONAL OU ELETRÔNICO, PARA FINS DE ESTUDO E PESQUISA, DESDE QUE CITADA A FONTE.

Assinatura:

Data:

Silva, Rodrigo Marques da

Alterações de saúde, resiliência e qualidade de vida de discentes de graduação em enfermagem no primeiro ano letivo / Rodrigo Marques da Silva. São Paulo, 2017.

$130 \mathrm{p}$.

Tese (Doutorado) - Escola de Enfermagem da Universidade de São Paulo.

Orientadora: Prof. Dr. Ana Lucia Siqueira Costa

Área de concentração: Enfermagem na Saúde do Adulto

1. Enfermagem. 2. Estudantes universitários. 3. Saúde mental. 4. Análise fatorial. I. Título. 
Nome: Rodrigo Marques da Silva

Titulo: Alterações de saúde, resiliência e qualidade de vida de discentes de graduação em enfermagem no primeiro ano letivo.

Tese apresentada ao Programa de Pós-Graduação em Saúde do Adulto da Escola de Enfermagem da Universidade de São Paulo para obtenção do título de Doutor em Ciências.

Aprovado em:

\section{Banca Examinadora}

Orientador: Prof. Dr.

Instituição: Assinatura:

Prof. Dr. Instituição:

Julgamento: Assinatura:

Prof. Dr. Instituição:

Julgamento: Assinatura:

Prof. Dr. Instituição:

Julgamento: Assinatura:

Prof. Dr. Instituição:

Julgamento: Assinatura:

Prof. Dr. Instituição:

Julgamento: Assinatura: 


\section{Dedicatória}

À Deus por ter guiado meus passos até o final desta etapa da minha carreira profissional;

Aos meus pais, por darem o suporte necessário durante os momentos de dificuldades, o que permitiu essa conquista.

Ao meu companheiro, por acreditar que tudo seria possível e ter a paciência necessária durante os períodos de angústia e afastamento. Sem ele nada disso teria sido realizado. 


\section{Agradecimentos}

À Professora Doutora Ana Lúcia Siqueira Costa, por acreditar em minha capacidade e conhecimento para conduzir um trabalho dessa magnitude com sucesso, apesar dos desafios. Sua acolhida em São Paulo, compressão e orientações nessa etapa de minha vida profissional foram indescritíveis. A você Ana, meu eterno agradecimento e admiração.

À Professora Dra . Margaret Heitkemper, pelo imenso carinho e comprometimento durante a revisão do trabalho no período em que estivemos juntos nos Estados Unidos e na avaliação do trabalho final no Brasil. O seu olhar atento e carinhoso fez diferença nesta pesquisa!

À Professora Dra ${ }^{\mathrm{a}}$. Laura de Azevedo Guido que, desde a graduação, guiou meus passos e decisões com carinho, honestidade e muito "penso", elementos sem os quais eu não chegaria até aqui. A você meu eterno agradecimento e admiração!

Ao CNPq, pela concessão de bolsa de doutorado, imprescindível para a realização do mesmo.

À minha família, pelo carinho e suporte quando as pedras se fizeram presentes no meu caminho.

Aos amigos, que entenderam minhas variações de humor e ausência em alguns momentos durante a condução.

A todos aqueles que contribuíram, direta ou indiretamente para a realização deste trabalho. 
Silva RM. Alterações de saúde, resiliência e qualidade de vida de discentes de graduação em enfermagem no primeiro ano letivo [tese]. São Paulo: Universidade de São Paulo, Escola de Enfermagem; 2017.

\section{RESUMO}

Introdução: Diferentes pesquisas apontam que os estressores acadêmicos podem impactar na saúde dos discentes de enfermagem. Por outro lado, sabe-se que alguns indivíduos são capazes de se adaptar a situações de adversidade (resiliência), apresentando melhores condições de saúde. No entanto, pouco se sabe se tais alterações estão relacionadas ao ingresso no curso superior, pois poucas pesquisas analisam tais alterações longitudinalmente, bem como as relações simultâneas entre os fenômenos de saúde e o papel da resiliência na melhoria da saúde dos discentes. Objetivos: identificar se ocorrem alterações na saúde, nos níveis de resiliência e na qualidade de vida de discentes após um ano do ingresso no curso de graduação em enfermagem; e analisar como se dão as relações simultâneas de causalidade entre estresse psicoemocional, sintomas depressivos, qualidade do sono e resiliência na explicação da qualidade de vida dos discentes um ano após o ingresso no curso. Método: Essa pesquisa organiza-se em duas etapas de abordagem quantitativa: metodológica (Calibração) e longitudinal. Na Fase 1, coletaram-se os dados com alunos do $2^{\circ}, 3^{\circ}$ e $4^{\circ}$ anos (respectivamente $4^{\circ}, 6^{\circ}$ e $8^{\circ}$ semestres) de uma universidade estadual de São Paulo. Na etapa seguinte, a coleta ocorreu com os alunos do $1^{\circ}$ ano $\left(1^{\circ}\right.$ e $2^{\circ}$ semestres de 2016) no início das aulas e ao final do ano letivo com os instrumentos já calibrados em duas universidades de São Paulo, uma estadual e outra federal. Nessas etapas, aplicaram-se os seguintes instrumentos: Formulário para caracterização sociodemográfica e acadêmica; Instrumento para Avaliação do Estresse em Discentes de Enfermagem, Center for Epidemiologic Studies Depression Scale, Índice de Qualidade de Sono de Pittsburgh; Escala de Resiliência de Wagnild \& Young; e o Instrumento de Avaliação de Qualidade de Vida. Utilizou-se a análise fatorial confirmatória para a calibração dos instrumentos e o teste ANOVA para modelos mistos para analisar as alterações de saúde, resiliência e qualidade de vida ao longo do ano letivo. A Modelagem de Equações Estruturais foi utilizada para compreender as relações de dependência entre as variáveis. Resultados: A estrutura fatorial e a consistência interna foram satisfatórias para explicar os fenômenos. 110 discentes participaram da calibração dos instrumentos e 117 compuseram a fase longitudinal em março e 100 em dezembro de 2016. Verificou-se aumento significativo do estresse psicoemocional em todos os domínios do instrumento; redução da duração e da qualidade subjetiva do sono; e aumento do estresse psicoemocional geral e dos sintomas depressivos. O modelo hipotetizado final presentou boa qualidade de ajuste e de resíduos. O estresse psicoemocional reduziu a qualidade do sono e aumentou a intensidade dos sintomas depressivos, os quais diminuíram a qualidade de vida direta e indiretamente (através do estresse). A resiliência reduziu os níveis de estresse e sintomas depressivos e melhorou a qualidade do sono. Conclusão: O ambiente acadêmico de enfermagem apresenta potencial para doenças, com impacto à qualidade de vida. O estresse psicoemocional é o preditor dos fenômenos analisados e a resiliência um fator protetor contra o estresse. Sugere-se que as instituições repensem seus elementos curriculares, promovam a resiliência e criem espaços de promoção à saúde dos alunos.

PALAVRAS-CHAVE: Enfermagem. Discentes de Enfermagem. Saúde Mental. Análise Fatorial. 
Silva RM. Health changes, resiliency and quality of life of nursing degree students after the first academic-year [thesis]. Sao Paulo: University of Sao Paulo, School of Nursing; 2017.

\begin{abstract}
Introduction: Several investigations highlight that academic stressors may impact on the health status of undergraduate nursing students. On other hand, the previous literature confirms that few individuals are able of adapting to adverse situations and, so, present a better health condition. However, it is not clear if the changes in health status are related to the nursing degree program once: few studies have longitudinally assessed health status changes; the simultaneous relations among health' phenomena; and the potential role of resilience on nursing students' health. Objectives: to identity if the health status, resilience and quality of life of nursing degree students change after the first academic-year; and to assess how the simultaneous relations of causality among psycho-emotional stress, depressive symptoms, sleep quality and resilience are arranged to explain the quality of life of nursing degree students after the first academic-year. Method: this research is organized in two phases, both of quantitative approach: Phase 1-methodologic (tools calibration) assessment; and Phase 2- longitudinal study. In the Phase 1 , data were gathered from students enrolled in the $2^{\text {nd }}, 3^{\text {rd }}$ and $4^{\text {th }}$ academic years (respectively $4^{\text {th }}, 6^{\text {th }}$, and $8^{\text {th }}$ semesters) of a state university of Sao Paulo. In the next phase, we gathered the data from $1^{\text {st }}$ year $\left(1^{\text {st }}\right.$ and $2^{\text {nd }}$ semesters of 2016) students at the starting of classes and one year after the first data collection with the calibrated instruments in two universities of Sao Paulo- one state and other federal. In these phases, we applied the following instruments: demographic and academic form; Instrument for stress evaluation in nursing students, Center for Epidemiologic Studies Depression Scale, Pittsburgh Sleep Quality Index; Connor-Davidson Resilience Scale; and the Instrument for Quality of Life Assessment. We used the confirmatory factor analysis to calibrate the instruments and the ANOVA for mixed models to assess the changes in health status across the first academic year. The Structural Equation Modelling was applied to evaluate the dependency relations among the variables. Results: the factorial structure and the internal consistency were satisfactory to explain the phenomena. 110 students attended the instruments' calibration phase. In the longitudinal phase, 117 students were included in March and 100 in December 2016. We found a significant increase of psycho-emotional stress in all instrument's domains; a decrease of duration and subjective quality of sleep; and an increase of general psychoemotional stress and depressive symptoms. The final hypothesized model showed good adjustment for quality and residues indexes. The psycho-emotional stress reduced the sleep quality and increased the depressive symptoms, which decreased the quality of life directly and indirectly (Through the stress). Resilience relieved the stress levels and the depressive symptoms and improved the sleep quality. Conclusion: the nursing academic environment has potential for illnesses, with impact on quality of life. The psycho-emotional stress is predictor of the assessed phenomenon and resilience is a protective factor against stress. We suggest that the teaching institutions rethink the curricular elements, promote the resilience and create spaces for students' health promotion.
\end{abstract}

KEYWORDS: Nursing. Nursing Students. Mental Health. Factor Analysis, Statistical. 


\section{LISTA DE ILUSTRAÇÕES}

Figura 1 - Modelo de diagrama de caminhos e suas representações gráficas São Paulo, 2016.

Figura 2 - Modelo Hipotético para o comportamento dos fenômenos da saúde na Fase 3 do Estudo. São Paulo, 2016.

Figura 3 - Procedimentos de coleta de dados. São Paulo, 2015.

Figura 4 - Distribuição dos discentes segundo o nível de estresse por fator do AEEE. São Paulo, 2016.

Figura 5 - Modelos de Mensuração para cada variável latente e suas respectivas variáveis observadas. São Paulo. 2016.

Figura 6 - Modelo Estrutural para o comportamento dos fenômenos da Saúde. São Paulo, 2016.

Figura 7 - Modelo de Mensuração do Instrumento de Avaliação de Estresse em Discentes de Enfermagem (AEEE). São Paulo, 2015.

Figura 8 - Modelo de Mensuração do Center for Epidemiologic Studies Depression Scale (CES-D). São Paulo, 2015.

Figura 9 - Modelo de Mensuração da Escala de Resiliência de Wagnild \& Young. São Paulo, 2015.

Figura 10 - Modelo de Mensuração do Instrumento de Avaliação de Qualidade de

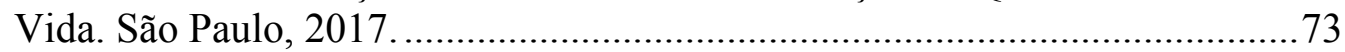

Figura 11 - Fluxo de Exclusão dos sujeitos de pesquisa. São Paulo, 2016..........................76

Figura 12 - Variação do nível de estresse psicoemocional por fator do AEEE em discentes de enfermagem após o primeiro ano letivo no curso de graduação. São Paulo, 2016.

Figura 13 - Qualidade de Sono reportada pelos discentes de enfermagem no Inventário de Qualidade do Sono de Pittsburg. São Paulo, 2016.

Figura 14 - Duração média do sono de discentes de enfermagem ao longo do ano letivo. São Paulo, 2016.

Figura 15 - Alteração dos níveis de estresse psicoemocional, sintomas depressivos, qualidade do sono, qualidade de vida e resiliência em discentes de enfermagem um ano após o ingresso no curso. São Paulo, 2016.

Figura 16 - Análise descritiva dos níveis de estresse psicoemocional geral nos discentes de enfermagem em março e dezembro de 2016.

Figura 17 - Modelos de Mensuração das variáveis latentes que compuseram o modelo estrutural inicial. São Paulo, 2016.

Figura 18 - Modelo estrutural inicial especificado em discentes de enfermagem. São Paulo, 2016.

Figura 19 - Modelos de Mensuração e Estrutural finais. São Paulo, 2016.

Figura 20 - Modelo estrutural final especificado em discentes de enfermagem. São Paulo, 2016. 


\section{LISTA DE QUADROS}

Quadro 1 - Elementos básicos utilizados no diagrama de caminhos. São Paulo, 2016. 


\section{LISTA DE TABELAS}

Tabela 1 - Índices de Ajuste e má qualidade de ajuste obtidas na análise fatorial confirmatória do Instrumento para Avaliação de Estresse em Discentes de Enfermagem. São Paulo, 2015..................................................68

Tabela 2 - Índices de Ajuste e má qualidade de ajuste obtidas na análise fatorial confirmatória do Center for Epidemiologic Studies Depression Scale (CES-D). São Paulo, 2015

Tabela 3 - Índices de Ajuste e má qualidade de ajuste obtidos para o Instrumento para a Escala de Resiliência de Wagnild \& Young. São Paulo, $2015 .$.

Tabela 4 - Índices de Ajuste e má qualidade de ajuste obtidos para o Instrumento de Avaliação de Qualidade de Vida (WHOQOL-BREF). São Paulo, 2015.

Tabela 5 - Valores de Alfa de Cronbach para os instrumentos analisados na Fase 1 da pesquisa. São Paulo, 2015.

Tabela 6 - Caracterização sociodemográfica dos discentes de enfermagem em Marco e Dezembro de 2016. São Paulo, 2016.

Tabela 7 - Características acadêmicas dos discentes de enfermagem em Marco e Dezembro de 2016. São Paulo, 2016.

Tabela 8 - Análise descritiva dos níveis de estresse psicoemocional geral nos discentes de enfermagem em março e dezembro de 2016. São Paulo, 2016.

Tabela 9 - Variação dos escores por domínio do CES-D, IQSP, WHOQOLBREF e Escala de Resiliência em discentes de enfermagem. São Paulo, 2016.

Tabela 10 - Índices de Ajuste e má qualidade de ajuste obtidos para o Modelo Estrutural hipotetizado inicial. São Paulo, 2016.

Tabela 11 - Índices de Ajuste e má qualidade de ajuste obtidos para o Modelo Estrutural final. São Paulo, 2016. 88

Tabela 12 - Regressão Linear para as relações de mediação e moderação presentes no modelo estrutural especificado em discentes de enfermagem. São Paulo, 2016. 


\section{SUMÁRIO}

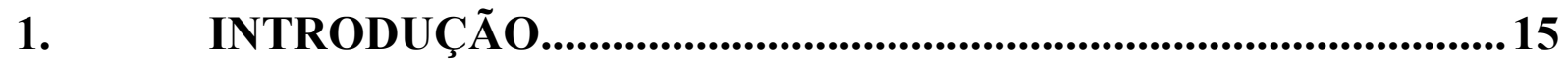

2. MODELAGEM DE EQUAÇÕES ESTRUTURAIS .......................20

2.1 CONCEITOS E APLICAÇÕES.............................................................................21

2.2 REPRESENTAÇÃO GRÁFICA DOS MODELOS DE MENSURAÇão E ESTRUTURAL -DIAGRAMA DE CAMINHOS ...............................................22

2.3 FASES DA MODELAGEM DE EQUAÇÕES ESTRUTURAIS .......................24

3. REVISÃO DE LITERATURA ………………................................27

4. QUESTÕES DE PESQUISA .............................................................41

5. OBJETIVOS …............................................................................... 43

6. HIPÓTESES DE PESQUISA ..............................................................45

6.1 FASE 1- CALIBRAÇÃO DOS INSTRUMENTOS ............................................46

6.2 FASE 2- ALTERAÇÕES NA SAÚDE, RESILIÊNCIA E QUALIDADE DE VIDA E EFEITO DOS FENÔMENOS DE SAÚDE SOBRE A QUALIDADE

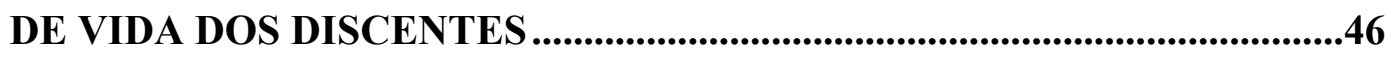

6.2.1 Avaliação das Alterações na Saúde, Resiliência e Qualidade de Vida .............46

6.2.2 Análise do efeito dos fenômenos de saúde sobre a qualidade de vida dos

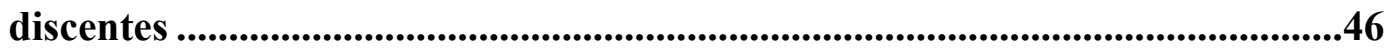

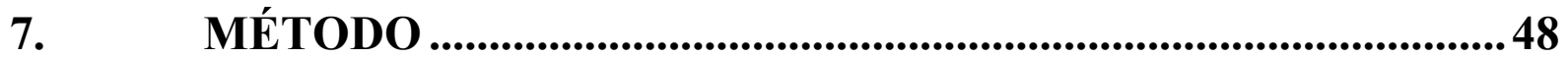

7.1 FASE 1- CALIBRAÇÃO DOS INSTRUMENTOS ..................................49

7.1.1 Delineamento do Estudo .............................................................................49

7.1.2 Local e População de Estudo .........................................................................50

7.1.3 Critérios de Inclusão/Exclusão .................................................................50

7.1.4 Coleta de dados e instrumentos ...................................................................50

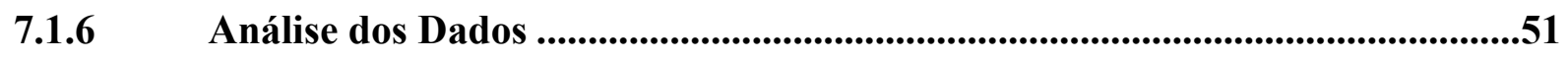

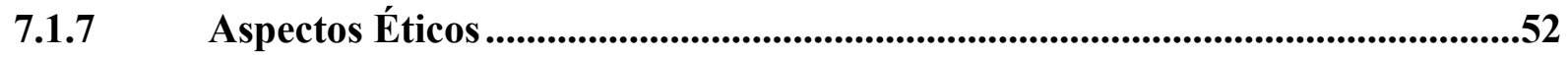

7.2 FASE 2- ALTERAÇÕES NA SAÚDE, RESILIÊNCIA E QUALIDADE DE VIDA E AVALIAÇÃO DAS RELAÇÕES SIMULTÂNEAS DE CAUSALIDADE ENTRE ESTRESSE PSICOEMOCIONAL, SINTOMAS DEPRESSIVOS, QUALIDADE DO SONO E 
RESILIÊNCIA NA EXPLICAÇÃO DA QUALIDADE DE VIDA DOS DISCENTES DE ENFERMAGEM. .53

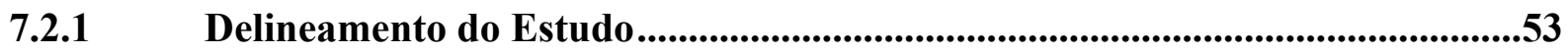

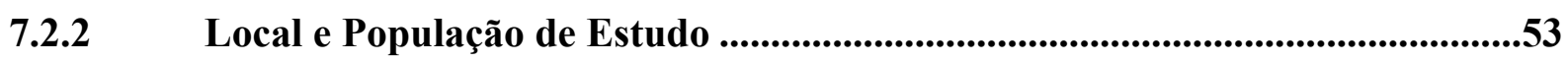

7.2.3 Critérios de Inclusão/Exclusão .....................................................................54

7.2.4 Variáveis do Estudo ..................................................................................54

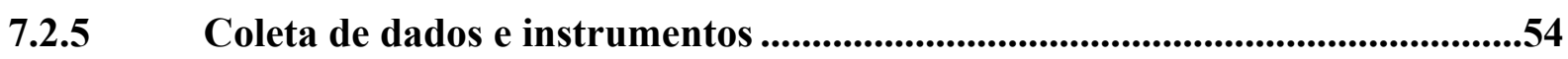

7.2.5.1 Formulário para caracterização sociodemográfica e acadêmica ....................56

7.2.5.2 Instrumento para Avaliação de Estresse em Discentes de Enfermagem

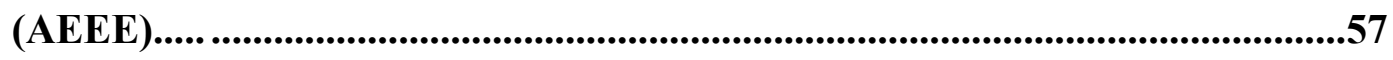

7.2.5.3 Center for Epidemiologic Studies Depression Scale (CES-D) ...........................58

7.2.5.4 Índice da Qualidade do Sono de Pittsburgh (IQSP) ............................................58

7.2.5.5 Escala de Resiliência de Wagnild \& Young..................................................59

7.2.5.6 Instrumento de Avaliação de Qualidade de Vida (WHOQOL-Bref) .................60

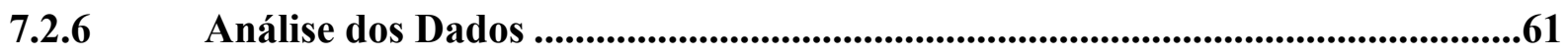

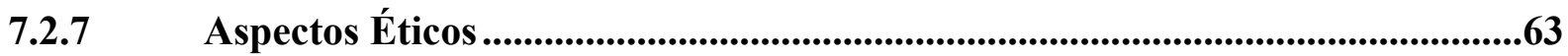

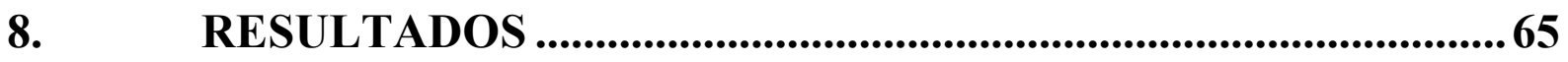

8.1 CALIBRAÇÃO DOS INSTRUMENTOS ........................................66

8.2 AVALIAÇÃO DAS ALTERAÇÕES NA SAÚdE, RESILIÊNCIA E QUALIDADE DE VIDA ......................................................................76

8.3 EFEITO DOS FENÔMENOS DE SAÚDE SOBRE A QUALIDADE DE VIDA DOS DISCENTES DE ENFERMAGEM

9. DISCUSSÃ

9.1 CALIBRAÇÃO DOS INSTRUMENTOS ............................................93

9.2 AVALIAÇÃO DAS ALTERAÇÕES NA SAÚdE, RESILIÊNCIA E QUALIDADE DE VIDA ......................................................................95

9.3 EFEITO DOS FENÔMENOS DE SAÚDE SOBRE A QUALIDADE DE VIDA DOS DISCENTES DE ENFERMAGEM ..................................99

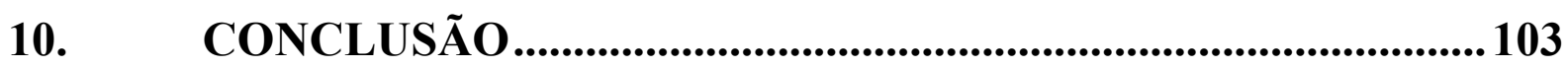

11. RECOMENDAÇÕ 


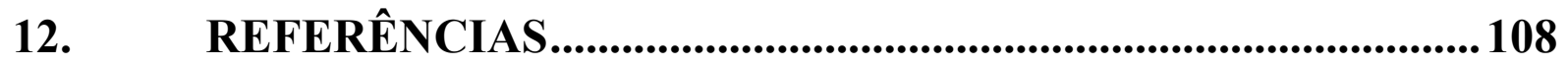
APÊNDICES ...........................................................................117 APÊNDICE A- FORMULÁRIO PARA CARACTERIZAÇÃo SOCIODEMOGRÁFICA E ACADÊMICA DOS DISCENTES..........118

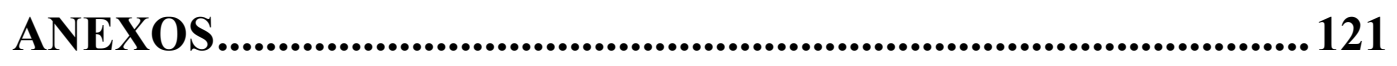
ANEXO 1- INSTRUMENTO PARA AVALIAÇÃO DE ESTRESSE EM DISCENTES DE ENFERMAGEM (AEEE) ............................................ 122 ANEXO 2- CENTER FOR EPIDEMIOLOGIC STUDIES DEPRESSION SCALE (CES-D) .............................................................123 ANEXO 3 - ÍNDICE DE QUALIDADE DO SONO DE PITTSBURGH

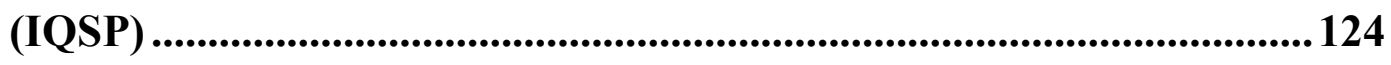
ANEXO 4- ESCALA DE RESILIÊNCIA DE WAGNILD \& YOUNG 126

ANEXO 5- INSTRUMENTO DE AVALIAÇÃO DE QUALIDADE DE VIDA (WHOQOL-BREF) 128 
1. INTRODUÇÃ̃O 


\section{INTRODUÇÃO}

O período em que o discente está matriculado no curso de graduação em enfermagem corresponde a uma etapa importante para formação profissional do enfermeiro, pois é quando o discente convive com a realidade desse profissional e as demandas dos serviços de saúde. Além disso, é preciso que o discente atenda as exigências curriculares e gerencie seu tempo para manter suas relações sociais e familiares.

Nesse contexto, tais discentes convivem com situações características da profissão e do contexto acadêmico que podem ser avaliadas como estressoras ${ }^{(1)}$. Em nível nacional, evidenciam-se, como potenciais estressores do ambiente acadêmico, as situações relativas ao período de provas, às tarefas extraclasses; e à transição da fase pré-universitária para o meio acadêmico $^{(2)}$. Adicionalmente, estudos internacionais destacam, como estressores, as atividades acadêmicas vivenciadas nos primeiros 12 meses de ingresso na faculdade; as experiências traumáticas de morte; responsabilidade para com o cuidado do outro; exigências quanto ao desempenho e relações interpessoais; e o sentimento de despreparo para as funções a serem exercidas nos campos de estágio e aulas práticas ${ }^{(3-4)}$. Além disso, verificam-se relatos da dificuldade de gerenciar o tempo para atender as demandas acadêmicas e conciliá-las às atividades pessoais e sociais como um estressor frequente entre os alunos ${ }^{(2,5-6)}$.

Tendo em vista o panorama identificado por diferentes pesquisas quanto aos estressores do ambiente acadêmico, é possível refletir sobre as repercussões à saúde dos discentes de enfermagem, o que inclui maiores níveis de estresse; aumento dos sintomas depressivos; e queda na qualidade do sono, com impacto à qualidade de vida. Nesse sentido, as pesquisas na área têm enfatizado diferentes situações preditoras de desgaste em discentes de enfermagem, dentre as quais, o ambiente universitário ${ }^{(7)}$, a carga de atividades e as tarefas relacionadas ao curso de graduação, à falta de conhecimentos e habilidades profissionais, à relação com professores e o ambiente clínico ${ }^{(8-9)}$.

Quanto ao estresse, conceituado como qualquer estímulo que demande do ambiente externo ou interno e que taxe ou exceda as fontes de adaptação de um indivíduo ou sistema social $^{(10)}$. Na presente pesquisa, esse fenômeno será compreendido no âmbito psicoemocional, ou seja, como a sensação subjetiva comumente experienciado na conjunção entre os sntimentos de estresse e de alterações de saúde. Sua ocorrência entre discentes de enfermagem já têm sido verificada em diferentes estudos ${ }^{(2,11-12)}$. Entre eles, uma pesquisa com 130 discentes de enfermagem do sul do Brasil verificou que 9,23\% apresentaram alto nível de estresse e $67,69 \%$ em médio nível de estresse ${ }^{(12)}$. Em pesquisa com 129 discentes de enfermagem de 
São Paulo, identificou-se que $24,6 \%$ dos alunos do $2^{\circ}$ ano e $25 \%$ dos alunos do $3^{\circ}$ ano apresentavam nível alto de estresse ${ }^{(11)}$. Ao analisar as relações entre o estresse e suas repercussões à saúde, estudos apontam correlação estatisticamente significativa entre estresse e sintomas depressivos ${ }^{(13-14)}$; alterações na qualidade do sono ${ }^{(15)}$; e qualidade de vida ${ }^{(16)}$.

Os sintomas depressivos podem levar ao sofrimento e a prejuízos sociais e ocupacionais importantes e, junto a avaliação clínica, podem configurar o transtorno depressivo, que é a quarta maior causa incapacitante no mundo ${ }^{(17)}$. Essa sintomatologia é avaliada com ênfase nos componentes afetivos e comportamentais, que incluem: humor deprimido; sentimentos de culpa e inutilidade; sensação de falta de suporte e desesperança; retardo psicomotor; perda de apetite; e distúrbios do sono ${ }^{(18)}$. Em estudo com uma amostra de 729 discentes de uma universidade dos EUA, 16,5\% apresentaram tais sintomas, 30,6\% depressão moderada e 23,2\% depressão severa ou moderadamente severa ${ }^{(19)}$. Em pesquisa conduzida com discentes do ensino médio na China, $6,4 \%$ deles possuíam tais sintomas ${ }^{(20)}$. Sobre a relação entre estresse e sintomas depressivos, essa foi verificada com significância estatística em pesquisa desenvolvida com aproximadamente 5000 discentes universitários canadenses, de forma que maiores níveis de estresse implicaram em maiores taxas de sintomas depressivos ${ }^{(21)}$. Além disso, alguns pesquisadores referem os sintomas depressivos como preditores da baixa qualidade do sono. Esta mesma associação foi verificado em pesquisa com 3186 discentes chineses na qual se observou que os alunos com sintomas depressivos possuíam 2,47 vezes mais chance de apresentar alterações na qualidade do sono ${ }^{(20)}$.

Da mesma forma que o estresse e os sintomas depressivos, a qualidade do sono também pode impactar negativamente na saúde dos discentes de enfermagem. Esse fenômeno é de especial importância entre os profissionais de saúde e discentes, enquanto futuros profissionais, pois a falta de um sono reestabelecedor contribui significativamente para os erros na assistência em saúde ${ }^{(22)}$. A ocorrência da baixa qualidade do sono foi verificada em $60 \%$ dos discentes analisados em uma pesquisa realizada em Chicago ${ }^{(15)}$ e em $71 \%$ dos discentes de outra investigação conduzida na Califórnia ${ }^{(23)}$, ambos de cursos universitários. Sobre as consequências da má qualidade do sono, pesquisa com 1074 discentes universitários do estado do Texas (EUA) verificou que o grupo que reportou insônia apresentava menores escores de qualidade do sono, bem como maiores escores de sintomas depressivos e ansiedade ${ }^{(24)}$. Em outra pesquisa com 35 discentes universitários também realizada no estado do Texas (EUA), foi verificado que as alterações no padrão do sono causam aumento dos sintomas depressivos ${ }^{(25)}$. Pesquisa realizada na Índia com 750 discentes de enfermagem verificou que discentes com 
melhor qualidade do sono apresentavam menos insônia e depressão, com capacidade de estudar por maior período diariamente ${ }^{(22)}$. No contexto brasileiro, verifica-se, em pesquisa realizada entre 49 universitários de uma instituição privada de São Paulo, correlação significativa e negativa entre a qualidade do sono e os escores de sintomas depressivos ${ }^{(26)}$. Dessa maneira, verifica-se que as manifestações neuroendócrinas do estresse levam à menor qualidade do sono e à sintomatologia depressiva nos discentes, além de a baixa qualidade do sono relacionar-se ao aumento dos sintomas depressivos, com impacto à qualidade de vida.

A qualidade de vida é definida, pela Organização Mundial de Saúde (OMS) no Projeto World Health Organization Quality of Life Instrument (WHOQOL), como o entendimento do indivíduo sobre sua própria percepção de vida, com base no contexto cultural e de valores em que estão inseridos, bem como, sua relação com os objetivos, expectativas, padrão e preocupações $^{(27)}$. Esse impacto foi verificado em pesquisa realizada com 800 discentes de medicina, no qual a sonolência diurna esteve associada à queda dos escores físico, psicológico e ambiental da qualidade de vida ${ }^{(28)}$. Ainda, em investigação com 1074 discentes universitários, aqueles com insônia crônica reportaram menor qualidade de vida ${ }^{(24)}$.

Com base no exposto, verifica-se que, ao ingressar na instituição de ensino superior, o discente de enfermagem fica exposto a diferentes situações estressoras, o que pode levar a alterações na saúde, com: maiores níveis de estresse psicoemocional, aumento de sintomas depressivos e queda na qualidade do sono. Por consequência, espera-se impacto negativo à qualidade de vida desses indivíduos. Por outro lado, mesmo frente a um ambiente potencialmente estressor, alguns indivíduos podem apresentar baixos níveis de estresse e, assim, menor chance de sofrerem impactos negativos à sua saúde ${ }^{(29-31)}$. Essa habilidade de o indivíduo se recuperar das adversidades e se adaptar positivamente a situações da vida é denominada resiliência ${ }^{(31)}$.

Tal fenômeno é compreendido como um processo dinâmico em que aspectos emocionais, socioculturais, ambientais e cognitivos interatuam e permitem que o ser humano enfrente, vença, fortaleça e se transforme a partir de experiências de adversidade e estresse ${ }^{(32-33)}$. Dessa forma, a resiliência tem sido entendida como uma habilidade individual capaz de promover a saúde e, assim, minimizar o estresse, a ansiedade, os sentimentos de raiva e os sintomas depressivos ${ }^{(32-33)}$. Assim, observa-se o aumento do interesse na resiliência por parte de pesquisadores e indivíduos que atuam no setor de saúde como reflexo da necessidade de investimento em prevenção de problemas e promoção da saúde mental ${ }^{(31)}$. A exemplo disso, em estudo longitudinal realizado com 1321 discentes de medicina de cinco estados norte- 
americanos, foi verificado que os indivíduos resilientes apresentaram menores escores de estresse psicoemocional e sintomas depressivos, bem como melhor qualidade de vida ${ }^{(29)}$. Em outra pesquisa realizada com 2069 discentes de medicina de três universidades chinesas, foi identificado que a resiliência exerceu efeito moderador sobre os problemas de saúde dos alu$\operatorname{nos}^{(30)}$. Embora tenham sido apresentadas diferentes pesquisas que compõem uma revisão narrativa elaborada pelo autor da presente pesquisa, alguns aspectos não estão claramente descritos e analisados na literatura nacional e internacional e, constitui-se, portanto, como lacunas na produção do conhecimento, a ser:

- a análise longitudinal da saúde após o ingresso no curso de graduação em enfermagem. Assim, será possível compreender quais são as alterações ocorridas na saúde do discente relacionadas à fase inicial do curso de graduação.

- Estudo da resiliência em discentes universitários são escassos no Brasil, em especial em discentes de enfermagem. Uma vez que esse fenômeno seja compreendido no ambiente universitário, será possível desenvolver e adotar ações para promovê-lo e assim, minimizar os riscos à saúde do discente.

- as relações simultâneas de causalidade entre estresse psicoemocional, sintomas depressivos, qualidade do sono, qualidade de vida e resiliência dos discentes de enfermagem durante a fase de formação. Assim, será possível identificar os preditores das alterações na saúde dos discentes e, futuramente, estabelecer intervenções sobre eles para melhoria da saúde, resiliência e qualidade de vida. Isso permitirá a formação de profissionais mais saudáveis e preparados para os desafios do mercado de trabalho, pois as intervenções podem ocorrer ainda durante a formação

- embora a baixa qualidade do sono apresente impacto negativo a saúde, representada pelas alterações físicas (sobrepeso/obesidade); cognitivas (redução da atenção e memória); e emocionais (alterações de humor e estresse psicoemocional), o que pode levar a queda no desempenho acadêmico, poucos estudos avaliam esse fenômeno em jovens adultos em fase de formação acadêmica, especialmente no Brasil.

- poucos estudos já foram realizados com Modelagem de Equações Estruturais (MEE) na enfermagem, método esse que permite, além de analisar um grupo de relações simultâneas de dependência, testar modelos teóricos criados pelo pesquisador a partir da experiência empírica e postulados teóricos. Assim, a modelagem permite compreender como um grupo de fenômenos se inter-relaciona na explicação de um dado desfecho em saúde. 
2. MODELAGEM DE EQUAÇÕES ESTRUTURAIS 


\section{MODELAGEM DE EQUAÇÕES ESTRUTURAIS}

\subsection{CONCEITOS E APLICAÇÕES}

A análise multivariada possibilita levantar questões de pesquisa específica e precisas de considerável complexidade em ambientes naturais. Isso viabiliza a construção de pesquisas teoricamente importantes e a avaliação de efeitos de variações paramétricas que naturalmente ocorrem, com base nos cenários onde eles acontecem. Assim, define-se análise multivariada como os métodos que, simultaneamente, analisam diferentes medidas sobre cada indivíduo ou objeto investigado $^{(34-35)}$.

A MEE é uma técnica de análise multivariada que combina a análise fatorial confirmatória e de regressão e é aplicada a resolução de problemas práticos a partir da testagem de modelos complexos, com múltiplas variáveis simultâneas e traços latentes ${ }^{(34)}$. Dessa maneira, um modelo teórico pode ser testado a partir de um modelo hipotético composto por um grupo de variáveis que explica os constructos e como esses construtos estão relacionados entre si $^{(36)}$.

Nesse modelo, um conjunto de informações são obtidas em um estudo empírico a fim de validar um conjunto de relações entre constructos por meio da imposição de parâmetros nas matrizes. As variáveis latentes, também chamadas de constructos, fatores ou variáveis indiretamente observáveis, são aquelas que não podem ser medidas ou avaliadas diretamente. Assim, elas são inferidas a partir de um grupo de variáveis medidas diretamente, por meio de testes, instrumentos, escalas ou entrevistas, denominadas variáveis observadas ou diretamente observáveis ${ }^{(34,36)}$.

Todo o modelo hipotético será composto pelas variáveis supracitadas e dividido em modelo de mensuração e estrutural. A relação entre cada variável latente e suas respectivas variáveis observadas constitui o que se denomina Modelo de Mensuração e as relações dos constructos (variáveis latentes) entre si constitui o Modelo Estrutural ${ }^{(36)}$. Neste último, as variáveis endógenas são aquelas determinadas pelo sistema de equações, ou seja, sofrem ação de outras variáveis em estudo. Já as exógenas, são determinadas por elementos ou fatores externos ao sistema ou modelo hipotetizado, sem influência de nenhuma variável do modelo ${ }^{(34)}$.

Ao se estabelecer um modelo estrutural de relações, cada variável irá desempenhar uma função hipotética, quais sejam: predição (independente), desfecho (dependente), mediação ou moderação. As primeiras são aquelas que não são influenciadas por nenhuma outra variável do modelo e as últimas recebem influência de pelo menos uma variável em estudo ${ }^{(36)}$. 
A variável mediadora é aquela que age como interveniente entre duas variáveis numa relação, ou seja, ela recebe influência da variável independente e influencia a variável dependente ${ }^{(37-}$

38). Sua inserção na equação estrutural neutraliza (Mediação total) ou reduz (Mediação parcial) o efeito da variável independente sobre a dependente ${ }^{(37)}$. Para confirmar a mediação, é preciso comparar o efeito direto entre variável independente e dependente com o impacto da variável independente sobre a variável dependente na existência da mediadora obtido pelo produto dos seus efeitos (independente $\rightarrow$ mediadora X mediadora $\rightarrow$ dependente) ${ }^{(38-39)}$. Se não houver relação direta significativa entre variável independente e dependente, a mediação não ocorre, pois não é possível comprar o efeito direto e mediado entre preditor e desfecho. Nesse caso, tem-se um efeito indireto que é aquele em que uma variável impacta sobre a outra, com uma terceira variável (ou mais) no meio dessa relação ${ }^{(37)}$. Variável moderadora, seja qualitativa ou quantitativa, é aquela que, quando inserida na equação, afeta a direção e/ou a forma e/ou a força da relação entre a variável independente e a dependente ${ }^{(37)}$.

\subsection{REPRESENTAÇÃO GRÁFICA DOS MODELOS DE MENSURAÇÃO E ESTRUTURAL -DIAGRAMA DE CAMINHOS}

O modelo hipotético (estrutural e de mensuração) é descrito na forma de um diagrama de caminhos, que, portanto, é composto por elementos gráficos que irão explicar a forma pela qual as variáveis inseridas no modelo interagem entre si, o que explica o(s) desfecho(s) em questão ${ }^{(34,36)}$.

As variáveis observadas são representadas por retângulos enquanto os constructos/fatores são apresentados de forma oval. Em modelos reflexivos, as setas são emitidas dos fatores em direção as variáveis observadas uma vez que todos essas últimas compartilham a mesma base conceitual e são conjuntamente modificadas quando um item é excluído. Quanto ao modelo estrutural, utilizam-se setas retilíneas unidirecionais a fim de indicar relação de causa- efeito, cuja origem é localizada na variável independente e a extremidade na variável dependente. As setas retas bidirecionais apontam uma relação não-recursiva entre as variáveis latentes, ou seja, uma relação mutua e reciproca. As setas curvilíneas bidirecionais (ou linha sem a ponta da seta) são utilizadas quando a finalidade for demonstrar correlação e covariância entre duas variáveis exógenas $^{(34,40-41)}$ (Quadro 1). 
Quadro 1- Elementos básicos utilizados no diagrama de caminhos. São Paulo, 2016.

\begin{tabular}{|l|c|}
\hline Descrição & Elemento Básico \\
\hline Variável Latente ou constructo & \\
\hline Variável Observada ou indicadora & \\
\hline Relação causal direta entre duas variáveis & \\
\hline Relação mútua entre duas variáveis latentes & \\
\hline Correlação entre duas variáveis latentes exógenas & \\
\hline Erro de Mensuração da variável observada & \\
\hline Erro de Mensuração da Variável latente & \\
\hline
\end{tabular}

Fonte: Silva RM. Alterações de saúde, resiliência e qualidade de vida de discentes de graduação em enfermagem no primeiro ano letivo [Tese]. São Paulo: EEUSP; 2016.

As variáveis endógenas são aquelas que recebem flechas de outras variáveis. Já as exógenas apenas emitem flechas. Quando uma variável recebe e emite flechas ao tempo, tem-se uma variável mista. Em se tratando de variável moderadora, é importante atentar para o tipo de seta utilizada, que, nesse caso deverá ser tracejada ${ }^{(34,40)}$ (Figura 1).

O erro associado de cada variável observada, ou seja, a variância decorrente de erros na coleta de dados ou na medida de dada variável, é representado pela letra "e" no centro de um círculo. Quando o erro associado for relativo ao fator, substitui-se a letra "e" pela letra "d"(34). As setas bidirecionais curvas entre duas variáveis observadas indicam que foi necessário proceder o controle de erro, o que ajuda a corrigir o modelo e melhorar os indicadores de ajuste (Figura 1).

Figura 1- Modelo de diagrama de caminhos e suas representações gráficas São Paulo, 2016.

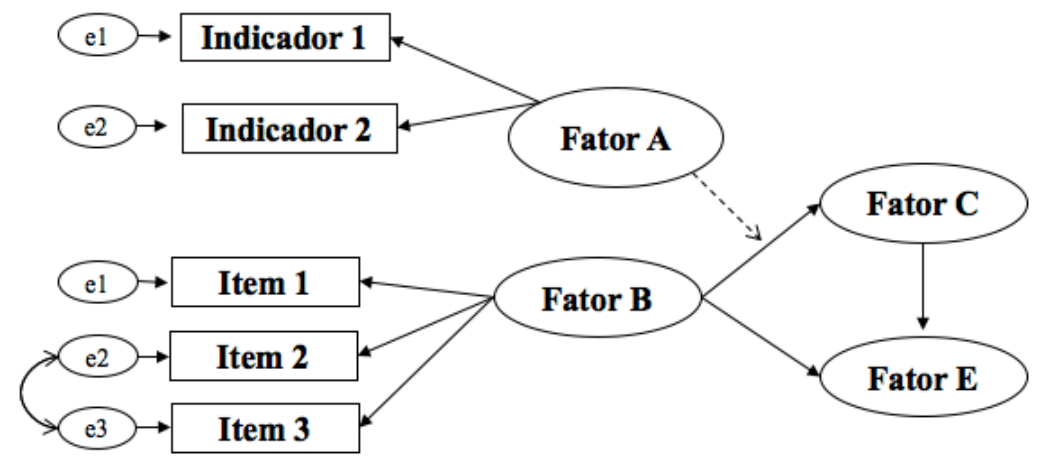

Fonte: Silva RM. Alterações de saúde, resiliência e qualidade de vida de discentes de graduação em enfermagem no primeiro ano letivo. [Tese]. São Paulo: EEUSP; 2016. 


\subsection{FASES DA MODELAGEM DE EQUAÇÕES ESTRUTURAIS}

A modelagem de equações estruturais, por se tratar de uma técnica de análise confirmatória, envolve os 4 estágios do processo de Análise Fatorial Confirmatória voltados ao modelo de mensuração (Estágio 1- Definição dos constructos individuais; Estágio 2- Desenvolvimento do modelo de mensuração geral; Estágio 3- Planejamento do estudo para produzir resultados empíricos; Estágio 4- Avaliação da validade do modelo de mensuração, bem como, dos estágios específicos voltados ao modelo estrutural; Estágio 5- Especificação do Modelo Estrutural; e Estágio 6- Avaliação da validade do modelo estrutural ${ }^{(34)}$.

No Estágio 1, são definidos os constructos que irão compor o modelo estrutural. São possíveis o uso de escalas múltiplas que incluem diferentes indicadores que medem o mesmo conceito de forma diferente a fim de se obter uma medida composta com maior confiabilidade. Além disso, é comum o uso de instrumentos de medida, sejam já validados ou construídos na ocasião pelo pesquisador ${ }^{(34,36)}$.

No Estágio 2, define-se como os itens ou indicadores que irão se conectar aos constructos, o que pode ser realizado por meio de diagrama de caminhos ou equações. Assim, obtém-se o modelo de mensuração para cada constructo. Nessa etapa, é preciso que o pesquisador seja cuidadoso na avaliação e seleção das variáveis utilizadas para medir um constructo a fim de evitar erros de especificação- representação insuficiente do traço latente devido à omissão de uma variável importante para a compreensão da variável latente. Por conseguinte, é possível uma avaliação errônea da importância das demais variáveis e falta de qualidade no ajuste do modelo proposto ${ }^{(36,40)}$.

No Estágio 3, deve-se planejar a coleta de dados para que sejam produzidos resultados empíricos que serão utilizados posteriormente para a validar os modelos de mensuração. Dessa forma, deve-se, incialmente, definir as escalas de mensuração, sem a necessidade de se padronizar escores ou o tipo de escala utilizada para os itens (ordinal, nominal, etc). Então, estima-se a amostra de pesquisa que na modelagem de equações é afetada pela técnica de estimação, distribuição multivariada, complexidade do modelo e quantidade de dados perdi$\operatorname{dos}^{(34)}$. A técnica de estimação adequada, ou seja, o algoritmo utilizado para identificar as estimativas para cada parâmetro, mais utilizado para distribuições normais e com variáveis indicadoras contínuas a técnica da Máxima Verossimilhança (MLE) ${ }^{(34,40)}$. A amostra não deve ultrapassar de 400 a 500 respondentes, pois, acima disso, MLE se torna muito sensível e as medidas de qualidade do ajuste tendem a ser ruins ${ }^{(40)}$. Assim, uma opção para dados categóricos e amostras menores é a técnica dos Mínimos Quadrados Ponderados Robustos que se ba- 
seia em matriz de correlação policórica e supõem uma distribuição subjacente contínua para os constructos dessas variáveis ${ }^{(42-43)}$. A complexidade dos modelos varia de acordo com o número de variáveis observadas e latentes inseridas no mesmo e, a medida que o modelo se torna mais complexo, é necessário o aumento amostral a fim de evitar problemas de identificação, ou seja, a falta de informação suficiente para encontrar uma solução para o conjunto de equações estruturais $^{(34)}$. Nesse contexto, para a obtenção de resultados válidos e estáveis, sugere-se entre 50 e 150 sujeitos para modelos com até 5 constructos e comunalidades elevadas $(0,6)^{(34)}$.

No estágio 4, deve-se avaliar a validade do modelo de mensuração, a qual dependerá da qualidade de ajuste e das evidências de validade de constructo. A qualidade de ajuste refere-se à avaliação da similaridade entre as matrizes de covariância observada e esperada. Nesse sentido, têm-se três tipos de indicadores de qualidade de ajuste, a ser: medidas absolutas, medidas incrementais e medidas de parcimônia. As primeiras indicam o quão bem a teoria proposta para o modelo se ajusta aos dados. Como exemplo deste tipo de medida, incluem-se: Qui-quadrado $(\chi 2)$; Qui-quadrado Normatizado ( $\chi 2$ / graus de liberdade); Índice de Qualidade do Ajuste(GFI); e Índice ajustado de qualidade do ajuste (AGFI). As medidas de parcimônia avaliam o quanto o modelo especificado se ajusta relativamente a algum modelo alternativo de referência (modelo nulo) ${ }^{(34,36)}$. Os índices frequentemente utilizados nesse caso são: Índice de Ajuste Normado (NFI); e Índice de Ajuste Comparativo (CFI) e Índice de Tucker Lewis(TLI). Dentre as medidas de parcimônia, que informam qual o modelo, em um conjunto de possíveis modelos concorrentes, ajusta-se melhor, destacam-se: Índice de Qualidade de Ajuste de Parcimônia (PGFI) e Índice de Ajuste Normado de Parcimônia (PNFI) ${ }^{(34,36)}$. Na análise do modelo de mensuração, somente medidas absolutas e incrementais são aplicadas. As medidas de parcimônia são utilizadas apenas para a avaliação da validade do modelo estrutural, pois tal medida só é possível a partir da comparação de diferentes modelos, sendo o de melhor ajuste aquele que apresentar o maior PGFI ou PNFI ${ }^{(34,36)}$.

Além dos indicadores de ajuste, é importante analisar a presença de resíduos (má qualidade de ajuste), ou seja, a diferença entre a covariância observada e esperada para cada indivíduo. Para isso, é possível utilizar a Raiz Padronizada do Erro Médio (SRMR), a Raiz do erro quadrático médio de aproximação (RMSEA). Para a análise de ajuste do modelo de mensuração, sugere-se o uso de pelo menos um indicador de cada tipo, ou seja, um índice absoluto, um índice incremental, além do $\chi 2$ e grau de liberdade, bem como a analise de má qualidade de ajuste ${ }^{(34)}$. 
No Estágio 5, especificação do Modelo Estrutural, o conjunto de relações de dependência entre os constructos é definido com base em dado referencial teórico. Vale destacar que por mais robusto que este método seja, é incapaz de transformar dados transversais (correlacionais) em dados longitudinais (causais). Assim, estudos transversais permitem a análise do conjunto de correlações, com predomínio da ideia de preditor x consequência e não exatamente causa $\mathrm{x}$ efeito (de pesquisas longitudinais) ${ }^{(44)}$. Para que o pesquisador possa verificar causalidade em MEE, é preciso que: haja forte associação entre variável causal e de efeito; sequência temporal de eventos onde a variável causal precede a variável de efeito (temporalidade); e não haver outro evento para explicar a causa e o efeito que não esteja incluído na análise (covariância legítima) ${ }^{(40)}$. Nesse sentido, para que o pesquisador defina o modelo de relações e as variáveis independentes e dependentes, é imprescindível conhecer profundamente a base teórica para a relação hipotetizada e as evidências anteriores de causa versus efeito ${ }^{(34)}$. Após a especificação do modelo estrutural, o pesquisador deverá analisar a validade do modelo estrutural (Estágio 6). Nesta etapa, seguem-se as mesmas diretrizes e indicadores de ajuste do estágio 4. No entanto, nessa fase, é possível analisar o ajuste competitivo do modelo (Avaliação de modelos concorrentes), processo no qual se compara o modelo proposto com um alternativo por meio de índices de parcimônia ou incrementais. Nesse caso, espera-se que os índices sejam melhores para o modelo proposto. É importante compreender que o bom ajuste do modelo proposto não indica que esse é o único modelo para explicar dada teoria. Modelos alternativos também podem fornecer bons índices de ajuste, o que o suscita a importância da evidencia teórica na seleção e validação do modelo explicativo. Para a validação final do modelo, além dos bons valores nas medidas de ajuste, é importante a obtenção de estimativas significantes na direção proposta para cada relação e a não trivialidade, testada com cargas padronizadas ${ }^{(34,42)}$. 
3. REVISÃO DE LITERATURA 


\section{REVISÃO DE LITERATURA}

\section{Estresse}

O termo estresse é amplamente utilizado devido à sua importância na vida das pessoas e está ligado a atividades laborais, ao trânsito das grandes cidades, à competitividade do mercado de trabalho, etc ${ }^{(45)}$.

Nesse sentido, desde a Pré-história, há o reconhecimento de que o homem sofria exaustão após situações como o trabalho, medo, exposição ao calor e frio, fome, sede, perda de sangue ou alguma doença ${ }^{(46)}$. O termo estresse deriva do latim e foi estudado, inicialmente, pela Física e pela Engenharia em referência a capacidade de uma estrutura metálica resistir até o seu rompimento ou deformação. No século XVII, estresse significava fadiga e cansaço, mas nos séculos seguintes passou a ter relação com o conceito de força, esforço e tensão ${ }^{(47)}$.

Na segunda metade do século XIX, Claude Bernard destacou a capacidade dos seres vivos em manter o equilíbrio do organismo a despeito das modificações externas, compreensão que foi definida como homeostase por Walter Cannon no século XX. Esse conceito foi importante nos estudos desse período e deu suporte aos achados de Hans Selye, que, ainda como discente de medicina, iniciou suas pesquisas sobre estresse em $1925^{(46,48)}$.

Nas décadas de 20 e 30, Selye utilizou o termo estresse pela primeira vez na área de saúde $^{(49)}$. Considerado o precursor da teoria do estresse, sua preocupação era com a "Síndrome do estar doente". Sendo assim, ele verificou que os pacientes, independentemente da etiologia, apresentavam sinais e sintomas comuns, o que incluía perda de peso, perda de apetite e diminuição da força muscular ${ }^{(46)}$.

Posteriormente, Selye descreveu as etapas do estresse biológico e a Síndrome de Adaptação Geral (SAG) ou do Estresse Biológico. Tal Síndrome foi definida como reação defensiva fisiológica do organismo em resposta a qualquer estímulo aversivo, tendo sido divida em três fases: reação de alarme, de resistência e de exaustão ${ }^{(48)}$. A primeira delas ocorre imediatamente após o confronto com o estressor e pode ser consciente ou não. É definida como uma mobilização química, uma reação comum do corpo que necessita atender as exigências, considerado como mecanismo básico para defender o organismo tanto de desafios como de ameaças à sua integridade. Em um curto espaço de tempo, se houver a persistência do estressor, ocorre a resistência. Nessa fase, o corpo trabalha para a sobrevivência e adaptação. Se o estressor persistir ou não ocorrer o equilíbrio, inicia-se a fase de exaustão, em que a adaptação não ocorre e podem surgir doenças, com risco de morte ${ }^{(46)}$. 
No século XX, Lazarus e Folkman definem estresse, a partir do modelo interacionista, como qualquer estímulo que demande do ambiente externo ou interno e que taxe ou exceda as fontes de adaptação de um indivíduo ou sistema social. Atualmente, é o modelo mais veiculado na literatura científica, uma vez que considera a interação entre o ambiente a pessoa ou o grupo como responsáveis e atuantes no processo ${ }^{(10,50)}$.

No modelo interacionista, entende-se que o estresse envolve, além das alterações orgânicas, uma fase na qual participam funções cognitivas, emocionais e comportamentais. Destaca-se que, nesse modelo, acontece uma avaliação cognitiva, que é entendida como um processo mental de localizar o evento ou situação em uma série de categorias avaliativas que são relacionadas com o significado de bem-estar da $\operatorname{pessoa~}^{(10)}$.

Nesse processo de categorização, são possíveis as avaliações primária e secundária que produzem respostas. Na primeira, o indivíduo identifica as demandas de determinada situação e define o significado do evento, que pode resultar em uma ação. Tal evento pode significar um desafio, uma ameaça ou ser irrelevante ao indivíduo. $\mathrm{O}$ resultado dessa primeira avaliação dependerá da natureza do estímulo e sua intensidade, da experiência prévia do indivíduo e de sua resposta à emoção vivenciada ${ }^{(10)}$. Caso o estressor seja definido como uma ameaça ou desafio, acontece a reação de estresse e a avaliação secundária será realizada. Nessa, são verificadas estratégias para o enfrentamento do estressor ${ }^{(10)}$.

Para o ambiente acadêmico, o estresse é definido como um conjunto de reações que ocorrem quando as exigências curriculares excedem os recursos adaptativos dos discentes ${ }^{(11)}$. Alguns aspectos do ambiente acadêmico podem contribuir para a ocorrência do estresse. Nesse sentido, Costa e Polak desenvolveram um instrumento que permite analisar o nível de estresse dos discentes segundo cada fator do ambiente acadêmico, a ser, Realização das Atividades Práticas, Comunicação Profissional, Gerenciamento do Tempo, Ambiente, Formação Profissional e Atividade Teórica ${ }^{(2)}$.

A Realização das Atividades Práticas compõem-se por itens que se referem ao conhecimento instrumental adquirido pelo aluno para a realização dos procedimentos e os sentimentos envolvidos na oferta do cuidado ao paciente; o Ambiente possui itens que retratam o grau de dificuldade sentido pelos alunos no acesso aos campos de estágio ou universidade, e as situações de desgaste que envolve os meios de transportes; os itens da Comunicação Profissional retratam as dificuldades sentidas na comunicação e na relação do indivíduo com os elementos do convívio profissional e as situações conflitantes que surgem; o Gerenciamento do Tempo é composto por itens relativos às dificuldades relatadas pelos discentes para conciliar 
as atividades estabelecidas na grade curricular com as exigências pessoais, emocionais e sociais; a Formação Profissional aborda itens relacionados à preocupação do aluno com o conhecimento adquirido na fase de formação acadêmica e o impacto que esse exerce sobre a sua vida profissional futura, incluindo a percepção das situações que poderá vivenciar quando profissional; e Atividade Teórica, com itens que apontam o grau de dificuldade sentida pelos discentes quanto ao conteúdo programático, às atividades desenvolvidas e à metodologia de ensino adotada ${ }^{(2)}$. Tais fatores podem representar estresse aos alunos de enfermagem em diferentes níveis e contribuir para a baixa qualidade do sono.

\section{Qualidade do Sono}

Desde a Antiguidade, o sono desperta curiosidade do ser humano. Hipócrates já associava a insônia ao aborrecimento e à tristeza e Aristóteles acreditava que o sono era necessário para manutenção da percepção a qual seria esgotada se utilizada ininterruptamente. Apesar do interesse despertado pelo sono e seus distúrbios, somente na segunda metade do século 20 ele deixou de ser objeto de interesse exclusivamente de filósofos e poetas e passou a ser estudado pelos cientistas ${ }^{(51-52)}$. Nesse sentido, os primeiros registros de potenciais elétricos do córtex cerebral humano foram observados em 1929 e receberam o nome de eletroencefalograma (EEG). Na década de 30, Loomis, Harvey e Hobart verificaram que o sono compunha-se de estágios recorrentes (denominados por letras), o que mais tarde iria forma o sono sem movimentos oculares rápidos (NREM). A identificação do sono com movimentos oculares rápidos(REM) só ocorrem em 1953 por Aserinsky e Kleitman, fato que inaugurou o entendimento do sono ${ }^{(51)}$.

O ciclo sono-vigília, em condições naturais, sincroniza-se com fatores ambientais e oscila em um período de 24 horas. Dentre os fatores ambientais, destacam-se alternância do dia-noite (claro-escuro), os horários escolares, de trabalho, de lazer e as atividades familiares. Além dessa sincronização ambiental, o ciclo sono-vigília é regulado endogenamente pelo núcleo supra-quiasmático, localizado no hipotálamo, considerado o relógio biológico para os mamíferos ${ }^{(51-52)}$. Além disso, o sono pode ser dividido em NREM (NonRapid Eye Movement) e REM (Rapid Eye Movement, de forma que o sono de um adulto jovem inclui de quatro a seis ciclos de REM-NREM. O primeiro ciclo é geralmente mais curto que o do início da manhã, com duração de aproximadamente 90 minutos. O indivíduo passa da vigília relaxada para o estágio 1 e, em seguida, para o estágio 2; gradualmente o sono torna-se mais profundo, com o aparecimento dos estágios 3 e 4, estágios do sono com ondas lentas. Após aproximadamente 
90 minutos do início do sono, inicia-se o sono REM, que tem duração média de 2 a 10 minutos e que delimita o final do primeiro ciclo do sono. Então, inicia-se o segundo ciclo a partir do estágio 2 e demais estágios ${ }^{(51-52)}$.

O sono possui uma função biológica fundamental na consolidação da memória, na visão binocular, na termorregulação, na conservação e restauração da energia, bem como na restauração do metabolismo energético cerebral. Além disso, ele atua como agente restaurador e homeostático, com influência sobre o estado de vigília do indivíduo ${ }^{(52)}$. Em condições naturais, os seres humanos precisam de certa regularidade no seu padrão do ciclo sono-vigília, porém há dois grupos de fatores que atuam de forma antagônica no processo de sincronização do ciclo claro-escuro, a ser: os fatores endógenos, que tendem a sincronizar o ciclo sonovigília em um ritmo regular no período de 24 horas; e as demandas do indivíduo, que compõem os fatores exógenos e que tendem a sincronizar o ciclo sono-vigília em um padrão diferente do ciclo claro-escuro, o que leva aos transtornos do sono ${ }^{(52)}$.

Os transtornos do sono trazem consigo diversas repercussões para os seres humanos, o que inclui disfunção autonômica, diminuição do desempenho profissional ou acadêmico, maior incidência de transtornos psiquiátricos e diminuição da vigilância, com maior risco à segurança pessoal e de acidentes. Os maus dormidores tendem a apresentar mais morbidades, menor expectativa de vida e envelhecimento precoce ${ }^{(52)}$. Por isso, grandes progressos no diagnóstico e tratamento dos transtornos do sono vem sendo realizados, muitos deles obtidos pelos centros de estudos do sono que têm se expandido e conduzido pesquisas no campo da físiologia do sono, seus mecanismos de regulação e suas alterações ${ }^{(51)}$.

Frente aos diferentes distúrbios do sono existentes, foi necessário organizar e uniformizar uma nomenclatura para os transtornos do sono. Assim, foi criada a primeira Classificação Diagnóstica dos Transtornos do Sono e Vigília em 1979. Em 1990, a American Sleep Disorders Association publicou uma nova classificação, novamente revisada em 1997. Essa última foi organizada a partir dos principais sintomas reportados pelos pacientes e organizou os transtornos do sono em quatro grandes grupos: dissonias; parassonias; transtornos do sono associados a desordens mentais, neurológicas ou outras; e transtornos do sono propostos ${ }^{(51)}$. Todavia, a Classificação Internacional de Transtornos do Sono, proposta em 2005, reclassifica os transtornos do sono com base também na fisiopatologia e no sistema corporal envolvido, além da apresentação sintomática. Nessa, os transtorno são divididos em oito categorias maiores, a ser: insônias; transtornos respiratórios relacionados ao sono; hipersonias não devidas aos transtornos respiratórios; transtornos de ritmo circadiano; parassonias; transtornos do mo- 
vimento relacionados ao sono; sintomas isolados, variantes aparentemente normais e questões não resolvidas; e outros transtornos do sono ${ }^{(51-52)}$.

No âmbito acadêmico, o equilíbrio entre fatores endógenos e exógenos na sincronização com ciclo claro e escuro é um desafio, pois, embora os primeiros naturalmente controlem o metabolismo basal para os períodos de sono e vigília, as demandas acadêmicas e hospitalares tendem a reduzir o sono e dessincronizar o ciclo dia-noite ${ }^{(51-52)}$. Nesse sentido, além das atividades curriculares em horário integral, os discentes de cursos da área de saúde estão expostos a outra situações, tais como a busca de uma boa qualificação profissional, as tarefas extracurriculares, os cursos complementares e atividades extracurriculares, tais como ligas acadêmicas, plantões, estágios, iniciações científicas e monitorias ${ }^{(52)}$.

Frente a isso, os discentes precisam decidir entre manter a regularidade do ciclo sonovigília e satisfazer as necessidades individuais de sono ou atender as demandas acadêmicas, sejam elas de cunho teórico ou prático. Frequentemente, observa-se que optam pela ultima opção e, portanto, apresentam padrão irregular do ciclo sono-vigília, geralmente caracterizado por modificação no horário de início e término do sono. Dessa forma, período de sono ao longo da semana costuma ser menor em comparação aos fins de semana devido às privações de sono durante os dias de aula ou trabalho ${ }^{(52-53)}$, o que impacta na qualidade do sono dos discente universitários.

Nesse contexto, a literatura descreve que a má qualidade do sono se relaciona ao aumento da morbidade por disfunção autonômica, distúrbios psiquiátricos, acidentes automobilísticos e de trabalho. Uma vez que o sono regular as funções cognitivas, a privação do sono e sua menor qualidade geral também comprometem a atenção, a memória e o desempenho acadêmico. Além disso, maus dormidores também estão mais propensos ao envelhecimento precoce, a depressão, a insuficiência renal, a intolerância à glicose, a hipercortisolemia e a diminuição da produtividade no trabalho ${ }^{(53)}$.

Portanto, as situações vivenciadas na formação acadêmica, ao alterarem o ciclo sonovigília, com redução do tempo de sono, insônia e sonolência diurna, podem alterar a qualidade do sono, com impacto biológico e psicológico ao discente de enfermagem. Dessa forma, diferentes instrumentos foram criados ao longo do tempo no intuito de avaliar a qualidade do sono, dentre os quais, destaca-se o Índice da Qualidade do Sono de Pittsburgh (IQSP) foi utilizado para avaliar a qualidade subjetiva do sono, tendo sido validado em 1989 por Buysse, Reynolds, Monk, Berman e Kupfer junto a pacientes com disfunção do sono em comparação a pacientes sem essas alterações ${ }^{(54)}$. Ele foi validado no Brasil por Bertolazi a fim de avaliar a 
qualidade do sono em relação ao últimos mês ${ }^{(51)}$. Posteriormente, esse instrumento foi aplicado em discentes universitários brasileiros de diferentes locais ${ }^{(52,55)}$. Neste instrumento, há dez questões, sendo: questão um a quatro- abertas; e cinco a 10- semiabertas. Tais questões são distribuídas em sete componentes, da seguinte forma: Qualidade subjetiva do sono (Questão 6); Latência do sono (Questões 2 e 5a); Duração do sono (Questão 4); Eficiência habitual de sono (Questões 1, 3 e 4) Distúrbios do sono (Questões 5b até a 5j); Uso de medicações para dormir (Questão 7); sonolência diurna e distúrbios durante o dia (Questões 8 e 9) ${ }^{(51)}$. A questão dez é de uso optativo e não será aplicada nessa pesquisa, uma vez que exige a presença de um companheiro de quarto para sua análise ${ }^{(51)}$. A pontuação global é gerada pela soma da pontuação de cada componente, o qual possui um peso que varia de 0 a 3 . Assim, o valor máximo possível é de 21 pontos, sendo que, quanto mais essa pontuação, pior a qualidade do sono. Os escores superiores a cinco pontos indicam má qualidade no padrão de sono. Para a conversão das respostas obtidas em cada questão para uma escala tipo likert, serão seguidas as instruções descritas em pesquisa com profissionais de saúde ${ }^{(56)}$. Na validação do instrumento para a realidade brasileira, o Alfa de Cronbach para todos os itens do instrumento foi de 0,82 , atestando consistência interna satisfatória ao instrumento ${ }^{(51)}$.

Esse instrumento e outros já desenvolvidos ao longo da história tem sido essencial na compreensão do processo de sono e suas alterações que podem acarretar alterações no funcionamento físico, ocupacional, social e cognitivo do indivíduo. Sobre esse último componente, há especial influência do sono na ocorrência de queda no desempenho acadêmico e desenvolvimento de sintomatologia depressiva ${ }^{(53,52)}$.

\section{Sintomas Depressivos}

Além das alterações no padrão e na qualidade do sono, uma das reações em resposta aos estressores pode ser a depressão. Atribui-se notável importância à hereditariedade e a fatores genéticos, que podem ter uma expressão bioquímica ao nível das sinapses, bem como a fatores ambientais ou psicológicos. No modelo cognitivo da depressão, embora a importância dos fatores biológicos, como a diminuição de certos neurotransmissores, os sintomas depressivos são compreendidos como resultado das distorções cognitivas de conteúdo negativo. Esses sintomas por si só podem não causar depressão, mas são aspectos fundamentais na manutenção do transtorno ${ }^{(57)}$.

O termo depressão tem sido empregado para designar tanto um estado afetivo normal, quanto um sintoma, uma síndrome e uma ou várias doenças. Enquanto síndrome, a depressão 
inclui, não só alterações do humor (tristeza, irritabilidade, falta da capacidade de sentir prazer, apatia), como alterações cognitivas, psicomotoras e vegetativas. Já no quadro de doença, a depressão tem sido classificada de diversas formas a depender do período histórico, da preferência dos autores e do ponto de vista adotado. Na literatura atual, a depressão encontra-se mencionada como transtorno depressivo maior, melancolia, distimia, depressão integrante do transtorno bipolar tipos I e II, depressão como parte da ciclotimia, etc ${ }^{(58)}$. Enquanto sintoma, a depressão pode aparecer em diferentes quadros clínicos, como transtorno de estresse póstraumático, demência, esquizofrenia, alcoolismo e doenças clínicas, bem como em resposta a situações estressantes ${ }^{(58)}$.

Nesse sentido, os sintomas depressivos podem levar ao sofrimento e a prejuízos sociais e ocupacionais importantes e, junto a avaliação clínica, podem configurar o transtorno depressivo, que é a quarta maior causa incapacitante no mundo ${ }^{(17)}$. Essa sintomatologia é avaliada com ênfase nos componentes afetivos e comportamentais, que incluem: humor deprimido; sentimentos de culpa e inutilidade; sensação de falta de suporte e desesperança; retardo psicomotor; perda de apetite; e distúrbios do sono ${ }^{(18)}$.

No contexto acadêmico, diferentes pesquisas já destacam ocorrência da sintomatologia depressiva em discentes universitários e seu impacto sobre componentes cognitivos, como o sono. Em estudo com 729 discentes de uma universidade dos EUA, 16,5\% apresentaram tais sintomas, $30,6 \%$ depressão moderada e $23,2 \%$ depressão severa ou moderadamente severa ${ }^{(19)}$. Em pesquisa conduzida com discentes do ensino médio na China, 6,4\% deles possuíam tais sintomas $^{(20)}$. A relação entre sintomas depressivos e qualidade do sono foi confirmada em pesquisa com 3186 discentes chineses na qual se observou que os alunos com sintomas depressivos possuíam 2,47 vezes mais chance de apresentar alterações na qualidade do sono ${ }^{(20)}$. Os pesquisadores atribuem esse fenômeno nessa população ao fato de que os discentes da área da saúde convivem com algumas características que conformam um ambiente acadêmico/profissional de intensos estímulos emocionais que levam ao adoecimento. Isso inclui o contato íntimo e frequente com a dor e o sofrimento; com a intimidade corporal e emocional de outras pessoas; com pacientes terminais; com pacientes difíceis e não aderentes ao tratamento, hostis, reivindicadores e cronicamente deprimidos; e com as incertezas e limitações do conhecimento médico e do sistema assistencial que não atende as demandas e expectativas dos pacientes ${ }^{(59)}$. Além disso, essa maior predisposição em discentes universitários da área de saúde parece estar relacionada à diferentes fatores estressores ao longo do curso como perda da liberdade pessoal, alto nível de exigência do curso, sentimento de desumanização, falta de 
tempo para o lazer e competição existente entre os colegas ${ }^{(60)}$. Dependendo dos mecanismos utilizados, dar-se-á uma adequada adaptação dentro dos limites possíveis. Caso contrário, não haverá adaptação e os efeitos serão perceptíveis de maneiras diversas, incluindo a ansiedade, depressão e outras morbidades psiquiátricas ${ }^{(59)}$.

Nesse contexto, tendo em vista o seu impacto à vida dos indivíduos, diferentes instrumentos psicométricos para a avaliação da sintomatologia depressiva ${ }^{(61-63)}$. Dentre esses, destaca-se a Center for Epidemiologic Studies Depression scale (CES-D) como um dos mais utilizados atualmente ${ }^{(17)}$. Ele foi validado para o português por Silveira e Jorge em $1998^{(64)}$ e aplicado em discentes universitários brasileiros por Filho e Teixeira em $2011^{(17)}$. O objetivo desse instrumento é avaliar a sintomatologia depressiva vivida na semana anterior com base nos principais aspectos afetivos, cognitivos, somáticos e comportamentais da depressão. Ele contém 20 itens sobre humor, sintomas somáticos, interações com os outros e funcionamento motor, os quais são distribuídos em quatro subescalas: Depressão, Interpessoal, Afeto Positivo e Somática/Iniciativa ${ }^{(17)}$. A subescala afetos positivos avalia aspectos de otimismo, esperança e satisfação de vida, que são teórica e empiricamente relacionados ao quadro depressivo ${ }^{(61)}$. A dimensão de depressão avalia afetos negativos tradicionais na descrição do quadro depressivo. Aspectos somáticos/iniciativa é uma subescalas que aborda as dificuldades de se engajar e manter as atividades cotidianas ${ }^{(61)}$. Por sua vez, a dimensão Interpessoal avalia crenças negativas que trazem dificuldades no funcionamento social.

\section{Qualidade de Vida}

Atualmente, a qualidade de vida passou a ser uma preocupação mundial. Ela foi e permanece sendo um desafio para estudiosos que se interessam em buscar mecanismos que possam ser implantados no cotidiano, objetivando apontar sugestões em busca de resultados satisfatórios em que o bem-estar do profissional, do paciente e da família, torna-se primordial nos aspectos éticos, sociais, culturais e financeiros. Pensando nesta temática, um grupo de especialistas em qualidade de vida da Organização Mundial de Saúde, elaborou um instrumento genérico de avaliação de qualidade de vida, usando um enfoque transcultural ${ }^{(27)}$.

No contexto universitário, a qualidade de vida de discentes vem sendo pesquisada desde a década de 80 e é definida como como a percepção de satisfação e felicidade, por parte do discente em relação a múltiplos domínios de vida à luz de fatores psicossociais e contextuais relevantes e estruturas de significados pessoais. Nessa população, os domínios de vida utilizados como indicador de qualidade de vida são: social; individual; acadêmico; gênero; 
finanças; moradia; serviços da universidade; administração universitária; e outros ${ }^{(65)}$. Em pesquisa conduzida com 264 discentes de Graduação em Enfermagem brasileiros, verificou-se que os escores de qualidade de vida na amostra total foram altos, porém, as médias nos diferentes anos do curso mostraram queda no decorrer do $2^{\circ}$ ano, quando os discentes são inseridos no campo prático ${ }^{(45)}$.

Embora os estudos já existentes, novas investigações ainda vem sendo desenvolvidos na tentativa de compreender de melhor o conceito de QVE, o que só será possível frente aos cenários de múltiplas investigações ${ }^{(65)}$. Isso ocorre porque diferentes fatores levam à falta de consenso sobre a definição de qualidade de vida, como o fato da multidisciplinaridade de uso do termo, a dificuldade em escolher quais os componentes ou dimensões do conceito que seriam mais importantes na definição, às diferenças com relação ao ambiente cultural e a multiplicidade de medidas de avaliação. Apesar dessas dificuldades, parece claro que qualidade de vida é interdisciplinar, sendo necessária a contribuição de diferentes áreas do conhecimento para o aprimoramento metodológico e conceitual ${ }^{(66)}$.

Embora essas considerações, a qualidade de vida é definida como um bem-estar físico, funcional, emocional e mental, incluindo elementos importantes da vida das pessoas como trabalho, família, amigos e outras circunstâncias do cotidiano. Essa definição da OMS deixa implícita a ideia de que o conceito de qualidade de vida é subjetivo, multidimensional e inclui elementos de avaliação, tanto positivos, como negativos ${ }^{(27,67)}$. A qualidade de vida diz respeito à maneira pela qual o indivíduo interage com o mundo externo, como é influenciado e como o influencia. O bem-estar é uma condição que emerge de um estado global de equilíbrio físico e psicoemocional $^{(68)}$.

Considera-se como qualidade de vida boa ou excelente aquela que ofereça um mínimo de condições para que os indivíduos inseridos possam desenvolver o máximo de suas potencialidades, sejam estas: viver, sentir e amar, trabalhar, produzindo bens e serviços, fazendo ciência ou artes. A qualidade de vida não é um simples modismo, algo passageiro a preencher o tempo dos leitores para, em seguida, ser descartada. Ao contrário, ela se constitui em um dos objetivos a serem alcançados no presente estágio de desenvolvimento da humanidade ${ }^{(69)}$.

Uma das preocupações mais crescentes nos últimos anos tem sido buscar critérios para se avaliar qualidade de vida e, por isso, diferentes são os instrumentos desenvolvidos com este objetivo $^{(70)}$. Nesse sentido, reuniões foram realizadas com representantes de governos e comunidades de várias partes do mundo e documentos importantes foram produzidos com o objetivo de se estabelecerem metas relativas à saúde. A preocupação com ambientes saudá- 
veis tem estado praticamente presente em todos os documentos produzidos e o envolvimento da comunidade têm sido notáveis uma vez que tais ambientes estão relacionados à qualidade de vida ${ }^{(70)}$.

A OMS interessou-se em estudar questões relativas à qualidade de vida e desenvolveu inicialmente um instrumento para avaliá-la, o denominado WHOQOL-100 e, posteriormente, o WHOQOL-Bref, ambos buscavam conhecer a qualidade de vida dos pacientes dos ambulatórios de psiquiatria. Desde a formalização do grupo de qualidade de vida da OMS, em 1991, e a apresentação das características psicométricas do estudo multicêntrico, o Project estendeuse a praticamente todo o mundo estando, atualmente, o WHOQOL (nas versões longa e abreviada) disponível em mais de 40 idiomas diferentes ${ }^{(27,71)}$.

O desenvolvimento do WHOQOL partiu de três pressupostos centrais: (1) a essência abrangente do conceito de qualidade de vida; (2) uma medida quantitativa, fiável e válida que pudesse ser construída e aplicada a várias populações; e (3) qualquer fator que afete a QV influencia um largo espectro de componentes incorporados no instrumento e este, por sua vez, serve para avaliar o efeito de intervenções de saúde específicas na qualidade de vida ${ }^{(27,67,71)}$.

O WHOQOL foi projetado para avaliar a qualidade de vida independente de questões culturais. Na sua elaboração, 15 centros participaram simultaneamente e criaram o WHOQOL - 100, instrumento de 100 questões, avaliando 6 domínios: físico, psicológico, nível de independência, relações sociais, meio ambiente e espiritualidade/crenças pessoais. No âmbito de cada domínio, 24 facetas específicas compõem o domínio particular em que se inserem. Adicionalmente, o instrumento contempla uma faceta geral que avalia a satisfação global com a qualidade de vida e a percepção geral de saúde. Cada faceta é avaliada através de quatro perguntas. Na versão portuguesa, foi acrescentada uma nova faceta à versão original, designada por FP25: Poder Político ${ }^{(27,67,71)}$. A partir do WHOQOL- 100 foi construída uma versão abreviada, o WHOQOL - Bref, um instrumento genérico de mensuração da qualidade de vida, contrapondo-se a outros instrumentos criados e adaptados para avaliá-la em situações específicas. Ele contém 26 questões, as quais obtiveram os melhores desempenhos psicométricos na versão de 100 itens. Na versão abreviada, são avaliados 4 domínios: Físico, Psicológico, Relações Sociais e Meio Ambiente ${ }^{(27,67,71)}$.

Portanto, o WHOQOL resulta de um consenso internacional, representando uma perspectiva transcultural, bem como multidimensional, que contempla a complexa influência da saúde física e psicológica, nível de independência, relações sociais, crenças pessoais e das suas relações com características do respectivo meio na avaliação subjetiva da qualidade de 
vida individual $^{(71)}$. Embora as situações vividas pelos discentes universitários, em especial aquelas da área de saúde possam contribuir para a sintomatologia depressiva, estudos recen-

tes ${ }^{(29-30)}$ destacam a existência de indivíduos resilientes ao estresse, os quais possuem um senso de significado que se opõe ao estresse e aos sintomas depressivos, como será visto a seguir.

\section{Resiliência}

$\mathrm{Na}$ década de 70 e 80, alguns pesquisadores americanos e ingleses passaram a investigar o porquê de alguns indivíduos vivenciarem certas situações mobilizantes e de certo modo, apresentarem pouco ou nenhum impacto aparente, fenômeno que foi denominado de resiliên$\operatorname{cia}^{(72)}$.

O tronco conceitual da resiliência origina-se do latim, resílio, que significa "ser elástico". O termo surgiu em 1807, no cenário científico moderno compondo o vocabulário da Física e da Engenharia, sendo o cientista inglês Thomas Young um de seus precursores ${ }^{(72)}$. Nas ciências humanas, o termo foi utilizado em 1960 e sugeriu-se uma inter-relação entre forças biológicas e psicológicas para alcançar os objetivos desejados. Nesse sentido, seria resiliente o indivíduo capaz de identificar seus problemas, opor-se as dificuldades e capaz de solucionar os problemas de forma adaptativa. Já na área da psicologia, inicialmente, a resiliência foi definida como invulnerabilidade, sendo tal definição substituída devido ao amadurecimento das pesquisas no campo da resiliência ${ }^{(73)}$. Além disso, por certo tempo, considerou-se que a personalidade resiliente era herdada geneticamente, o que dava ao resilientes uma suposta invulnerabilidade, porém, com o passar das décadas, essa perspectiva tornou-se limitada.

Atualmente, ainda considera-se que, por ser amplo, conflituoso, dinâmico, o conceito resiliência ainda está em fase de estruturação na Psicologia ${ }^{(72)}$. De forma geral, atualmente, compreende-se a resiliência como a habilidade de o indivíduo se recuperar das adversidades e se adaptar positivamente a situações da vida é denominada resiliência ${ }^{(31)}$. Assim, mesmo frente a um ambiente potencialmente estressor, esses indivíduos podem apresentar baixos níveis de estresse e, assim, menor chance de sofrerem impactos negativos à sua saúde ${ }^{(31)}$. Ainda, a resiliência é um processo dinâmico no qual aspectos emocionais, socioculturais, ambientais e cognitivos interatuam e permitem que o ser humano enfrente, vença, fortaleça e se transforme a partir de experiências de adversidade ${ }^{(32-33)}$.

Uma vez que sofre influência de fatores externos, pesquisadores salientam que a resiliência não pode ser julgada como um escudo protetor, tornando a pessoa rígida, invulnerável 
e resistente às adversidades. Assim, a resiliência consiste em um estado de resistência que depende da interação recíproca entre as influências do ambiente e do indivíduo, o que leva este a identificar qual a melhor atitude a ser tomada em determinado contexto ${ }^{(74-76)}$.

Nesse contexto, há fatores de proteção e de risco à personalidade resiliente. Os fatores de proteção caracterizam-se pelas influências que modificam ou melhoram a resposta individual à dada situação e que, portanto, predispõe a mudança ou reversão das circunstâncias potencialmente negativas ${ }^{(77)}$. A exemplo disso, destacam-se as relações parentais satisfatórias, presença de fontes de apoio social e familiar, autoimagem positiva e espiritualidade (PINHEIRO, 2004). Já os fatores de risco são aqueles que aumentam a possibilidade de desadaptação do sujeito diante de uma situação de perigo, o que inclui a desvantagem socioeconômica, falta de apoio social e familiar, baixa autoestima ${ }^{(77)}$. Embora essenciais à compressão da resiliência, é importante compreender que os fatores de risco não são uma sentença para não adaptação e que os fatores de proteção podem diminuir o impacto dos primeiros, facilitando a identificação de oportunidades para reverter os efeitos do estresse ${ }^{(77)}$. Nesse sentido, a resiliência não é uma característica fixa ou somente um produto. Ela pode surgir ou desaparecer em certos momentos conforme a relação indivíduo- ambiente e estar presente apenas em determinadas áreas da vida da pessoa. Dessa forma, a resiliência tem sido entendida como uma habilidade individual capaz de promover a saúde uma vez que se opõem ao estresse, a ansiedade e os sentimentos de raiva ${ }^{(32-33)}$.

Frente a esses benefícios, o campo de estudo da resiliência tem se expandido como reflexo da necessidade de investimento em prevenção de doenças e promoção da saúde ${ }^{(31)}$. Atualmente as pesquisas têm abarcado o ambiente universitário, pois esse é um local no qual os discentes passam a maior parte de seu dia, estabelecem relações e adquirem novos aprendizados. Dependendo da forma como cada um relaciona-se com esse ambiente, ele pode funcionar como um fator de risco - um local hostil, no qual não há espaço para falar o que pensa, em que não se sente bem-vindo e não apresenta relacionamentos satisfatórios - ou um fator de proteção - quando há um local harmonioso, no qual encontra pessoas acolhedoras, que o escutam e demonstram sentimentos positivos ${ }^{(72,77)}$. Quando a relação do discente com o espaço universitário é positiva e os fatores de proteção são fortalecidos, a possibilidade de atitudes resilientes e do desenvolvimento da personalidade resiliência é maior, com efeitos positivos sobre a saúde e qualidade de vida desses indivíduos, fato já verificado atualmente na literatura científica. A exemplo disso, em estudo longitudinal realizado com 1321 discentes de medicina de cinco estados norte-americanos, foi verificado que os indivíduos resilientes apresentaram 
menores escores de estresse psicoemocional e sintomas depressivos, bem como melhor qualidade de vida ${ }^{(29)}$. Em outra pesquisa realizada com 2069 discentes de medicina de três universidades chinesas, foi identificado que a resiliência exerceu efeito moderador sobre os problemas de saúde dos alunos ${ }^{(30)}$.

Nesse sentido, é importante que as instituições de ensino identifiquem os fatores de risco e promovem um ambiente com elementos positivos, quem fortaleçam as atitudes resilientes por parte dos discentes, tendo em vista seus benefícios à saúde física e mental dessa população. Isso é especialmente importante porque a não adaptação ao ambiente universitário, além de afetar a saúde, pode impactar em médio prazo, no desempenho acadêmico e na qualidade da formação acadêmica, e, em longo prazo, na qualidade do cuidado prestado. 
4. QUESTÕES DE PESQUISA 


\section{QUESTÕES DE PESQUISA}

Com base nos resultados das pesquisas anteriores e as lacunas na produção científica nacional e internacional, questiona-se:

- Ocorrem alterações na saúde (estresse psicoemocional, sintomas depressivos e qualidade do sono), nos níveis de resiliência e na qualidade de vida de discentes após um ano do ingresso no curso de graduação em enfermagem?

- Como se dão as relações simultâneas de causalidade entre estresse psicoemocional, sintomas depressivos e resiliência na explicação da qualidade de vida dos discentes de enfermagem um ano após o ingresso no curso de graduação? 
5. OBJETIVOS 


\section{OBJETIVOS}

- Verificar se ocorrem alterações na saúde (estresse psicoemocional, sintomas depressivos e qualidade do sono), nos níveis de resiliência e na qualidade de vida de discentes após um ano do ingresso no curso de graduação em enfermagem.

- Analisar como se dão as relações simultâneas de causalidade entre estresse psicoemocional, sintomas depressivos, qualidade do sono e resiliência na explicação da qualidade de vida dos discentes de enfermagem um ano após o ingresso no curso de graduação. 
6. HIPÓTESES DE PESQUISA 


\section{HIPÓTESES DE PESQUISA}

As hipóteses desse projeto de pesquisa foram fundamentadas nos resultados das pesquisas conduzidas no Brasil e no âmbito internacional. Ademais, as relações já verificadas entre os fenômenos aqui apresentados são complexas e já foram analisadas sob diferentes delineamentos e populações. No entanto, buscar-se-á identificar as causas das alterações na saúde dos alunos para que se possa, futuramente, elaborar uma intervenção com foco na causa de tais alterações. Para tal, esse estudo será composto de duas fases, a ser: Fase 1- Calibração dos instrumentos; e Fase 2- Avaliação das alterações na saúde, na resiliência e na qualidade de vida; e do efeito dos fenômenos de saúde sobre a qualidade de vida dos discentes, cujas hipóteses são descritas abaixo:

\subsection{FASE 1- CALIBRAÇÃO DOS INSTRUMENTOS}

Hipótese - Espera-se que todos os instrumentos mantenham sua estrutura interna originalmente validada para mensurar estresse psicoemocional, sintomas depressivos, qualidade do sono, resiliência e qualidade de vida em discentes de enfermagem.

\subsection{FASE 2- ALTERAÇÕES NA SAÚDE, RESILIÊNCIA E QUALIDADE DE VIDA E EFEITO DOS FENÔMENOS DE SAÚDE SOBRE A QUALIDADE DE VIDA DOS DISCENTES}

\subsubsection{Avaliação das Alterações na Saúde, Resiliência e Qualidade de Vida}

Hipóteses - Ocorrem alterações na saúde dos discentes de enfermagem após um ano de ingresso no curso, com: elevação do nível de estresse psicoemocional; elevação dos sintomas depressivos; redução da qualidade do sono; e redução da qualidade de vida. Adicionalmente, espera-se que o aluno fortaleça suas características de resiliência, ao longo de um ano, a partir da experiência com os fatores de estresse vivenciados desde o início da vida acadêmica.

\subsubsection{Análise do efeito dos fenômenos de saúde sobre a qualidade de vida dos discentes}

\section{Hipóteses}


- O estresse psicoemocional leva à baixa qualidade do sono ${ }^{(19)}$ e aos sintomas depressivos ${ }^{(13-}$ ${ }^{14,21)}$ em Discentes de Enfermagem.

- $\mathrm{O}$ estresse psicoemocional contribui diretamente para a baixa qualidade de vida entre os discentes de enfermagem ${ }^{(16,78)}$.

- Os discentes com maior intensidade de sintomas depressivos possuem maior chance de apresentar baixa qualidade de vida $^{(79)}$.

- Os alunos com baixa qualidade do sono possuem maior chance de apresentar baixa qualidade de vida ${ }^{(24)}$.

- A qualidade de sono pode impactar nas funções cognitivas e levar aos sintomas depressi$\operatorname{vos}^{(25-26)}$.

- O aumento da intensidade dos sintomas depressivos contribuem para reduzir a qualidade do sono $^{(20)}$.

- Os sintomas depressivos mediam a relação entre o estresse psicoemocional e a qualidade de vida $^{(16,78-79)}$.

- A qualidade do sono media a relação entre o estresse psicoemocional e a qualidade de vi$\mathrm{da}^{(24,80)}$.

- A resiliência contribui diretamente para aumentar a qualidade de vida ${ }^{(29)}$.

-A resiliência reduz os níveis de estresse psicoemocional ${ }^{(29-30)}$ e reduz a intensidade dos sintomas depressivos ${ }^{(29-30)}$ e melhora a qualidade do sono ${ }^{(81)}$. Assim, mesmo sob condições estressantes, os alunos tendem a apresentar melhor qualidade de vida na presença de níveis mais altos de resiliência.

Figura 2- Modelo Hipotético para o comportamento dos fenômenos da saúde na Fase 3 do Estudo. São Paulo, 2016.

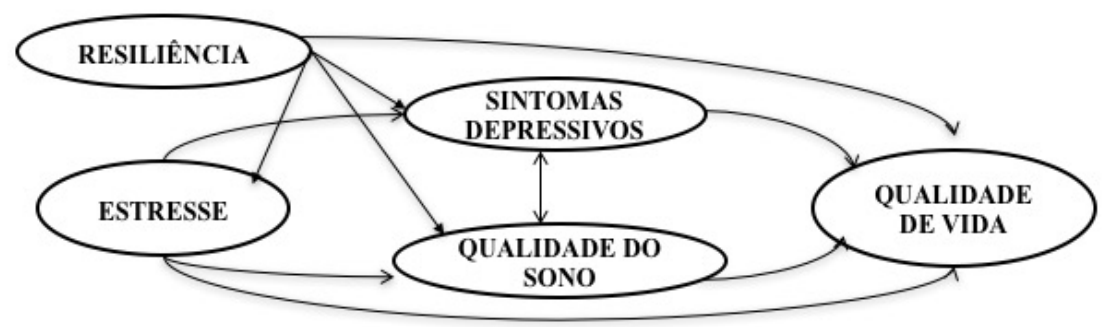

Fonte: Silva RM. Alterações de saúde, resiliência e qualidade de vida de discentes de graduação em enfermagem no primeiro ano letivo. [Tese]. São Paulo: EEUSP; 2016. 
7. MÉTODO 


\section{MÉTODO}

Nessa seção, são descritos os procedimentos realizados para o alcance dos objetivos propostos neste estudo. Para melhor compreensão das etapas percorridas, essa seção está dividida em duas partes, a ser: Fase 1- Calibração dos instrumentos; e Fase 2- Alterações na saúde, na resiliência e na qualidade de vida; e avaliação das relações simultâneas de causalidade entre estresse psicoemocional, sintomas depressivos, qualidade do sono e resiliência na explicação da qualidade de vida dos discentes de enfermagem. Todos os elementos metodológicos e as informações específicas pertinentes são descritos em cada fase.

\subsection{FASE 1- CALIBRAÇÃO DOS INSTRUMENTOS}

\subsubsection{Delineamento do Estudo}

Nessa fase, trata-se de um estudo metodológico que visa à investigação de métodos de coleta e organização dos dados, o que inclui o desenvolvimento, validação e avaliação de ferramentas e métodos e, portanto, favorece a condução de investigações com maior rigor ${ }^{(80)}$. Nessa investigação esse delineamento foi utilizado para avaliar o ajuste dos instrumentos à população de pesquisa (Calibração) visto que os instrumentos, além de terem sido validados há mais de dois anos ${ }^{(2,17,32,51,67)}$, foram validados com discentes universitários ${ }^{(17)}$ e populações gerais $^{(32,51,67)}$, porém sem incluir a realidade específica da formação em enfermagem. Esses aspectos impactam na precisão (capacidade de produzir resultados coerentes com a realidade) e confiabilidade dos instrumentos (capacidade de produzir os mesmos resultados em diferentes medições) e, por consequência, em sua validade ${ }^{(34-35)}$. Sobre isso, como os fenômenos psi$\operatorname{cossociais~}^{(39)}$ não são facilmente mensuráveis, sendo apenas observável sua manifestação (variável latente), a calibração ${ }^{(39)}$ desse tipo de instrumento deve ser realizada por meio de técnicas de análise multivariada que permite aferir a sensibilidade, validade e confiabilidade dos dados recolhidos ${ }^{(34-35)}$. Campos ${ }^{(35)}$ refere que esse tipo de análise deve ser realizada antes da apresentação dos resultados de qualquer estudo que envolva aplicação de escalas, pois é a única maneira de se avaliar a qualidade dos dados obtidos.

Essa fase do estudo foi conduzida segundo à abordagem quantitativa, a qual é amplamente utilizada em pesquisas e representa, em princípio, a intenção de garantir a precisão dos resultados, evita distorções de análise e interpretação, o que possibilita, consequentemente, uma margem de segurança quanto às inferências ${ }^{(82)}$. 


\subsubsection{Local e População de Estudo}

Essa fase da pesquisa foi desenvolvida em uma universidade estadual localizada no estado de São Paulo (Instituição A) no segundo semestre de 2015 junto aos discentes matriculados no segundo, terceiro e quarto anos do curso de enfermagem, respetivamente no $4^{\circ}, 6^{\circ}$ e $8^{\circ}$ semestres letivos. O curso de Bacharelado é composto por 37 disciplinas obrigatórias, distribuídas em quatro anos (ou oito semestres letivos), sendo 80 alunos selecionados anualmente pelo vestibular da Fundação Universitária para o Vestibular (FUVEST) e do Sistema de Seleção Unificada (SISU). O curso é oferecido em período integral e as aulas ocorrem em unidade específica ao curso de enfermagem ou em unidades que sediam outros cursos na área de Medicina e Saúde Pública, bem como em unidades do campus (Faculdade de Filosofia, Letras e Ciências Humanas, Faculdade de Educação, Instituto de Química, Instituto de Ciências Biomédicas, Instituto de Biociências e Instituto de Psicologia). A carga horária total do curso é de 4.170 horas, com uma estrutura curricular organizada em três ciclos, a ser: Ciclo das Necessidades (1.530 horas), do Cuidado (1.710horas) e da Prática Profissional (930 horas). Além disso, a instituição oferece a opção de Licenciatura a partir do $5^{\circ}$ semestre, o que demanda a realização de disciplinas específicas que somam 765 horas adicionais, o que totaliza nove semestres letivos (Carga horária total de 5765 horas) ${ }^{(83)}$.

\subsubsection{Critérios de Inclusão/Exclusão}

Foram incluídos discentes que, no segundo semestre de 2015, estavam regulamente matriculados no segundo, terceiro e quarto anos do curso da Instituição A (respectivamente no $4^{\circ}, 6^{\circ}$ e $8^{\circ}$ semestres) e possuíam mais de 18 anos.

Foram excluídos aqueles que, no período de coleta, estavam impedidos de realizar todas as disciplinas do semestre seguinte devido a reprovações no semestre anterior.

\subsubsection{Coleta de dados e instrumentos}

A coleta de dados para a calibração dos instrumentos ocorreu em fevereiro de 2016, por meio do envio do protocolo de pesquisa via e-mail e de forma presencial junto aos alunos de enfermagem. Esse foi composto pelos seguintes instrumentos (descritos em detalhes no item 5.2.5): Formulário para caracterização sociodemográfica e acadêmica (Instrumento 1) (Apêndice A); Instrumento para Avaliação do Estresse em Discentes de Enfermagem (AEEE) (Instrumento 2) (Anexo 1), Center for Epidemiologic Studies Depression Scale (CES-D) (Instrumento 3) (Anexo 2), Índice de Qualidade de Sono de Pittsburgh (IQSP) (Instrumento 
4) (Anexo 3); Escala de Resiliência de Wagnild \& Young (Instrumento 5) (Anexo 4); Instrumento de Avaliação de Qualidade de Vida (WHOQOL-Bref) (Instrumento 6) (Anexo 5).

A abordagem dos discentes ocorreu da seguinte forma: inicialmente, o pesquisador buscou, junto ao serviço de graduação, as disciplinas a serem ministradas na Instituição A e a listagem de alunos matriculados no segundo, terceiro e quarto anos do referido curso. Nesse contexto, foi percorrido o seguinte fluxo de procedimentos:

- Etapa 1: Foi escolhido disciplina oferecida na própria unidade e específica do curso de enfermagem. Então, foi realizado contato (através de e-mail) com o docente responsável pela disciplina escolhida para a apresentação da finalidade e objetivos da pesquisa, assim como, o fluxo operacional de coleta de dados (docente colaborador).

-Etapa 2- Após este encontro e autorização deste docente, foi agendado dia e horário, de acordo com a escolha do mesmo, para o primeiro encontro com os discentes em sala de aula.

- Etapa 3- Realizou-se a apresentação, em sala de aula, dos objetivos da pesquisa e a entrega dos TCLEs aos alunos que aceitarem participar do estudo. O tempo para a exposição dos objetivos do estudo foi de 5 minutos, aproximadamente, para não comprometer o andamento da aula.

- Etapa 4- Os instrumentos foram enviados aos alunos que aceitarem participar do estudo, com prazo de dez dias para devolução dos instrumentos por e-mail ao pesquisador. Destaca-se que esse meio de comunicação permite que o aluno responda ao protocolo de forma fracionada, o que reduz o viés de respostas induzidas pelo cansaço devido ao notável número de itens dos instrumentos.

- Etapa 5- Após a abordagem online, os alunos que não haviam respondido os questionários via e-mail foram localizados presencialmente em sala de aula pelo pesquisador após agendamento com o docente responsável.

\subsubsection{Análise dos Dados}

Para organização e análise dos dados, foi criado um banco de dados no programa Excel (Office 2010) e utilizado o Pacote estatístico R (Versão 3.3.0) e o complemento Lavaan (Latente Variable Analysis) (Versão 0.5-20). As variáveis qualitativas foram apresentadas em valores absolutos (n) e percentuais ( $\mathrm{n} \%)$. As variáveis quantitativas foram expostas em medidas descritivas: valores mínimos e máximos, média e desvio padrão. 
Realizou-se Análise Fatorial Confirmatória (AFC) a fim de confirmar se a estrutura interna encontrada na fase inicial de validação do instrumento ainda se mantém para explicar os fenômenos latentes em discentes de enfermagem ${ }^{(34)}$. O método de estimação utilizado foi o dos mínimos quadrados ponderados robusto. Como indicadores de ajuste, destacam-se ${ }^{(34)}$, como mínimo adequado, o uso de pelo menos um índice de incremental, um índice absoluto, além do $\chi 2$ (Qui-quadrado) e Grau de Liberdade(GL), além de pelo menos um índice de má qualidade de ajuste. Dessa forma, serão utilizadas as respectivas medidas absolutas e valores de ajustes: $\chi^{2}$ (Ajuste $=>0,05$ ), $\chi^{2}$ normatizado (Ajuste $=<3,0$ ), baseado no GL; Índice de Qualidade do Ajuste (GFI) (Ajuste $=>0,95$ ). Como medidas incrementais, foram utilizados: Índice de Ajuste Comparativo (CFI) (Ajuste $=>0,92$ ) e Índice de Tucker Lewis (TLI) (Ajuste= $>0,92)^{(34)}$. Já como medida de má qualidade de ajuste, destacam-se: Raiz do erro quadrático médio de aproximação (RMSEA) (Ajuste $=\mathrm{r}<0,08$ considerando CFI $>0,92$ ) e Raiz Padronizada do Resíduo Médio (SRMR)(Ajuste $=r<0,09$ considerando CFI $>0,92)^{(34)}$. Além dos indicadores de ajuste do modelo, foram utilizados Carga Fatorial (Valores adequados=0,4 a 0,6) e Correlação de Pearson $(0,5$ a 0,7$)$ para avaliação da contribuição de cada variável observável para as variáveis latentes ${ }^{(34)}$. Adicionalmente, para a carga fatorial, considerou-se a seguinte classificação para a tomada de decisão sobre possíveis exclusões dos itens: cargas com os valores $>0,71$ excelente; $>0,63$ muito boas; $>0,55$ boas; $>0,45$ razoáveis e $>0,32$ pobres $^{(84)}$.

Além disso, essas medidas permitem avaliar a existência de colinearidade (quando apresentam valores extremos) e baixo poder discriminatório (quando apresentam valores abaixo do mínimo esperado). Para análise de confiabilidade dos instrumentos, utilizou-se o coeficiente Alfa de Cronbach (Alfa $>0,7)^{(34)}$.

\subsubsection{Aspectos Éticos}

Após a aprovação do projeto no Comitê de Ética em Pesquisa (CEP) (parecer $\left.n^{0} 1.363 .890\right)$ e sua apreciação em relação à viabilidade e mérito pelo Comitê de Pesquisa, ambos da Instituição A, foi submetida emenda ao mesmo CEP para a inclusão da fase de calibração dos instrumentos junto aos alunos do segundo ano, com aprovação no referido comitê sob parecer $n^{0} 1.400 .103$. Posteriormente, foi solicitada extensão da coleta de dados para calibração junto aos alunos do terceiro e quarto anos, cuja aprovação foi emitida sob parecer $\mathrm{n}^{\circ}$ 1.508.522.

Atendendo às Diretrizes e Normas Regulamentadoras de Pesquisas Envolvendo Seres Humanos (Resolução CNS 466/12), foi entregue presencialmente um Termo de Consentimen- 
to Livre e Esclarecido, com informações referentes à pesquisa, o qual foi assinado em duas vias (uma para o sujeito e outra para o pesquisador), com autorização de participação voluntária na pesquisa. Ademais, foi apresentado ao CEP o Termo de Confidencialidade, o qual afirma o compromisso dos pesquisadores diante da utilização e preservação do material por um período de cinco anos. Assegurou-se aos discentes a não divulgação de dados individuais que possibilitem ou facilitem a identificação dos sujeitos.

\subsection{FASE 2- ALTERAÇÕES NA SAÚdE, RESILIÊNCIA E QUALIDADE DE VIDA E AVALIAÇÃO DAS RELAÇÕES SIMULTÂNEAS DE CAUSALIDADE ENTRE ESTRESSE PSICOEMOCIONAL, SINTOMAS DEPRESSIVOS, QUA- LIDADE DO SONO E RESILIÊNCIA NA EXPLICAÇÃO DA QUALIDADE DE VIDA DOS DISCENTES DE ENFERMAGEM.}

\subsubsection{Delineamento do Estudo}

Realizou-se um estudo longitudinal prospectivo, com abordagem quantitativa. O estudo longitudinal prospectivo consiste no acompanhamento de um grupo de sujeitos por um período de tempo e permite a mensuração de variáveis que poderão predizer desfechos futu$\operatorname{ros}^{(85)}$. A abordagem quantitativa em pesquisa é amplamente utilizada e representa, em princípio, a intenção de garantir a precisão dos resultados, evitar distorções de análise e interpretação, proporcionar uma margem de segurança quanto às inferências ${ }^{(82)}$. Destaca-se que essa etapa da pesquisa teve o intuito de avaliar as alterações na saúde, resiliência e qualidade de vida dos discentes de enfermagem ao longo do ano, bem como as relações de dependência entre os fenômenos analisados.

\subsubsection{Local e População de Estudo}

Essa fase da pesquisa foi desenvolvida na Instituição A (Universidade Estadual) e na Instituição B (Universidade Federal), ambas localizadas no estado de São Paulo. A população do estudo foi composta por todos os discentes de enfermagem do primeiro ano de ambas as instituições que aceitaram voluntariamente participar da pesquisa mediante a assinatura do Termo de Consentimento Livre e Esclarecido (TCLE) após serem informados sobre os objetivos e características do estudo. 
A Instituição B foi criada em 1939 e conta com unidade de ensino específica para o curso de enfermagem. O curso de bacharelado em Enfermagem é ministrado em período integral e com duração de quatro anos (8 semestres letivos), o que totaliza uma carga horária de 4652 horas, distribuídas em três campos de formação, a ser: Ciências Biológicas e da Saúde, Ciências Humanas e Sociais e Ciência da Enfermagem. O ingresso ocorre por meio do Sistema de Seleção Unificado (SiSU). São ofertadas 88 vagas anualmente, com seleção de 80 discentes no sistema universal e 8 no sistema de cotas (racial e escola pública). A estrutura organizacional é constituída pelos departamentos de Enfermagem Clínica e Cirúrgica, Administração e Saúde Coletiva, Enfermagem Pediátrica e Enfermagem na Saúde da Mulher ${ }^{(86)}$. As características da Instituição A foram citadas no item 5.1.2.

\subsubsection{Critérios de Inclusão/Exclusão}

Foram incluídos discentes regulamente matriculados no $1^{\circ}$ semestre do primeiro ano de cada instituição e maiores de 18 anos.

Foram excluídos aqueles que, no período de coleta, estavam impedidos de realizar todas as disciplinas do semestre seguinte devido a reprovações no semestre anterior.

\subsubsection{Variáveis do Estudo}

$\mathrm{Na}$ análise das alterações de saúde, resiliência e qualidade de vida dos alunos, o ambiente acadêmico do curso de graduação de enfermagem foi considerado a variável preditora e os demais fenômenos em análise (Estresse psicoemocional, sintomas depressivos e a qualidade do sono, resiliência e qualidade de vida) as variáveis de desfecho.

Para a avaliação dos comportamentos dos fenômenos, o estresse psicoemocional foi considerado variável preditora e a qualidade de vida a variável de desfecho. A resiliência, os sintomas depressivos e a qualidade do sono foram definidas como variáveis mediadoras da relação entre estresse psicoemocional e qualidade de vida, ou seja, esses fenômenos podem minimizar o efeito do estresse psicoemocional sobre a qualidade de vida, mas sem modificar o tipo de relação esperada (direta ou inversa).

\subsubsection{Coleta de dados e instrumentos}

Essa fase foi conduzida com os discentes de enfermagem matriculados no $1^{\circ}$ ano do 
curso de ambas as instituições no período de março de 2016 a dezembro de 2016. A coleta envolveu a aplicação de um protocolo de pesquisa em dois momentos, a ser: no início das aulas no curso de graduação (março de 2016) e ao final do segundo semestre (dezembro de 2016/ última semana de aula). Esse protocolo foi composto pelos seguintes instrumentos: Formulário para caracterização sociodemográfica e acadêmica (Instrumento 1) (Apêndice A); Instrumento para Avaliação do Estresse em Discentes de Enfermagem (AEEE) (Instrumento 2) (Anexo 1), Center for Epidemiologic Studies Depression Scale (CES-D) (Instrumento 3) (Anexo 2), Índice de Qualidade de Sono de Pittsburgh (IQSP) (Instrumento 4) (Anexo 3); Escala de Resiliência de Wagnild \& Young (Instrumento 5) (Anexo 4); Instrumento de Avaliação de Qualidade de Vida (WHOQOL-Bref) (Instrumento 6) (Anexo 5); Uma vez que o protocolo de pesquisa foi composto por seis instrumentos, a coleta foi desenvolvida em 4 etapas (Figura 3).

Figura 3- Procedimentos de coleta de dados. São Paulo, 2015.

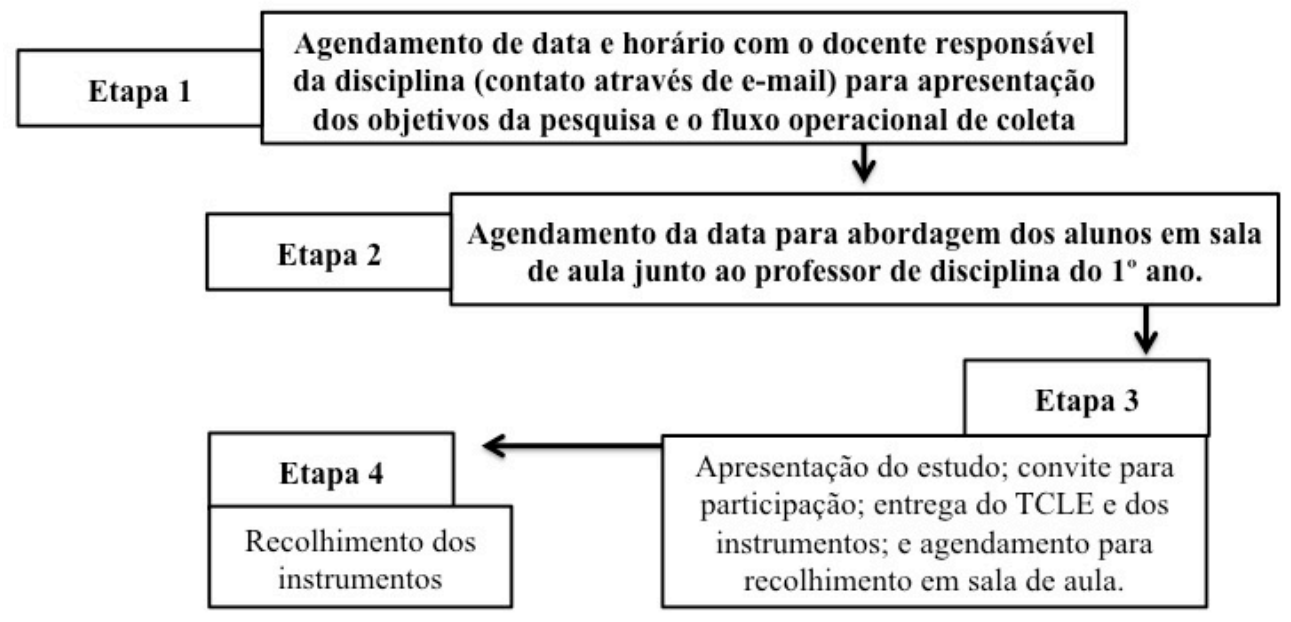

Fonte: Adaptado de Pires CGS. Fatores de risco cardiovascular entre graduanda(o)s do primeiro e último anos letivos. [Tese]. Salvador: UFBA: 2013.

Inicialmente, o pesquisador buscou, junto ao serviço de graduação das instituições pesquisadas, as disciplinas a serem ministradas nos cursos de enfermagem das Instituições A e B e a listagem de alunos matriculados no primeiro ano dos referidos cursos. Baseado nessas informações, se deu o seguinte fluxo:

Etapa 1: foi agendado dia e horário com o docente responsável por uma dessas disciplinas específicas do curso de enfermagem (contato através de e-mail) para que fosse apresentado a finalidade, objetivos da pesquisa, assim como, o fluxo operacional de coleta de dados (docente colaborador). 
Etapa 2- Após este encontro e autorização deste docente, foi agendado dia e horário, de acordo com a escolha do mesmo, para o primeiro encontro com os discentes. Destaca-se que todo este procedimento visa evitar qualquer interferência no andamento das aulas.

Etapa 3- Realizou-se a apresentação, em sala de aula, dos objetivos da pesquisa e a entrega dos TCLEs e dos instrumentos aos alunos que aceitarem participar do estudo. O tempo para a exposição dos objetivos do estudo foi de, aproximadamente, 5 minutos para não comprometer o andamento da aula. Nesse período, também foram entregues os questionários e foi agendada uma data com os alunos para recolhimento dos mesmos.

Etapa 4- Os questionários foram recolhidos na data previamente agendada com os alunos em sala de aula durante o intervalo. O recolhimento em sal de aula contou com o auxílio dos representantes de turma e de discentes que se propuseram voluntariamente a auxiliar nesse processo. Assim, ao longo da semana, eles recolheram os protocolos com os colegas de classe e, na data agendada, o pesquisador captou os protocolos diretamente com os referidos discentes. Além disso, como estratégia para aumento da adesão à pesquisa, foram enviados individualmente, via e-mail, os resultados individuais de cada fenômeno avaliado aos discentes que participaram da pesquisa.

O mesmo fluxo foi utilizado para a $2^{\mathrm{a}}$ coleta de dados, realizada ao final do $2^{\mathrm{o}}$ semestre de 2016.

\subsubsection{Formulário para caracterização sociodemográfica e acadêmica}

O Formulário para caracterização da população do estudo abordou as seguintes variáveis sociodemográficas: iniciais do nome, e-mail, número telefônico, data de nascimento, sexo, se possui filhos e quantos (se sim), etnia, situação conjugal, cidade de residência, local de residência, com quem reside, tipo de instituição onde o ensino médio foi cursado na sua maior parte, forma de ingresso no curso de graduação, realização de atividades de lazer, prática de esportes, fontes de renda, dependente financeiro, renda mensal total recebida em salários mínimos, despesa mensal em salários mínimos, suficiência da renda mensal para a manutenção, uso de contraceptivo oral ou injetável, uso de fármaco ou substância (chá, café, energético, etc) para inibir o sono; uso de fármaco ou substância para conseguir dormir; hábito de fumar, número de cigarros consumidos por dia, consumo de bebida alcoólica, frequência do consumo de bebida alcoólica; acadêmicas: tempo gasto para chegar à instituição de ensino, cidade universitária e campo de estágio, meio de transporte, mês e ano do início do curso, 
semestre letivo atual, número de disciplinas cursadas no semestre atual, carga horária no semestre atual, número diário de horas de estudo, realização e tipo de atividades extracurriculares exercidas, participação em grupo de pesquisa, tempo dedicado ao grupo de pesquisa semanalmente, atividade de trabalho, experiência profissional na área da saúde, frequentou outro curso superior, satisfação com o curso e interesse em desistir do curso.

\subsubsection{Instrumento para Avaliação de Estresse em Discentes de Enfermagem (AEEE)}

O Instrumento para Avaliação de Estresse em Discentes de Enfermagem (AEEE) foi proposto por Costa e Polak em $2009^{(2)}$ e é composto por 30 itens agrupados em seis domínios: Realização das atividades práticas (Itens 4,5,7,9,12 e 21); Comunicação profisssional (Itens 6,8,16 e 20); Gerenciamento do tempo (Itens 3,18,23, 26 e 30); Ambiente(Itens 11,22,24 e 29); Formação profissional (Itens 1,15,17,19,25 e 27); Atividade teórica (Itens 2,10,13,14 e 28). Os itens apresentam-se em escala tipo likert de quatro pontos em que: zero - "não vivencio a situação"; um- "não me sinto estressado com a situação"; dois - "me sinto pouco estressado com a situação"; e três- "me sinto muito estressado com a situação"(2). Para identificação da intensidade de estresse psicoemocional por fator do AEEE, foram utilizados quartis de risco, conforme apresentado na Figura 3.

Figura 4-Distribuição dos discentes segundo o nível de estresse por fator do AEEE. São Paulo, 2016.

\begin{tabular}{|c|c|c|c|c|}
\hline \multirow{2}{*}{ Domínios } & \multicolumn{4}{|c|}{$\begin{array}{c}\text { Classificação da intensidade de estresse e os quartis } \\
\text { correspondentes de pontuação }\end{array}$} \\
\hline & $\begin{array}{c}\text { Baixo nivel } \\
\text { de estresse } \\
(25 \%)\end{array}$ & $\begin{array}{c}\text { Médio nível } \\
\text { de estresse } \\
(50 \%)\end{array}$ & $\begin{array}{c}\text { Alto nivel } \\
\text { de estresse } \\
(75 \%)\end{array}$ & $\begin{array}{l}\text { Muito Alto nível } \\
\text { de estresse } \\
(100 \%)\end{array}$ \\
\hline $\begin{array}{l}\text { Dominio I ( } 6 \text { itens }) \\
0 \text { a } 18 \text { pontos }\end{array}$ & $\begin{array}{c}0-9 \\
\text { pontos }\end{array}$ & $\begin{array}{l}10-12 \\
\text { pontos }\end{array}$ & $\begin{array}{l}13-14 \\
\text { pontos }\end{array}$ & $\begin{array}{l}15-18 \\
\text { pontos }\end{array}$ \\
\hline $\begin{array}{l}\text { Dominio } 2 \text { ( } 4 \text { itens) } \\
0 \text { a } 12 \text { pontos }\end{array}$ & $\begin{array}{c}0-5 \\
\text { pontos }\end{array}$ & $\begin{array}{c}6 \\
\text { pontos }\end{array}$ & $\begin{array}{l}7-8 \\
\text { pontos }\end{array}$ & $\begin{array}{l}9-12 \\
\text { pontos }\end{array}$ \\
\hline $\begin{array}{c}\text { Dominio } 3 \text { ( } 5 \text { itens) } \\
0 \text { a } 15 \text { pontos } \\
\end{array}$ & $\begin{array}{r}0-10 \\
\text { pontos }\end{array}$ & $\begin{array}{l}11-12 \\
\text { pontos }\end{array}$ & $\begin{array}{l}13-14 \\
\text { pontos }\end{array}$ & $\begin{array}{c}15 \\
\text { pontos }\end{array}$ \\
\hline $\begin{array}{l}\text { Dominio } 4 \text { ( } 4 \text { itens) } \\
0 \text { a } 12 \text { pontos }\end{array}$ & $\begin{array}{c}0-7 \\
\text { pontos }\end{array}$ & $\begin{array}{c}8-10 \\
\text { pontos }\end{array}$ & $\begin{array}{c}11 \\
\text { pontos }\end{array}$ & $\begin{array}{c}12 \\
\text { pontos }\end{array}$ \\
\hline $\begin{array}{l}\text { Dominio } 5 \text { ( } 6 \text { itens }) \\
0 \text { a } 18 \text { pontos }\end{array}$ & $\begin{array}{c}0-9 \\
\text { pontos }\end{array}$ & $\begin{array}{c}10 \\
\text { pontos }\end{array}$ & $\begin{array}{l}11-12 \\
\text { pontos }\end{array}$ & $\begin{array}{l}13-18 \\
\text { pontos }\end{array}$ \\
\hline $\begin{array}{l}\text { Domínio } 6 \text { ( } 5 \text { itens }) \\
0 \text { a } 15 \text { pontos }\end{array}$ & $\begin{array}{c}0-9 \\
\text { pontos }\end{array}$ & $\begin{array}{l}10-11 \\
\text { pontos }\end{array}$ & $\begin{array}{l}12-13 \\
\text { pontos }\end{array}$ & $\begin{array}{l}14-15 \\
\text { pontos }\end{array}$ \\
\hline
\end{tabular}

Fonte: Costa ALS, Polak C. Construção e validação de instrumento para avaliação de estresse em discentes de enfermagem (AEEE). Rev. Esc. Enferm. USP. 2009; 43(N.esp.):1017-26. 
Para verificar o nível de estresse psicoemocional geral por discente, será realizada a soma dos escores atribuídos aos 30 itens do instrumento, sendo comparados os escores de estresse psicoemocional obtidos no início e no final do primeiro ano letivo de curso.

Os valores de Alfa obtidos para os domínios do AEEE no processo de validação foram respectivamente: 0,806 (Realização de Atividades Práticas), 0,768 (Comunicação Profissional), 0,717 (Gerenciamento do Tempo), 0,866 (Ambiente), 0,772 (Formação Profissional), 0,720 (Atividade Teórica) ${ }^{(2)}$.

\subsubsection{Center for Epidemiologic Studies Depression Scale (CES-D)}

A CES-D foi validada semanticamente para o português por Silveira e Jorge em $1998^{(64)}$ e aplicada em discentes universitários brasileiros por Filho e Teixeira em $2011^{(17)}$. O objetivo desse instrumento é avaliar a sintomatologia depressiva vivida na semana anterior à aplicação do instrumento. Ele contém 20 itens escalares sobre humor, sintomas somáticos, interações com os outros e funcionamento motor. Esses são distribuídos em quatro subescalas, a ser: Depressão (Itens 3,6,9,10,14,17 e 18), Interpessoal (Itens 15 e 19), Afeto Positivo (Itens $4,8,12,16$ ) e Somática/Iniciativa (Itens $1,2,5,7,11,13$ e 20). Tais itens são dispostos em escala tipo Likert de quatro pontos, sendo $0=$ Raramente (menos que 1 dia), $1=$ Durante pouco tempo (1-2 dias), 2= Durante um tempo moderado (3-4 dias), 3= Durante a maior parte do tempo (57 dias $)^{(17)}$. O escore final varia de zero a 60 pontos. Na versão norte-americana, o ponto de corte para identificar sintomas depressivos, considerando todos os itens da escala, é $\geq 16$ pontos ${ }^{(61)}$. No entanto, para discentes universitários brasileiros, o ponto de corte que melhor identifica os sintomas depressivos é $\geq 15^{(64)}$.

Os valores de Alfa de Cronbach obtidos no processo de validação do instrumento para discentes universitários brasileiros foram respectivamente de: 0,89 para os 20 itens; 0,86 para a subescala Depressão; de 0,70 para a subescala Interpessoal; 0,65 para a subescala Afeto positivo; e de 0,75 para a subescala Somática/ iniciativa ${ }^{(17)}$.

\subsubsection{4 Índice da Qualidade do Sono de Pittsburgh (IQSP)}

O Índice da Qualidade do Sono de Pittsburgh (IQSP) foi utilizado para avaliar a qualidade subjetiva do sono, tendo sido validado em 1989 por Buysse, Reynolds, Monk, Berman e Kupfer junto a pacientes com disfunção do sono em comparação a pacientes sem essas alterações ${ }^{(54)}$. Ele foi validado no Brasil por Bertolazi a fim de avaliar a qualidade do 
sono em relação ao últimos mês ${ }^{(51)}$. Posteriormente, esse instrumento foi aplicado em discentes universitários brasileiros de diferentes locais ${ }^{(52,55)}$. Neste instrumento, há dez questões, sendo: questão um a quatro- abertas; e cinco a 10- semiabertas. Tais questões são distribuídas em sete componentes, da seguinte forma: Qualidade subjetiva do sono (Questão 6); Latência do sono (Questões 2 e 5a); Duração do sono (Questão 4); Eficiência habitual de sono (Questões 1, 3 e 4) Distúrbios do sono (Questões 5b até a 5j); Uso de medicações para dormir (Questão 7); sonolência diurna e distúrbios durante o dia (Questões 8 e 9) ${ }^{(51)}$. A questão dez é de uso optativo e não será aplicada nessa pesquisa, uma vez que exige a presença de um companheiro de quarto para sua análise ${ }^{(51)}$. A pontuação global é gerada pela soma da pontuação de cada componente, o qual possui um peso que varia de 0 a 3 . Assim, o valor máximo possível é de 21 pontos, sendo que, quanto mais essa pontuação, pior a qualidade do sono. Os escores superiores a cinco pontos indicam má qualidade no padrão de sono. Para a conversão das respostas obtidas em cada questão para uma escala tipo likert, serão seguidas as instruções descritas em pesquisa com profissionais de saúde ${ }^{(56)}$.

$\mathrm{Na}$ validação do instrumento para a realidade brasileira, o Alfa de Cronbach para todos os itens do instrumento foi de 0,82 , atestando consistência interna satisfatória ao instrumento $^{(51)}$.

\subsubsection{Escala de Resiliência de Wagnild \& Young}

A escala de resiliência, desenvolvida por Wagnild \& Young junto a mulheres adul$\operatorname{tas}^{(31)}$, foi adaptada e traduzida para a realidade brasileira junto a discentes de escolas públicas em $2005^{(32)}$. Esse instrumento mede os níveis de adaptação psicossocial positiva em face de eventos de vida importantes. Ele possui 25 itens em escala tipo likert, variando de 1 (discordo totalmente) a 7 (concordo totalmente), distribuídos em 3 fatores, a ser: Resoluções de Ações e Valores (Itens 1,2,6,8,10,12,14,16,18,19,21,23,24 e 25), Independência e determinação (Itens 5,7,9,11,13 e 22) e Autoconfiança e capacidade de adaptação a situações (Itens $3,4,15,17$ e 20$)^{(32-33)}$. Esses fatores correspondem aos atributos que dão suporte ao enfrentamento dos problemas da vida, incluindo competência nas relações sociais, a capacidade de resolução de problemas, a conquista de autonomia e o sentido ou propósito para a vida e o futuro $^{(32-33)}$. Os escores da escala oscilam de 25 a 175 pontos, sendo que quanto maior o escore, mais elevada é a resiliência do sujeito. Um resultado abaixo dos 121 é considerado pelos autores do instrumento como "reduzida resiliência"; entre 121 e 145, como "resiliência moderada"; e acima dos 145, "resiliência elevada"(87). No processo de validação, o instrumento 
apresentou boa propriedades psicométricas, com Alfa de Cronbach de 0,80 para a amostra total $^{(32)}$.

\subsubsection{Instrumento de Avaliação de Qualidade de Vida (WHOQOL-Bref)}

O WHOQOL- BREF, elaborado pela OMS em $1998^{(71)}$ e validado para o português em $2000^{(67)}$ é um instrumento genérico de mensuração da qualidade de vida (QV), contrapondo-se a outros instrumentos criados e adaptados para avaliá-la em situações específicas. Trata-se de um instrumento composto por 26 itens, dentre os quais: duas questões abertas sobre qualidade de vida e 24 itens em escala Likert de cinco pontos (1 - 5). Os 24 itens são distribuídos em quatro domínios que denotam uma percepção individual de qualidade de vida para cada faceta particular da QV, a ser: Físico (Itens 3,4,10,15,16,17 e 18), Psicológico (itens 5,6, 7, 11, 19 e 26), Relações Sociais (Itens 20, 21 e 22) e Meio-ambiente (Itens $8,9,12,13,14,23,24$ e 25) ${ }^{(67)}$. Os outros dois itens são avaliados separadamente, de maneira que: o Item 1 denota a percepção do indivíduo em relação a sua QV; e o Item 2 avalia a percepção do mesmo em relação à satisfação com a sua saúde ${ }^{(67)}$.

Para análise de WHOQOL-Bref, inicialmente, os itens 3, 4 e 26 devem ter sua escala invertida da seguinte forma: $1=5 ; 2=4 ; 3=3 ; 4=2 ; 5=1$. Após esse processo, deve-se calcular a média por domínio, obtida pela soma das pontuações atribuídas a cada item do domínio e dividida pelo número de itens que compõem o referido domínio ${ }^{(67,71)}$. Para que os escores do WHOQOL-BREF possam ser comparáveis aos do WHOQOL-100, a média de cada domínio deve ser multiplicada por 4. Para a análise da qualidade de vida Geral, deve-se realizar a média de todos os itens por indivíduo. Quanto maiores os escores obtidos no domínios e na avaliação geral, maior será a qualidade de vida apresentada pelo sujeito ${ }^{(67,71)}$. Já os domínios são classificados com base na média, da seguinte forma: necessita melhorar (quando for 1 até $2,9)$; regular (3 até 3,9); boa (4 até 4,9) e muito boa $(5)^{(67,71)}$. Quando mais de $20 \%$ dos itens não forem respondidos pelo sujeito, o mesmo deve ser excluído da análise. Quando um item não for respondido, a média deve ser calculada com base nos valores dos demais itens. Quando mais de dois itens estiverem ausentes, o escore do domínio não deve ser calculado (com exceção do domínio 3, onde só pode ser realizada a análise do escore se nenhum item estiver faltando $)^{(67,71)}$.

Na validação, o WHOQOL-Bref apresentou boa consistência interna, medida pelo coeficiente Alfa de Cronbach, para as 26 questões $(\alpha=0,90)$ e para cada um dos domínios separadamente, a ser: Domínio Físico $(\alpha=0,83)$, Domínio Psicológico $(\alpha=0,78)$, Domínio 
Relações Sociais $(\alpha=0,69)$ e Domínio Meio Ambiente $(\alpha=0,71)^{(67)}$.

\subsubsection{Análise dos Dados}

Para organização e análise dos dados, foi criado um banco de dados no programa Excel (Office 2010) e utilizado o Pacote estatístico R (Versão 3.3.0) e o complemento lavaan (Latente Variable Analysis)(Versão 0.5-20). Os instrumentos foram analisados conforme descrito anteriormente, preconizando-se a análise descrita pelos autores dos instrumentos. As variáveis qualitativas foram apresentadas em valores absolutos(n) e percentuais (n\%). As variáveis quantitativas foram expostas em medidas descritivas: valores mínimos e máximos, média e desvio padrão.

Para avaliar as alterações de saúde, resiliência e qualidade de vida dos discentes de enfermagem, utilizou-se o teste ANOVA-modelo com efeitos mistos para comparar as médias obtidas ao longo do tempo para cada fenômeno. Os resultados foram considerados estatisticamente significantes se $\mathrm{p}<0,05$. O alfa de Cronbach foi aplicado para análise da confiabilidade dos instrumentos aplicados.

A fim de atender o último objetivo dessa pesquisa, realizou-se uma Análise Multivariada por meio da técnica de Modelagem de Equações Estruturais. Essa técnica de análise possibilita a testagem de um modelo teórico a partir de um modelo hipotético composto por um grupo de variáveis que explica os constructos e como esses se relacionam entre $\mathrm{si}^{\left({ }^{(36)}\right.}$. Dessa forma, a MEE permitiu conhecer as relações entre os fenômenos que compõe a saúde dos discentes (variáveis latentes) e definir/confirmar o papel de cada um deles (preditores, mediadores e desfecho) conforme modelo hipotético. Logo, o efeito do estresse psicoemocional, sintomas depressivos, qualidade do sono e resiliência sobre a qualidade de vida pôde ser compreendido.

O modelo de mensuração, ou seja, aquele que envolve as relações entre variáveis latentes (Estresse psicoemocional, qualidade do sono, sintomas depressivos, qualidade de vida e resiliência) e suas respectivas variáveis observadas (itens e fatores), é apresentado na Figura 5. 
Figura 5- Modelos de Mensuração para cada variável latente e suas respectivas variáveis observadas. São Paulo. 2016.
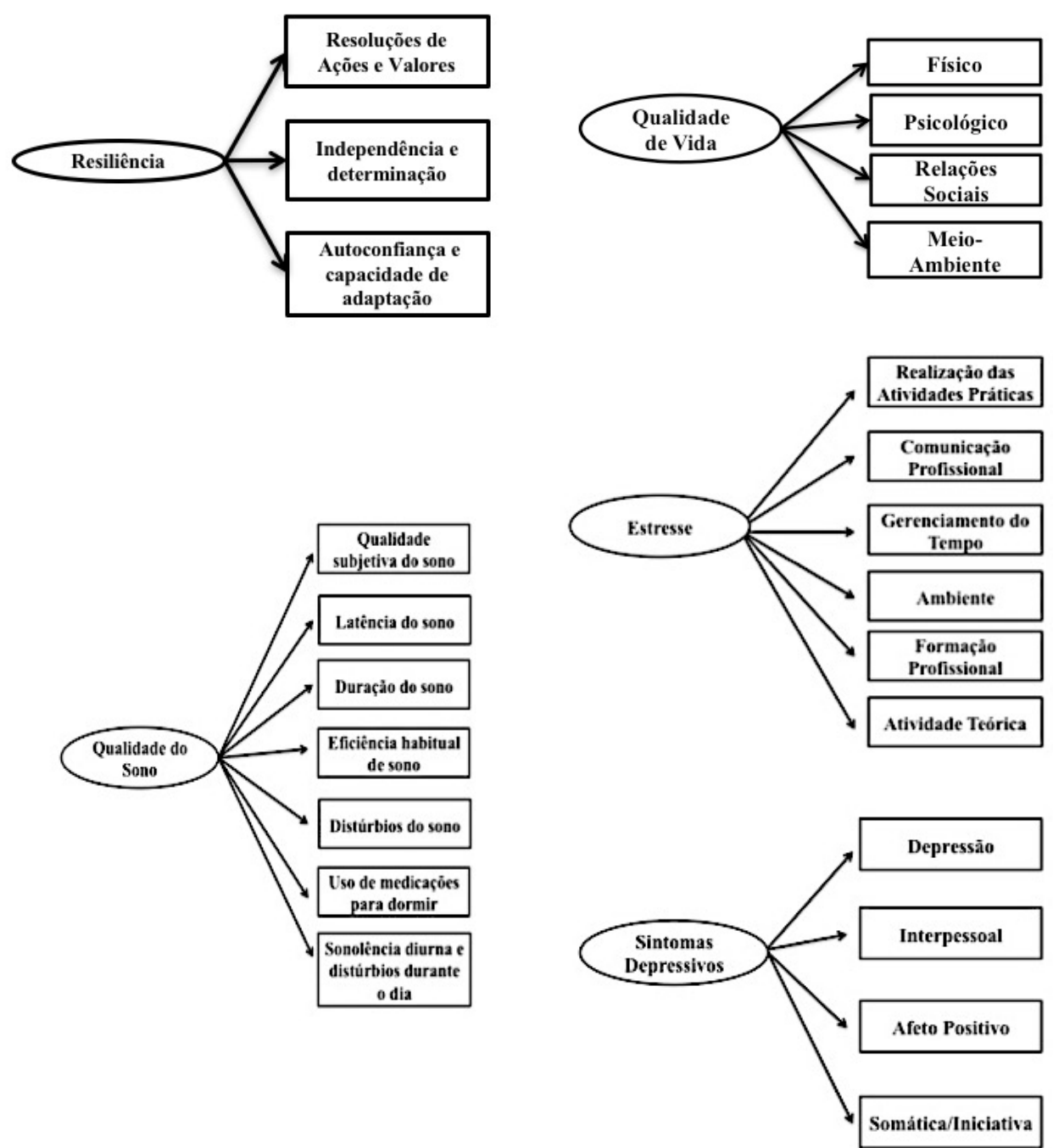

Fonte: Silva RM. Alterações de saúde, resiliência e qualidade de vida de discentes de graduação em enfermagem no primeiro ano letivo. [Tese]. São Paulo: EEUSP; 2016.

A modelagem de equações estruturais, por se tratar de uma técnica confirmatória, envolve os 4 estágios do processo de Análise Fatorial Confirmatória voltados ao modelo de mensuração (Estágio 1- Definição dos constructos individuais; Estágio 2- Desenvolvimento do modelo de mensuração geral; Estágio 3- Planejamento do estudo para produzir resultados empíricos; Estágio 4- Avaliação da validade do modelo de mensuração), bem como dois estágios específicas voltados ao modelo estrutural (Estágio 5- Especificação do Modelo Estrutural; e Estágio 6- Avaliação da validade do modelo estrutural) ${ }^{(34)}$. Nessa pesquisa, os estágios 1, 2, 3, 4 e 5 já foram atendidos, conforme demonstrado acima, sendo o estágio de validação do modelo estrutural (Estágio 6) possível a partir dos dados empíricos coletados (Figura 6). 
Figura 6- Modelo Estrutural para o comportamento dos fenômenos da Saúde. São Paulo, 2016.

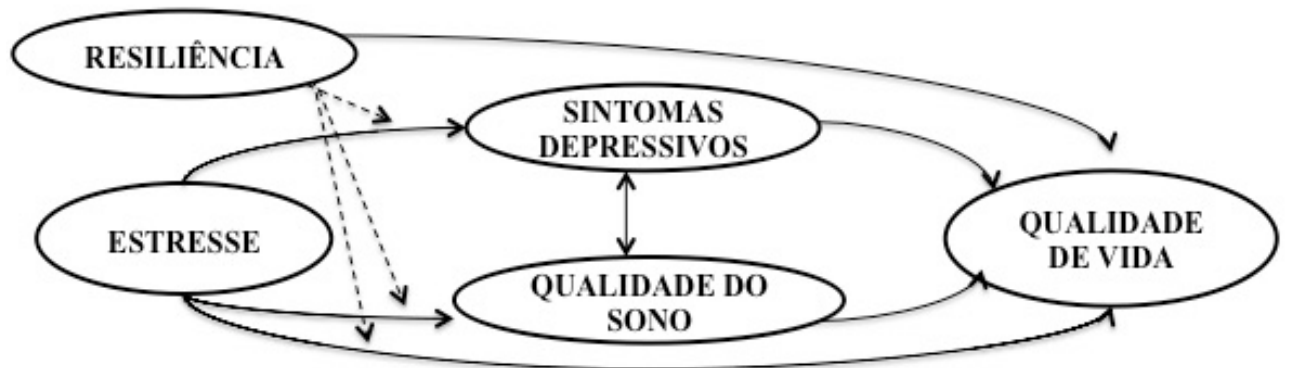

Fonte: Silva RM. Alterações de saúde, resiliência e qualidade de vida de discentes de graduação em enfermagem no primeiro ano letivo [Tese]. São Paulo: EEUSP; 2016.

Dessa maneira, após a coleta dos dados empíricos, foi realizada a validação do modelo estrutural. Utilizaram-se os dados de ambas as coletas para a análise do modelo. Assim, foi possível identificar o efeito dos fenômenos experimentados no início do curso sobre a variação da qualidade de vida (diferença entre os escores do final e do início do ano). Para analisar mediação entre as variáveis latentes, foram confirmados os seguintes pressupostos: 1) Existência de relação significativa entre o grupo de variáveis de interesse (preditor e desfecho; preditor e mediador; e mediador e desfecho); 2) Havendo significância nos três casos, realizou-se o produto do efeito (Beta) da relação preditor-mediador pelo da relação mediadordesfecho, obtendo-se o Efeito Mediador; 3) Comparou-se o efeito mediador com o efeito da relação direta entre preditor e desfecho, havendo mediação quando o efeito da relação mediadora foi maior que da relação direta, levando a redução (mediação parcial) ou nulidade (mediação total) do impacto da variável preditora sobre o desfecho ${ }^{(39)}$.

Os índices de ajustes e método de estimação (mínimos quadrados ponderados robusto) utilizados para a análise de validade do modelo estrutural nessa fase foram os mesmos utilizados na AFC da Fase (Calibração dos instrumentos), conforme item 5.1.6.

\subsubsection{Aspectos Éticos}

Após apreciação e aprovação do projeto pelo Comitê de Ética em Pesquisa (CEP) da Instituição A, sob parecer $n^{0} 1.363 .890$, foi submetida ementa ao CEP para inclusão da Instituição B como local de coleta de dados, sendo essa aprovada sob parecer $n^{0} 1.400 .103$. Posteriormente, o projeto foi submetido ao Serviço de Pesquisa da Instituição B para que fosse apreciado quanto à viabilidade e mérito, sendo também aprovado pela comissão responsável. 
O desenvolvimento da pesquisa, desde o aprimoramento do projeto até a fase e análise e divulgação dos resultados, foi realizado em parceria com a $\operatorname{Prof}^{\mathrm{a}} \operatorname{Dr}^{\mathrm{a}}$. Margaret Heitkemper. Ela é referência na análise de associação de sintomas clínicos e emocionais e atua na School of Nursing no Biobehavioral Nursing and Health Systems Department, University of Washington, Departamento Biobehavioral.

Foi entregue ao CEP, mediante apresentação do estudo e seus objetivos, o Termo de Confidencialidade, o qual afirma o compromisso dos pesquisadores diante da utilização e preservação do material por um período de cinco anos. Além disso, atendendo às Diretrizes e Normas Regulamentadoras de Pesquisas Envolvendo Seres Humanos (Resolução CNS 466/12), foi encaminhado um Termo de Consentimento Livre e Esclarecido junto aos instrumentos, com informações referentes à pesquisa, o qual foi assinado em duas vias (uma para o sujeito e outra para o pesquisador), autorizando a participação voluntária na pesquisa. 
8. RESULTADOS 


\section{RESULTADOS}

Os achados estão apresentados em três etapas, a ser: calibração dos instrumentos, avaliação das alterações de saúde, resiliência e qualidade de vida; e efeito dos fenômenos de saúde (estresse psicoemocional, sintomas depressivos, qualidade do sono e resiliência) sobre a qualidade de vida dos discentes de enfermagem.

\subsection{CALIBRAÇÃO DOS INSTRUMENTOS}

No período de coleta, havia 206 discentes de enfermagem da Instituição A matriculados: 77 do segundo ano, 64 do terceiro ano e 65 do quarto ano. Desses, aceitaram participar do estudo, $43(39,1 \%)$ alunos do segundo ano, $30(27,3 \%)$ do terceiro ano e $37(33,6 \%)$ do quarto ano, o que levou a uma população de acesso de 110 discentes.

Verifica-se predomínio de discentes do sexo feminino (92,7\%), com média etária de $21,87( \pm 3,26)$ anos, solteiros-sem companheiro $(76,4 \%)$, sem filhos $(96,4 \%)$, que residem em São Paulo $(86,4 \%)$, com a família $(75,5 \%)$ e em casa própria $(68,5 \%)$.

$\mathrm{Na}$ Figura 7, apresentam-se os resultados obtidos na análise fatorial confirmatória do modelo de mensuração do AEEE. 
Figura 7- Modelo de Mensuração do Instrumento de Avaliação de Estresse em Discentes de Enfermagem (AEEE). São Paulo, 2015.

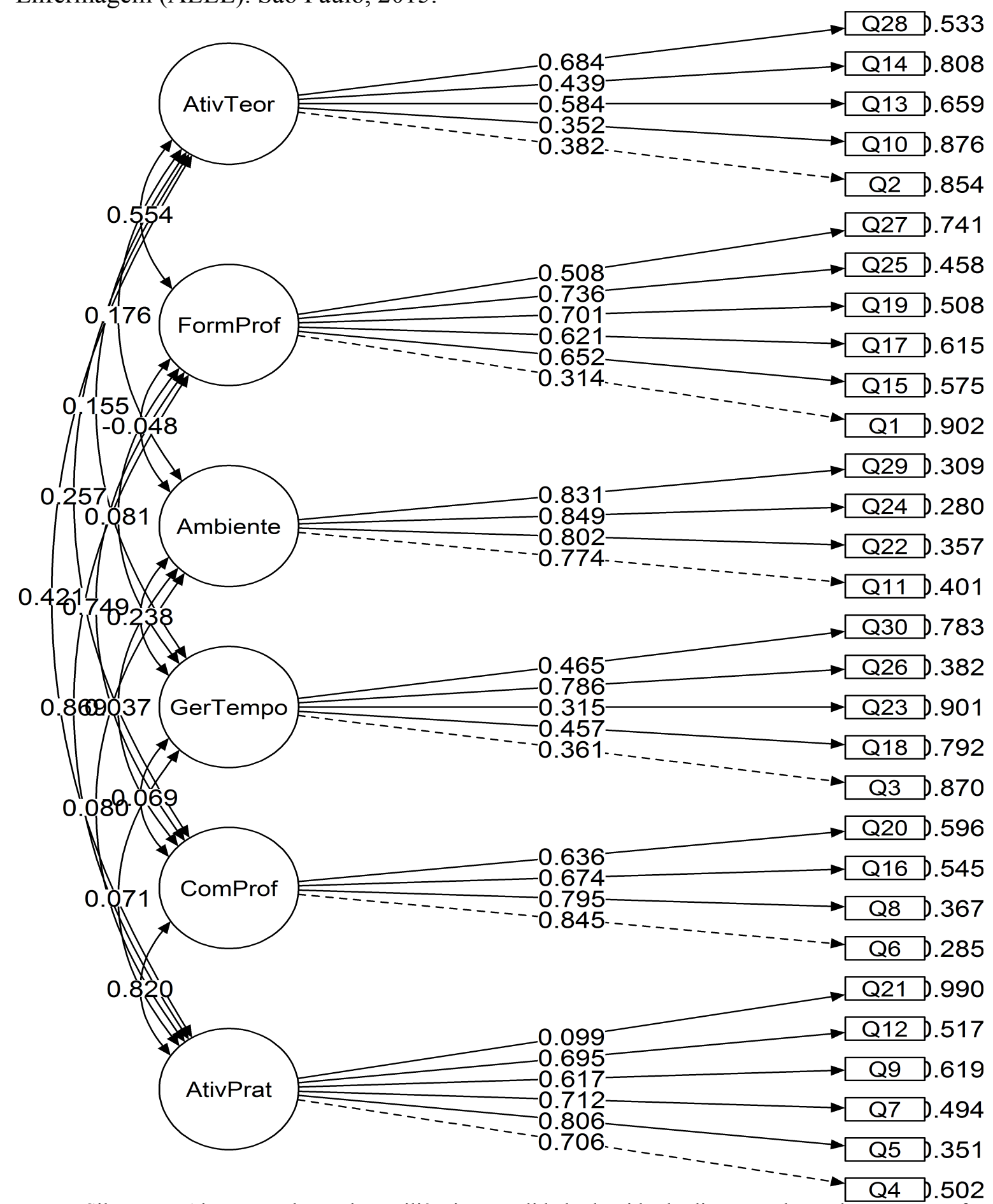

Fonte: Silva RM. Alterações de saúde, resiliência e qualidade de vida de discentes de graduação em enfermagem no primeiro ano letivo. [Tese]. São Paulo: EEUSP; 2015.

Na Figura 7, verifica-se que as cargas fatoriais variaram de 0,099(Item 21 - Realização de Atividades Práticas) a 0,849(Item 24- Ambiente) ao longo dos itens do instrumento. Na análise por fatores, os valores mínimos e máximo encontrados foram respectivamente: 0,099(Item 21) e 0,806(Item 5) no fator Realização de Atividade Prática; 0,636(Itm 20) e 
0,845(Item 6), fator Comunicação Profissional; 0,315(Item 23) e 0,786(Item 26) no fator Gerenciamento do Tempo; 0,774(Item 11) e 0,849(Item 24) no fator Ambiente; 0,314(Item 1) e 0,736(Item 25) no fator Formação Profissional; e 0,352 (Item 10) e 0,684(Item 28) no fator Atividade Teórica. As cargas fatoriais de todos os itens dos domínios Ambiente e Comunicação Profissional foram satisfatórias. Já nos domínios Atividades Práticas (AP) e Formação Profissional (FP), houve um item em cada domínio cujas cargas foram inferiores ao esperado, a ser: itens 21(AP), com 0,099; e 1(FP), com 0,314. Nos domínios Atividades Teóricas (AT) e Gerenciamento do Tempo (GT), observa-se que dois itens de cada domínio estão abaixo dos valores desejados (classificados como pobres), a ser: itens 3 e 23 (GT), com valores de 0,361 e 0,315 respectivamente; e itens 10 e 2(AT), com valores entre 0,352 e 0,382 respectivamente. À exceção do item 21 do domínio atividade teórica, cuja carga fatorial foi de 0,099, os demais apresentaram valores próximos aos limites previstos, considerados de razoável (Item 1- 0,314) a Excelente (Item 0,849) e levaram a índices de ajuste adequados (Tabela 1). Com base nisso, afirma-se que a maior parte dos itens descritos na Figura 7 (variáveis observadas) explicam satisfatoriamente os fatores de estresse do AEEE (variáveis latentes). Além disso, as correlações entre fatores desse instrumento confirmam que esses se comportam, mesmo que com intensidades distintas, de forma interdependente para explicar o constructo em questão, ou seja, o estresse psicoemocional acadêmico.

Tabela 1- Índices de Ajuste e má qualidade de ajuste obtidas na análise fatorial confirmatória do Instrumento para Avaliação de Estresse em Discentes de Enfermagem. São Paulo, 2015.

\begin{tabular}{lcc}
\hline & $\begin{array}{c}\text { Valores Obser- } \\
\text { vados }\end{array}$ & $\begin{array}{c}\text { Valores Espera- } \\
\text { dos }\end{array}$ \\
\cline { 2 - 3 } Medidas Absolutas & & \\
\hline$\chi 2$ & 609,79 & $>0,05$ \\
GL & 390,00 & - \\
$\chi 2$ normatizado $(\chi 2 / G L)$ & 1,564 & $<3,0$ \\
P valor & 0,000 & $<0,05$ \\
GFI & 0,987 & $>0,95$ \\
\hline Medidas Incrementais & & \\
\hline CFI & & $>0,92$ \\
TLI & 0,886 & $>0,92$ \\
\hline Má Qualidade de Ajuste & 0,873 & \\
\hline RMSEA & & $\mathrm{r}<0,08$ \\
SRMR & 0,073 & $\mathrm{r}<0,09$ \\
\hline
\end{tabular}


Fonte: Silva RM. Alterações de saúde, resiliência e qualidade de vida de discentes de graduação em enfermagem no primeiro ano letivo. [Tese]. São Paulo: EEUSP; 2015.

Os valores obtidos, conforme descrito na Tabela 1, indicam que as medidas de ajuste absolutas vêm ao encontro dos valores esperados. As medidas de má qualidade de ajuste, que indicam a presença de resíduos no instrumento, também se encontram dentro de um limite aceitável. Já os valores encontrados para as medidas incrementais, embora um pouco abaixo do valor esperado, podem ser considerados satisfatórios, dado o número amostral desse estudo e os bons resultados obtidos nos demais indicadores. Dessa forma, os índices de ajuste encontrados atestam validade de constructo ao AEEE para avaliar estresse psicoemocional em discentes de enfermagem. Na Figura 8, apresentam-se os resultados obtidos na análise fatorial confirmatória do modelo de mensuração do CES-D.

Figura 8- Modelo de Mensuração do Center for Epidemiologic Studies Depression Scale (CES-D). São Paulo, 2015.

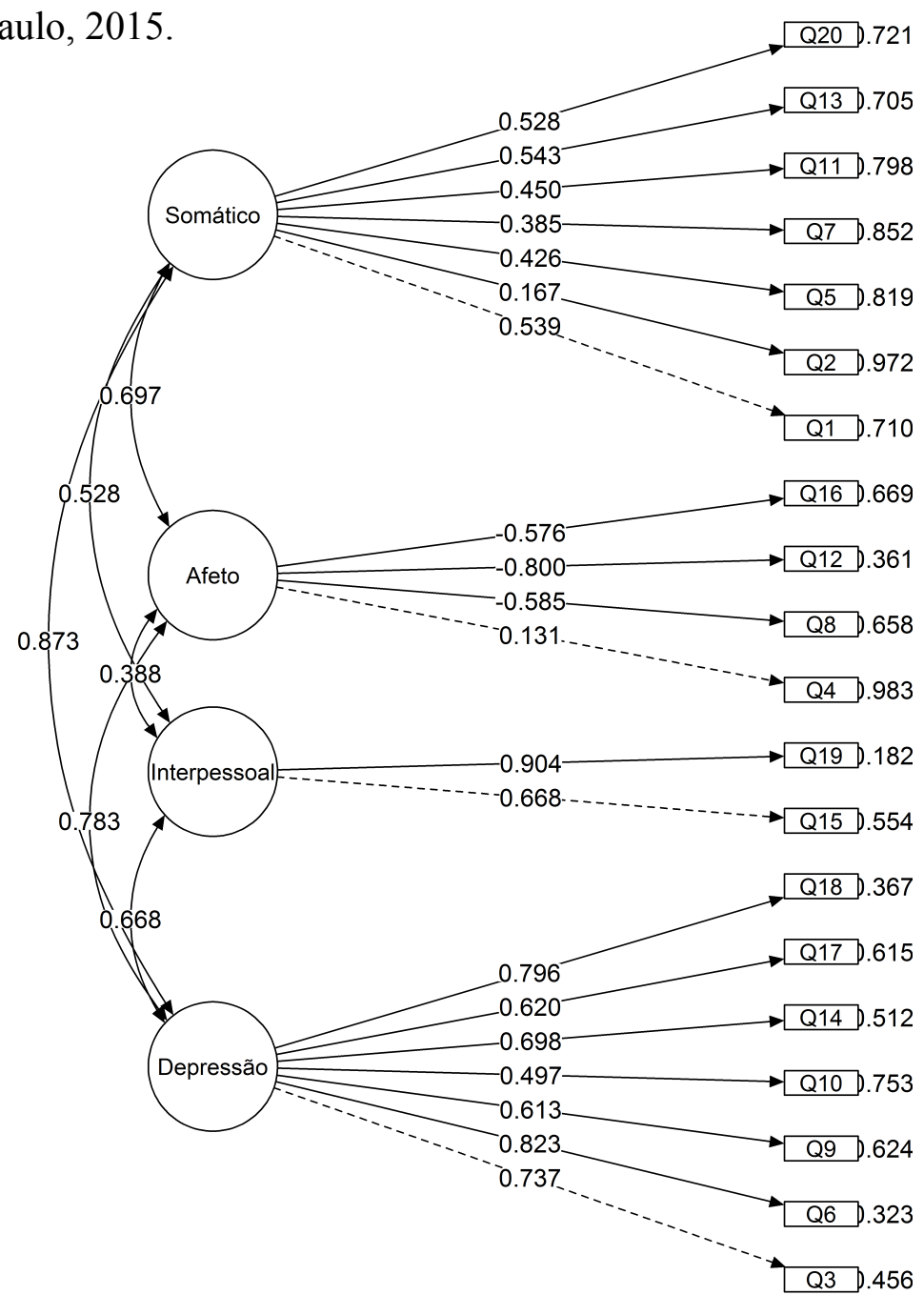

Fonte: Silva RM. Alterações de saúde, resiliência e qualidade de vida de discentes de graduação em enfermagem no primeiro ano letivo. [Tese]. São Paulo: EEUSP; 2015. 
Na Figura 8, as cargas fatoriais variam de 0,134(Item 4- Afeto Positivo) a 0,905(Item 19- Interpessoal). Ao avaliar as cargas fatoriais nos domínios, verifica-se os valores mínimos e máximos obtidos foram: 0,497 (Item 10) e 0,821 (Item 6) no domínio Depressão; 0,134 (Item 4) e 0,800 (Item 12) no domínio Afeto Positivo; 0,669(Item 15) e 0,905 (Item 19) no domínio Interpessoal; e 0,157 (Item 2) e 0,542 (Item 13) no domínio Somático.

Observa-se o predomínio de cargas fatoriais adequadas, que variam de razoáveis a excelentes, o que evidencia que os itens contribuem satisfatoriamente para explicar as variáveis latentes (domínios) em questão. Embora os itens 2 e 4 tenham apresentado cargas fatoriais classificadas como pobres, respectivamente 0,157 e 0,134 , a estrutura fatorial acima resultou em valores de ajuste satisfatórios (Tabela 2). Por isso, eles foram mantidos no instrumento. As correlações entre os domínios do CES-D apresentaram valores satisfatórios, o que confirma seu comportamento interdependente na explicação do constructo em questão, ou seja, dos sintomas depressivos.

Na Tabela 2, descrevem-se os índices de Qualidade de Ajuste e má qualidade de ajuste do Center for Epidemiologic Studies Depression Scale (CES-D).

Tabela 2- Índices de Ajuste e má qualidade de ajuste obtidas na análise fatorial confirmatória do Center for Epidemiologic Studies Depression Scale (CES-D). São Paulo, 2015.

\begin{tabular}{lcc}
\hline & $\begin{array}{c}\text { Valores Obser- } \\
\text { vados }\end{array}$ & $\begin{array}{c}\text { Valores Espe- } \\
\text { rados }\end{array}$ \\
\cline { 2 - 3 } Medidas Absolutas & & \\
\hline$\chi 2$ & 207,784 & $>0,05$ \\
$\mathrm{GL}$ & 164,000 & - \\
$\chi 2$ normatizado $(\chi 2 / \mathrm{GL})$ & 1,267 & $<3,0$ \\
P valor & 0,012 & $<0,05$ \\
GFI & 0,993 & $>0,95$ \\
\hline & & \\
Medidas Incrementais & & $>0,92$ \\
\hline CFI & 0,969 & $>0,92$ \\
\hline TLI & 0,964 & \\
\hline & & $\mathrm{r}<0,08$ \\
Má Qualidade de Ajuste & & $\mathrm{r}<0,09$ \\
\hline RMSEA & 0,050 & \\
SRMR & 0,068 & \\
\hline
\end{tabular}

Fonte: Silva RM. Alterações de saúde, resiliência e qualidade de vida de discentes de graduação em enfermagem no primeiro ano letivo. [Tese]. São Paulo: EEUSP; 2015. 
Verifica-se, na Tabela 2, que todos os valores encontrados para os indicadores de ajuste e de má qualidade de ajuste (resíduos) foram adequados. Isso indica que o CES-D apresenta validade de constructo para avaliar sintomas depressivos em discentes de enfermagem. $\mathrm{Na}$ Figura 9, apresentam-se os resultados obtidos na análise fatorial confirmatória do modelo de mensuração da Escala de Resiliência de Wagnild \& Young.

Figura 9- Modelo de Mensuração da Escala de Resiliência de Wagnild \& Young. São Paulo, 2015.

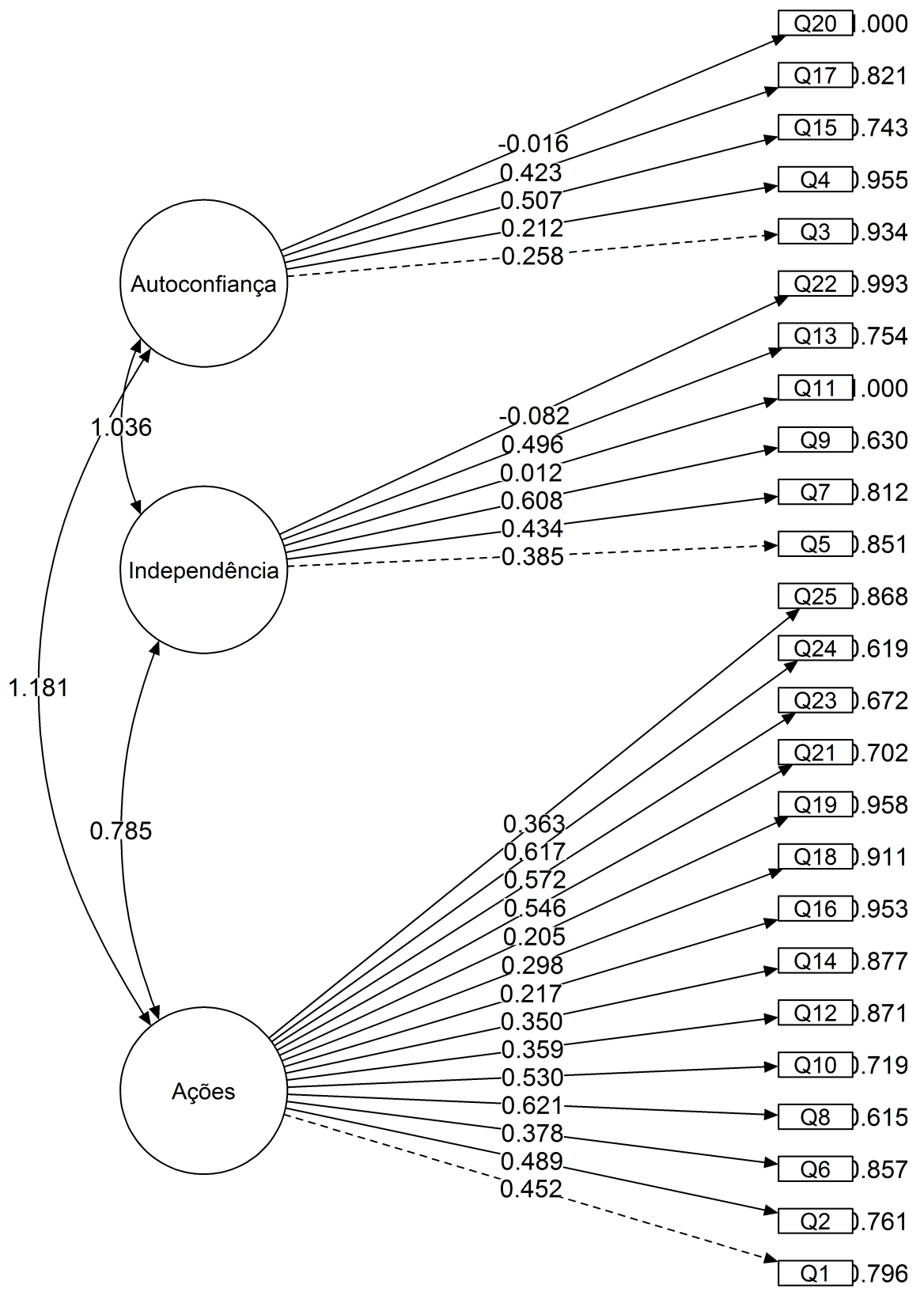

Fonte: Silva RM. Alterações de saúde, resiliência e qualidade de vida de discentes de graduação em enfermagem no primeiro ano letivo. [Tese]. São Paulo: EEUSP; 2015. 
Na Figura 9, observa-se que as cargas fatoriais variam de -0,016(Item 20 - Autoconfiança) a 0,621(Item 8- Ações) ao longo de todos os itens. $\mathrm{Na}$ análise por domínios, os valores mínimos e máximo encontrados foram respectivamente: -0,016(Item 20) e 0,507(Item 15) no domínio Autoconfiança; -0,082(Item 22) e 0,608(Item 9) no domínio Independência; e 0,205(Item 19) e 0,621 (Item 8) no domínio Ações. Quantos às cargas fatoriais, os itens $3($ Carga $=0,258), 4($ Carga $=0,212)$ e $20($ Carga $=-0,016)$ do Domínio Autoconfiança; 11(Carga $=0,012)$ e 22(Carga $=-0,082)$ do Domínio Interdependência; e dos itens 14(Carga $=0,350), 16(\mathrm{Carga}=0,217)$ e $18(\mathrm{Carga}=0,298)$ do domínio Ações apresentaram valores abaixo do esperado, todos eles classificados como pobres. No entanto, prevalecerem itens com cargas fatoriais satisfatórias, classificadas de razoáveis a muito boas, o que confirma a capacidade de os itens explicarem satisfatoriamente as variáveis latentes do instrumento em questão. Ainda, ao considerar que a estrutura proposta produziu índices de ajuste adequados para a amostra dessa pesquisa, nenhum item foi excluído da Escala. Por fim, verificam-se correlações satisfatórias entre domínios da escala, o que confirma a sua estrutura interdependente para a compreensão da resiliência. Na Tabela 3, descrevem-se os índices de Qualidade de Ajuste e má qualidade de ajuste da Escala de Resiliência de Wagnild \& Young.

Tabela 3- Índices de Ajuste e má qualidade de ajuste obtidos para o Instrumento para a Escala de Resiliência de Wagnild \& Young. São Paulo, 2015.

\begin{tabular}{lcc}
\hline & $\begin{array}{c}\text { Valores Ob- } \\
\text { servados }\end{array}$ & $\begin{array}{c}\text { Valores Espe- } \\
\text { rados }\end{array}$ \\
\hline Medidas Absolutas & 396,485 & \\
\hline$\chi 2$ & 272,000 & $>0,05$ \\
GL & 1,458 & - \\
$\chi 2$ normatizado $(\chi 2 / \mathrm{GL})$ & 0,000 & $<3,0$ \\
P valor & 0,994 & $>0,05$ \\
GFI & & \\
\hline Medidas Incrementais & 0,831 & $>0,95$ \\
\hline CFI & 0,814 & $>0,92$ \\
TLI & & \\
\hline Má Qualidade de Ajuste & 0,067 & $\mathrm{r}<0,08$ \\
\hline RMSEA & 0,096 & $\mathrm{r}<0,09$ \\
SRMR & & \\
\hline
\end{tabular}

Fonte: Silva RM. Alterações de saúde, resiliência e qualidade de vida de discentes de graduação em enfermagem no primeiro ano letivo. [Tese]. São Paulo: EEUSP; 2015.

Na Tabela 3, verifica-se que os valores encontrados para as medidas absolutas e de má qualidade de ajuste (resíduos) foram satisfatórios e que os valores de CFI e TLI ficaram pouco abaixo do esperado. Isso confirma a Escala de Resiliência de Wagnild \& Young como um 
instrumento que apresenta validade de constructo para identificar resiliência em discentes de enfermagem. Na Figura 10, apresentam-se os resultados obtidos na análise fatorial confirmatória do modelo de mensuração do Instrumento de Avaliação de Qualidade de Vida (WHOQOL-BREF).

Figura 10- Modelo de Mensuração do Instrumento de Avaliação de Qualidade de Vida. São Paulo, 2017.

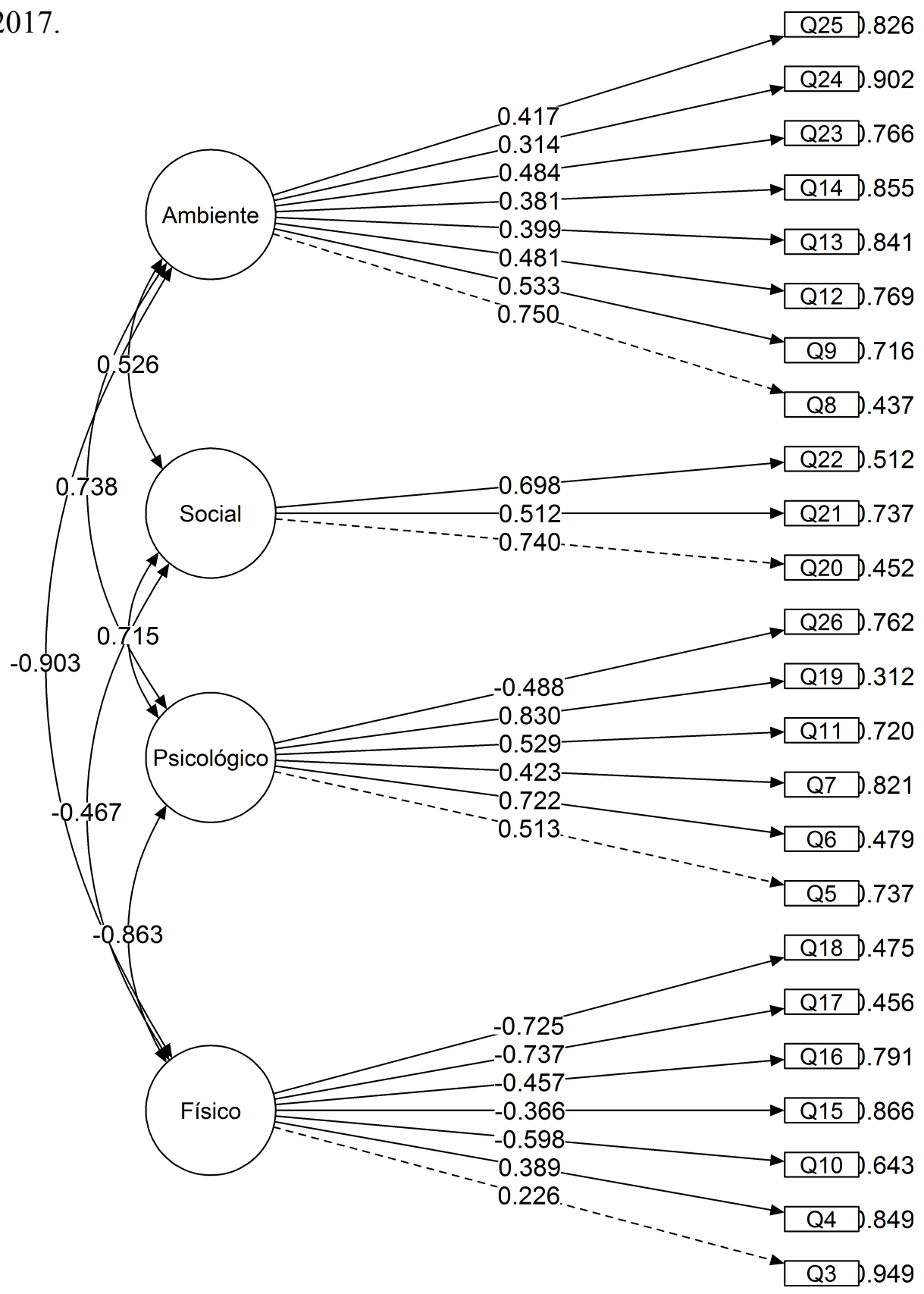

Fonte: Silva RM. Alterações de saúde, resiliência e qualidade de vida de discentes de graduação em enfermagem no primeiro ano letivo. [Tese]. São Paulo: EEUSP; 2015. 
Quanto a Figura 10, verifica-se que as cargas fatoriais variam de -0,226 (Item 3 - Domínio Físico) a 0,830 (Item 19- Domínio Psicológico) ao longo dos itens da escala. Na análise por domínios, os valores mínimos e máximo encontrados foram respectivamente: 0,314(Item 24) e 0,750(Item 8) no domínio Ambiente; 0,512(Item 21) e 0,740(Item 20) no domínio Social; 0,423 (Item 7) e 0,830 (Item 19) no domínio Psicológico; e 0,226(Item 3) e 0,737(Item 17) no domínio Físico. Embora os itens 3(Carga=0,226), 4(Carga=0,389) e $15(\mathrm{Carga}=-0,366)$ do domínio Físico e os itens $12(\mathrm{Carga}=0,481), 14(\mathrm{Carga}=0,381)$ e 24(Carga $=0,314)$ do domínio Ambiente tenham apresentado valores próximos ao mínimo esperado (classificadas de pobres a razoáveis), predominam itens com cargas fatoriais satisfatórias, classificadas como cargas que variam de razoável à excelente. Isso evidencia que os itens contribuem satisfatoriamente para explicar as variáveis latentes (domínios) em questão. Os itens com valores próximos ao mínimo adequado foram mantidos, pois, junto aos demais itens, produziram boa qualidade de ajuste ao instrumento (Tabela 4). As correlações entre os domínios apresentaram valores satisfatórios, o que confirma seu comportamento interdependente na explicação da qualidade de vida em discentes de enfermagem. Na Tabela 4, descrevem-se os índices de Qualidade de Ajuste e má qualidade de ajuste do Instrumento de Avaliação de Qualidade de Vida (WHOQOL-BREF).

Tabela 4- Índices de Ajuste e má qualidade de ajuste obtidos para o Instrumento de Avaliação de Qualidade de Vida (WHOQOL-BREF). São Paulo, 2015.

\begin{tabular}{lcc}
\hline & $\begin{array}{c}\text { Valores Obser- } \\
\text { vados }\end{array}$ & $\begin{array}{c}\text { Valores Espe- } \\
\text { rados }\end{array}$ \\
\cline { 2 - 3 } Medidas Absolutas & & \\
\hline$\chi 2$ & 384,657 & $>0,05$ \\
GL & 246 & - \\
$\chi 2$ normatizado $(\chi 2 / G L)$ & 1,564 & $<3,0$ \\
P valor & 0,000 & $<0,05$ \\
GFI & 0,994 & $>0,95$ \\
\hline & & \\
Medidas Incrementais & & $>0,92$ \\
\hline CFI & 0,915 & $>0,92$ \\
TLI & 0,904 & \\
\hline & & $\mathrm{r}<0,08$ \\
Má Qualidade de Ajuste & & $\mathrm{r}<0,09$ \\
\hline RMSEA & 0,073 & \\
SRMR & 0,082 & \\
\hline
\end{tabular}

Fonte: Silva RM. Alterações de saúde, resiliência e qualidade de vida de discentes de graduação em enfermagem no primeiro ano letivo [Tese]. São Paulo: EEUSP; 2017. 
Verifica-se, na Tabela 4, que os valores de CFI e TLI foram próximos ao mínimo esperado. Já os valores das medidas absolutas de qualidade de ajuste e as medidas de má qualidade de ajuste (resíduos) foram adequados. Isso indica que a versão reduzida do instrumento apresenta validade de constructo para mensurar qualidade de vida em discentes de enfermagem.

Quanto ao Índice da Qualidade do Sono de Pittsburgh (IQSP), esse apresenta alguns domínios que contém apenas um item, bem como itens que contém unidades de medida diferentes (escala likert e horas), o que inviabilizou a análise fatorial confirmatória. Na validação do instrumento original, a análise de confiabilidade ocorreu por meio do Alfa de Cronbach e teste-reteste; e a validade foi estabelecida com base em grupos de bons e maus dormidores ${ }^{(51)}$. Dessa forma, com base nos valores satisfatórios obtidos nessa análise prévia, optou-se por manter e utilizar o IQSP nessa pesquisa. Os resultados da análise de confiabilidade dos instrumentos utilizados nessa etapa da pesquisa são apresentados na Tabela 5.

Tabela 5- Valores de Alfa de Cronbach para os instrumentos analisados na Fase 1 da pesquisa. São Paulo, 2015.

\begin{tabular}{|c|c|}
\hline Instrumento & Alfa de Cronbach \\
\hline AEEE & 0,852 \\
\hline Realização de Atividade Prática & 0.759 \\
\hline Comunicação Profissional & 0.821 \\
\hline Gerenciamento do Tempo & 0.554 \\
\hline Ambiente & 0.882 \\
\hline Formação Profissional & 0.768 \\
\hline Atividade Teórica & 0.632 \\
\hline CES-D & 0,746 \\
\hline Depressão & 0.857 \\
\hline Interpessoal & 0.752 \\
\hline Afeto Positivo & 0.475 \\
\hline Somático & 0.627 \\
\hline IQSP & 0,763 \\
\hline Escala de Resiliência & 0,804 \\
\hline
\end{tabular}




\begin{tabular}{cc}
\hline WHOQOL-BREF & 0,880 \\
\hline Físico & 0.701 \\
Psicológico & 0.746 \\
Social & 0.653 \\
Ambiente & 0.710
\end{tabular}

Fonte: Silva RM. Alterações de saúde, resiliência e qualidade de vida de discentes de graduação em enfermagem no primeiro ano letivo [Tese]. São Paulo: EEUSP; 2015.

$\mathrm{Na}$ Tabela 5, observa-se que os instrumentos apresentaram valores de alfa satisfatórios $(>0,7)$ na análise geral (para todos os itens e na maioria dos domínios/fatores, sendo, portanto, considerados confiáveis para a aplicação em discentes de enfermagem.

\subsection{AVALIAÇÃO DAS ALTERAÇÕES NA SAÚDE, RESILIÊNCIA E QUALI- DADE DE VIDA}

Após a confirmação da validade de constructo dos instrumentos utilizados, esses foram aplicados em março e dezembro de 2016. O fluxo de exclusão dos discentes segundo os critérios de elegibilidade é apresentado abaixo (Figura11).

Figura 11- Fluxo de Exclusão dos sujeitos de pesquisa. São Paulo, 2016.

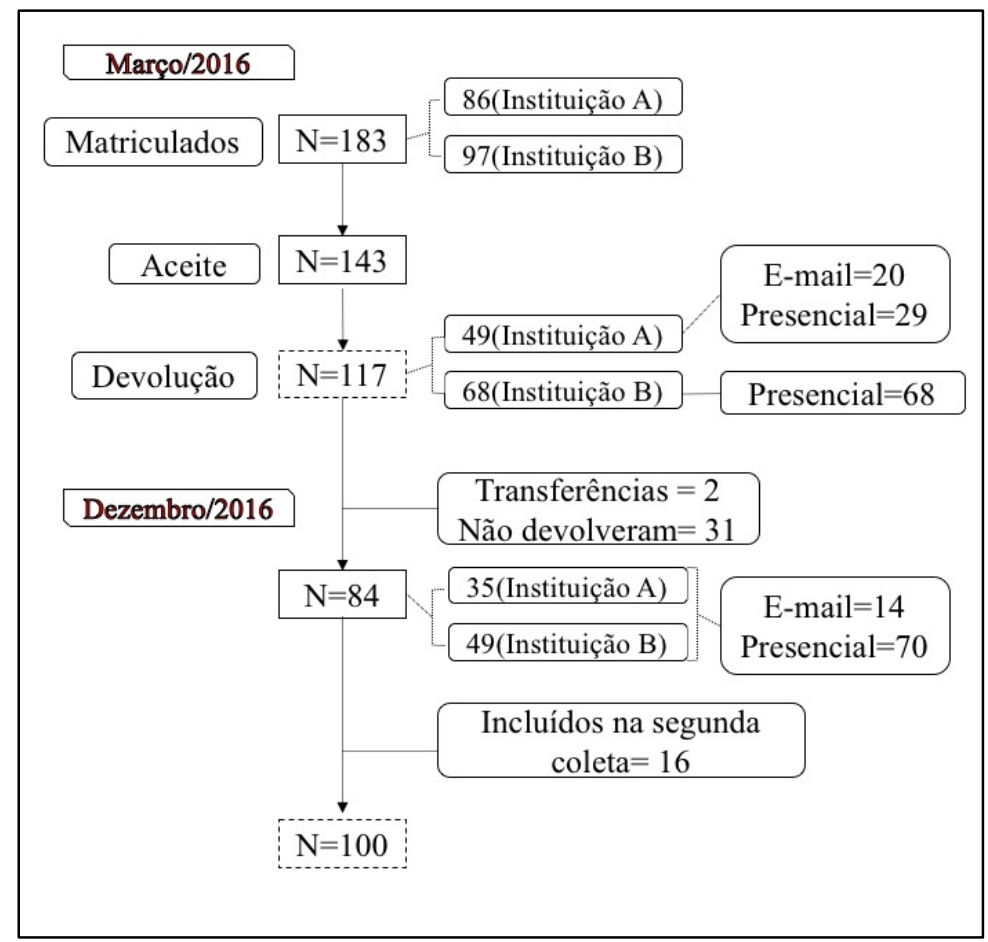

Fonte: Silva RM. Alterações de saúde, resiliência e qualidade de vida de discentes de graduação em enfermagem no primeiro ano letivo [Tese]. São Paulo: EEUSP; 2016. 
Conforme observado na Figura 11, em março, dos 183 alunos matriculados nas duas instituições pesquisadas, 143 aceitaram participar da pesquisa, porém 117 devolveram os instrumentos preenchidos. Em dezembro, dos 117 alunos incluídos na pesquisa, 33 foram excluídos, o que totalizou 84 discentes de enfermagem acompanhados em ambos os períodos. Todavia, 16 alunos que não haviam participado da coleta em março solicitaram a participação no estudo na segunda coleta e foram incluídos. Portanto, a amostra de dezembro compôs-se por 100 discentes de enfermagem. Na Tabela 6, apresenta-se a caracterização sociodemográfica dos discentes de enfermagem nos dois períodos analisados.

Tabela 6- Caracterização sociodemográfica dos discentes de enfermagem em Marco e Dezembro de 2016. São Paulo, 2016.

\begin{tabular}{|c|c|c|}
\hline \multirow[t]{2}{*}{ Variáveis sociodemográficas* } & $\begin{array}{c}\text { Março de } \\
2016(n=117)\end{array}$ & $\begin{array}{l}\text { Dezembro de } \\
2016(n=100)\end{array}$ \\
\hline & $\begin{array}{c}\text { n(\%) ou } \\
\text { Média (DP) }\end{array}$ & $\begin{array}{c}\text { n(\%) ou Mé- } \\
\text { dia (DP) }\end{array}$ \\
\hline Sexo(Feminino) & $99(84,6 \%)$ & $88(88,0 \%)$ \\
\hline Idade & $20,73(4,4)$ & $20,90(5,1)$ \\
\hline Situação Conjugal (Solteiro/Sem companheiro) & $98(83,8 \%)$ & $78(78 \%)$ \\
\hline Filhos (Não) & $112(95,7 \%)$ & $98(98 \%)$ \\
\hline Reside em SP(Sim) & $100(85,5 \%)$ & $83(83 \%)$ \\
\hline Reside com (Família) & $94(80,3 \%)$ & $81(81 \%)$ \\
\hline Reside em (Apartamento/Casa própria) & $77(65,8 \%)$ & $65(65 \%)$ \\
\hline Ensino Médio (Escola Privada) & $60(51,3 \%)$ & $52,0(52 \%)$ \\
\hline Esporte (Não) & $77(65,8 \%)$ & $76(76 \%)$ \\
\hline Lazer (Sim) & $71(60,7 \%)$ & $61(61 \%)$ \\
\hline Fonte de renda (Recursos da Família) & $81(69,2 \%)$ & $66(66 \%)$ \\
\hline Fármaco para inibir o sono (Sim) & $67(57,3 \%)$ & $52(52 \%)$ \\
\hline Fármaco para conseguir dormir (Não) & $104(88,9 \%)$ & $85(85 \%)$ \\
\hline Tabagista (Não-nunca fumou) & $107(91,5 \%)$ & $88(88 \%)$ \\
\hline Consumo de Bebida Alcoólica (Sim) & $74(63,2 \%)$ & $65(65 \%)$ \\
\hline Frequência do consumo de & $38(32,5 \%)$ & $36(36 \%)$ \\
\hline
\end{tabular}


Bebida Alcoólica

Semanalmente

$31(26,5 \%)$

$26(26 \%)$

*As categorias predominantes para cada variável são apresentadas.

Fonte: Silva RM. Alterações de saúde, resiliência e qualidade de vida de discentes de graduação em enfermagem no primeiro ano letivo [Tese]. São Paulo: EEUSP; 2016.

Na Tabela 6, verifica-se predomínio de discentes do sexo feminino, jovens (com aproximadamente 20 anos de idade), solteiros, sem filhos, que residem na cidade de São Paulo, em apartamento ou casa própria com a família, da qual dependem financeiramente para a própria manutenção mensal. Embora realizem atividade de lazer, não sejam tabagistas e não consumam fármacos para conseguir dormir, houve predomínio de discentes que não praticam atividade esportivas, utilizam fármacos para inibir o sono e que consomem bebidas alcoólicas mensamente ou semanalmente. Na Tabela 7, apresenta-se a caracterização acadêmica dos discentes de enfermagem nos dois períodos analisados.

Tabela 7- Características acadêmicas dos discentes de enfermagem em Marco e Dezembro de 2016. São Paulo, 2016.

\begin{tabular}{|c|c|c|}
\hline \multirow[t]{2}{*}{ Variáveis acadêmicas* } & $\begin{array}{c}\text { Março de } \\
\text { 2016(n=117) }\end{array}$ & $\begin{array}{l}\text { Dezembro de } \\
2016(n=100)\end{array}$ \\
\hline & $\begin{array}{c}\text { N (\%) ou } \\
\text { Média (DP) }\end{array}$ & $\begin{array}{c}\text { N (\%) ou Mé- } \\
\text { dia (DP) }\end{array}$ \\
\hline Tempo gasto até à insti- Instituição $\mathrm{A}$ & $68,3(26,1)$ & $63,4(27,1)$ \\
\hline tuição (Minutos) Instituição B & $71,7(41,1)$ & $70,4(45,4)$ \\
\hline Horas de Estudo por dia & $2,7(1,3)$ & $6,0(2,5)$ \\
\hline Número de disciplinas cursadas & $11(2,9)$ & $10,4(2,8)$ \\
\hline Atividades Extracurriculares (Sim) & $66(56,4 \%)$ & $51(51,0 \%)$ \\
\hline Possui atividade de Trabalho (Não) & $109(93,2 \%)$ & $89(89,0 \%)$ \\
\hline Satisfeito com o curso (Sim) & $103(88,0 \%)$ & $88(88,0 \%)$ \\
\hline Interesse em desistir do curso (Não) & $75(64,1 \%)$ & $53(53,0 \%)$ \\
\hline Carga Horária semes- Instituição A & $442,9(160,1)$ & $555(0)$ \\
\hline Instituição B & $848,6(253,9)$ & $1016,3(194,8)$ \\
\hline
\end{tabular}

*As categorias predominantes para cada variável são apresentadas.

**Média obtida a partir dos valores informados pelos alunos.

Fonte: Silva RM. Alterações de saúde, resiliência e qualidade de vida de discentes de graduação em enfermagem no primeiro ano letivo. [Tese]. São Paulo: EEUSP; 2016. 
Na Tabela 7, observa-se que, em ambos os períodos analisados, os discentes dispensam aproximadamente 1 hora para chegarem até as instituições de ensino. Eles não exercem atividades de trabalho, estão matriculados em aproximadamente 10 a 11 disciplinas ao longo do ano letivo, sob uma carga horária semestral média que varia de 555 (Instituição A) a 1016 (Instituição B) e estão satisfeitos com o curso. Evidencia-se que, ao longo do ano, os discentes deixam de realizar atividades extracurriculares, mudam sua percepção sobre desistir do curso e estudam mais tempo diariamente. Na Figura 12, apresenta-se a variação do estresse psicoemocional segundo cada fator do AEEE ao longo do referido ano.

Figura 12- Variação do nível de estresse psicoemocional por fator do AEEE em discentes de enfermagem após o primeiro ano letivo no curso de graduação. São Paulo, 2016.

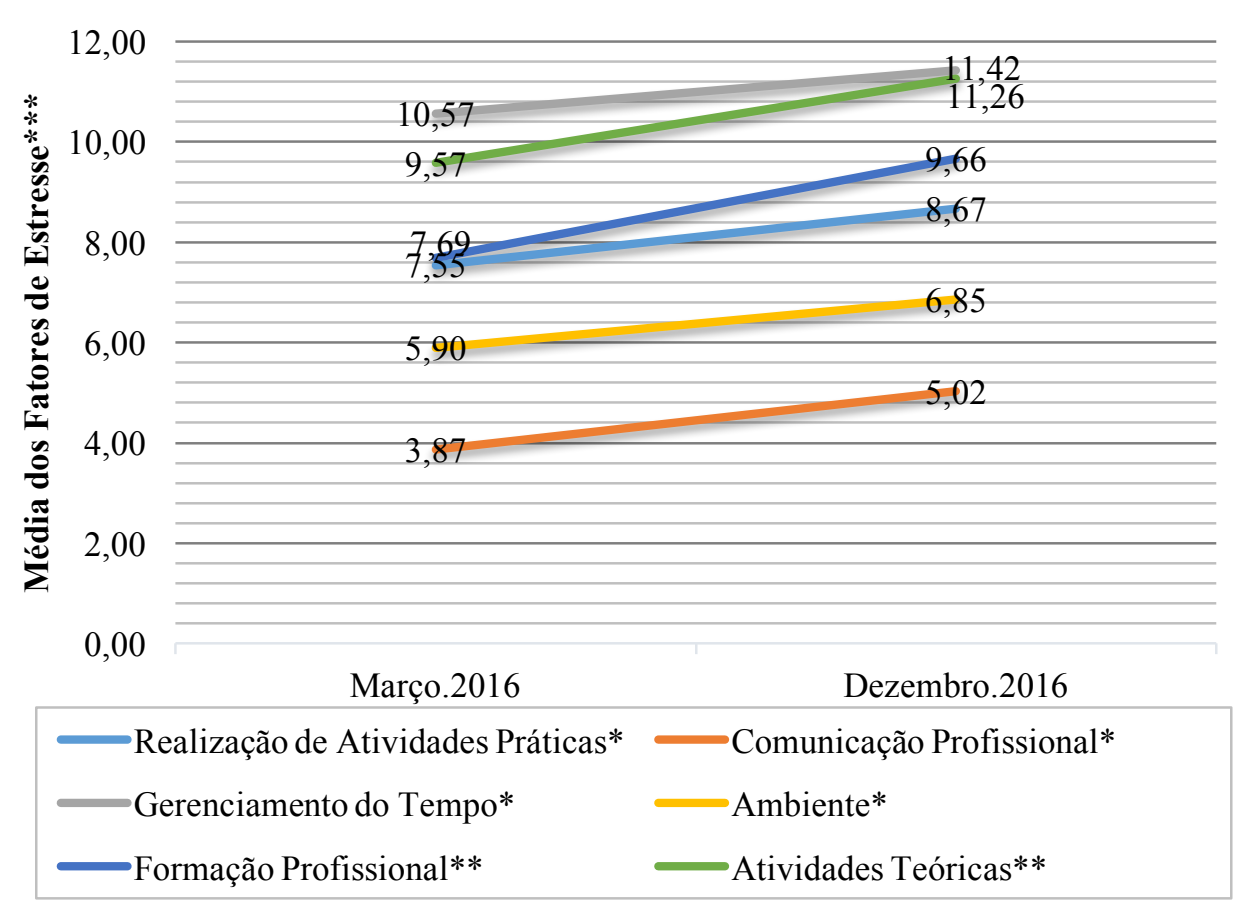

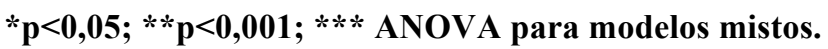

Fonte: Silva RM. Alterações de saúde, resiliência e qualidade de vida de discentes de graduação em enfermagem no primeiro ano letivo. [Tese]. São Paulo: EEUSP; 2016.

Na Figura 12, verifica-se, entre março e dezembro de 2016, aumento estatisticamente significativo nos níveis de estresse psicoemocional em todos os domínios do AEEE: Realização de Atividades Práticas ( $\mathrm{p}=0,038)$; Gerenciamento do Tempo $(\mathrm{p}=0,014)$; Comunicação Profissional $(p=0,007)$; Ambiente $(p=0,003)$; Formação Profissional $(p<0001)$ e Atividades Teóricas $(\mathrm{p}<0,001)$. Na Tabela 8 , apresenta-se a análise descritiva dos níveis de estresse psicoemocional geral nos discentes de enfermagem em março e dezembro de 2016. 
Tabela 8- Análise descritiva dos níveis de estresse psicoemocional geral nos discentes de enfermagem em março e dezembro de 2016. São Paulo, 2016.

\begin{tabular}{|c|c|c|c|c|c|c|c|c|}
\hline \multirow[b]{3}{*}{$\begin{array}{l}\text { Domínios } \\
\text { AEEE }\end{array}$} & \multicolumn{8}{|c|}{ Nível de Estresse } \\
\hline & \multicolumn{2}{|c|}{ Baixo } & \multicolumn{2}{|c|}{ Médio } & \multicolumn{2}{|c|}{ Alto } & \multicolumn{2}{|c|}{ Muito Alto } \\
\hline & $\begin{array}{l}\mathrm{M}^{*} \\
\mathrm{n}(\%)\end{array}$ & $\begin{array}{l}D^{* *} \\
\mathrm{n}(\%)\end{array}$ & $\begin{array}{c}\mathrm{M} \\
\mathrm{n}(\%)\end{array}$ & $\begin{array}{c}\mathrm{D} \\
\mathrm{n}(\%)\end{array}$ & $\begin{array}{c}\mathrm{M} \\
\mathrm{n}(\%)\end{array}$ & $\begin{array}{c}\mathrm{D} \\
\mathrm{n}(\%)\end{array}$ & $\begin{array}{c}\mathrm{M} \\
\mathrm{n}(\%)\end{array}$ & $\begin{array}{c}\mathrm{D} \\
\mathrm{n}(\%)\end{array}$ \\
\hline $\begin{array}{l}\text { Realização de } \\
\text { Atividade Prá- } \\
\text { tica }\end{array}$ & $83(70,9)$ & $60(51,3)$ & $21(17,9)$ & $16(13,7)$ & $10(\mathbf{8 , 5})$ & $12(\mathbf{1 0}, \mathbf{3})$ & $3(\mathbf{2}, \mathbf{6})$ & $12(\mathbf{1 0 , 3})$ \\
\hline $\begin{array}{l}\text { Comunicação } \\
\text { Profissional }\end{array}$ & $86(73,5)$ & $57(48,7)$ & $13(11,1)$ & $12(10,3)$ & $9(7,7)$ & $15(\mathbf{1 2 , 8})$ & $9(7,7)$ & $16(13,7)$ \\
\hline $\begin{array}{l}\text { Gerenciamento } \\
\text { do Tempo }\end{array}$ & $52(44,4)$ & $27(23,1)$ & $31(26,5)$ & $40(34,2)$ & $28(23,9)$ & $23(19,7)$ & $6(5, \mathbf{1})$ & $10(\mathbf{8 , 5})$ \\
\hline Ambiente & $87(74,4)$ & $57(48,7)$ & $16(13,7)$ & $24(20,5)$ & $1(\mathbf{0 , 9})$ & $7(\mathbf{6 , 0})$ & $13(\mathbf{1 1}, \mathbf{1})$ & $12(10,3)$ \\
\hline $\begin{array}{l}\text { Formação Pro- } \\
\text { fissional }\end{array}$ & $89(76,1)$ & $52(44,4)$ & $5(4,3)$ & $7(6,0)$ & $14(12)$ & $17(14,5)$ & $9(7,7)$ & $24(\mathbf{2 0 , 5})$ \\
\hline $\begin{array}{l}\text { Atividade Teó- } \\
\text { rica }\end{array}$ & $59(50,4)$ & $26(22,2)$ & $27(23,1)$ & $25(21,4)$ & $24(20,5)$ & $29(24,8)$ & $7(\mathbf{6}, \mathbf{0})$ & $20(\mathbf{1 7}, \mathbf{1})$ \\
\hline
\end{tabular}

*M: Março de 2016

*D: Dezembro de 2016

Fonte: Silva RM. Alterações de saúde, resiliência e qualidade de vida de discentes de graduação em enfermagem no primeiro ano letivo. [Tese]. São Paulo: EEUSP; 2016.

Na Tabela 8, observa-se que a realização de atividades práticas representou, em março, alto e muito alto estresse psicoemocional para $8,5 \%$ e $2,6 \%$ dos discentes respectivamente, valores que aumentaram para $10,3 \%$ em dezembro. O gerenciamento do tempo representava muito alto estresse psicoemocional para 5,1\% dos discentes no início do ano letivo, com elevação para 8,5\% em dezembro. Da mesma forma, os fatores Comunicação Profissional e Ambiente que, em março, significavam alto estresse psicoemocional para 7,7\% e $0,9 \%$ dos acadêmicos respectivamente, foram percebidos em dezembro como altamente estressantes para $12,8 \%$ e $6 \%$ da população respectivamente. Ao início do ano, 7,7\% e $6 \%$ dos discentes percebiam muito alto estresse psicoemocional nos domínios Formação Profissional e Atividades Teóricas respetivamente. Ao final desse período, esses valores se elevaram para 20,5\% e 17,1\% respectivamente. Na Tabela 9, demonstra-se a variação dos escores no período analisado segundo os domínios do CES-D, IQSP, WHOQOL-BREF e Escala de Resiliência em discentes de enfermagem. 
Tabela 9- Variação dos escores por domínio do CES-D, IQSP, WHOQOL-BREF e Escala de Resiliência em discentes de enfermagem. São Paulo, 2016.

\begin{tabular}{|c|c|c|c|}
\hline \multirow[t]{2}{*}{ Variável** } & \multicolumn{2}{|c|}{ Médias(DP) } & \multirow[b]{2}{*}{ P-valor } \\
\hline & Março & Dezembro & \\
\hline \multicolumn{4}{|l|}{ CESD } \\
\hline Depressão & 13,78 & 14,71 & 0,210 \\
\hline Interpessoal & 3,00 & 3,48 & 0,060 \\
\hline Afeto Positivo & 9,36 & 9,58 & 0,336 \\
\hline Somática/Iniciativa & 16,00 & 17,21 & $0,007 *$ \\
\hline \multicolumn{4}{|l|}{ IQSP } \\
\hline Qualidade Subjetiva do Sono & 1,51 & 1,81 & $0,001^{*}$ \\
\hline Latência Sono & 1,29 & 1,36 & 0,622 \\
\hline Duração do sono & 1,38 & 1,78 & $0,009^{*}$ \\
\hline Eficiência Habitual do Sono & 0,46 & 0,38 & 0,295 \\
\hline Distúrbios do Sono & 2,38 & 2,29 & 0,426 \\
\hline Uso de medicamento para dormir & 0,15 & 0,19 & 0,171 \\
\hline Sonolência diurna & 2,65 & 2,71 & 0,077 \\
\hline \multicolumn{4}{|l|}{ Escala de Resiliência } \\
\hline Ações e Valores & 5,06 & 4,97 & 0,511 \\
\hline Independência e determinação & 3,90 & 4,00 & 0,512 \\
\hline Autoconfiança e capacidade de adap- & 5,22 & 5,23 & \\
\hline tação & & & 0,987 \\
\hline
\end{tabular}

WHOQOL-BREF

\begin{tabular}{llll}
\hline Físico & 57,24 & 54,93 & 0,088 \\
Psicológico & 56,55 & 54,79 & 0,118 \\
Social & 61,47 & 62,92 & 0,773 \\
Meio ambiente & 50,24 & 49,67 & 0,172 \\
\hline
\end{tabular}

*Valor estatisticamente significativo $(\mathrm{p}<0,05)$

**ANOVA para modelos mistos.

Fonte: Silva RM. Alterações de saúde, resiliência e qualidade de vida de discentes de graduação em enfermagem no primeiro ano letivo. [Tese]. São Paulo: EEUSP; 2016.

$\mathrm{Na}$ Tabela 9, observa-se aumento estatisticamente significativo nos escores do domínio somática/iniciativa, o que implica maior dificuldades de se engajar e manter atividades 
$\operatorname{cotidianas}^{(61)}$. Na Figura 13, apresenta-se a avaliação da qualidade de Sono reportada pelos discentes de enfermagem no Inventário de Qualidade do Sono de Pittsburg.

Figura 13- Qualidade de Sono reportada pelos discentes de enfermagem no Inventário de Qualidade do Sono de Pittsburg. São Paulo, 2016.

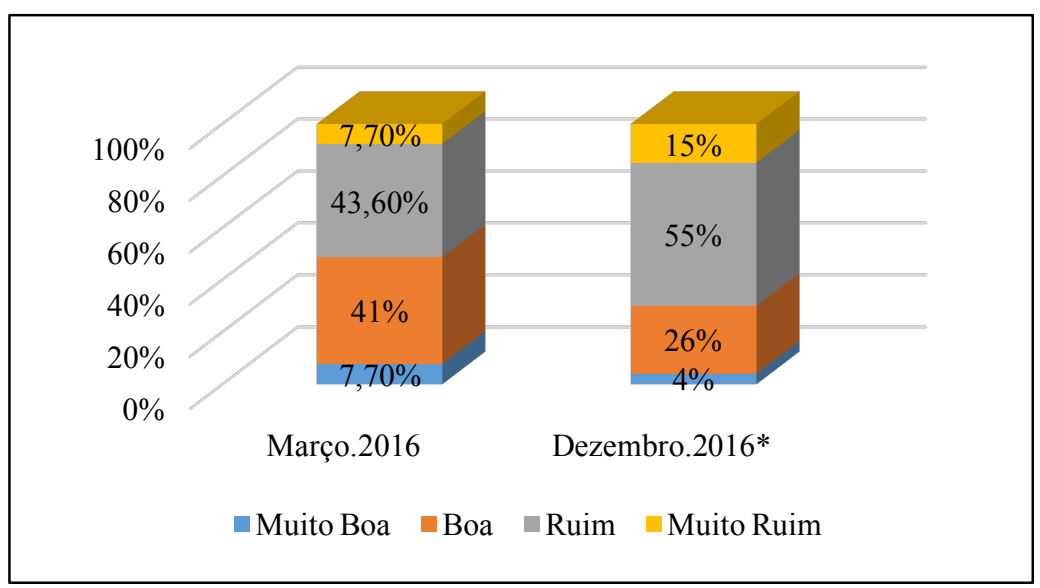

Nota: Esses dados foram obtidos a partir das respostas da amostra ao Item 6 do IQSP. $* \mathrm{P}<0,005$

Fonte: Silva RM. Alterações de saúde, resiliência e qualidade de vida de discentes de graduação em enfermagem no primeiro ano letivo. [Tese]. São Paulo: EEUSP; 2016.

Na Figura 13, verifica-se diferença significativa na qualidade do sono reportada entre Março e Dezembro de 2016 ( $p=0,03$ ), sendo que 41\% deles reportaram "muito boa" qualidade de sono (Item 6 do IQSP) em março e $26 \%$ em dezembro. Todavia, uma variação oposta foi observada naqueles que referiram qualidade do sono ruim (Março- 7,7\% e dezembro- 15\%). Na Figura 14, verificam-se os valores médios de duração do sono dos discentes de enfermagem no mês anterior a aplicação do instrumento.

Figura 14 Duração média do sono de discentes de enfermagem ao longo do ano letivo. São Paulo, 2016.

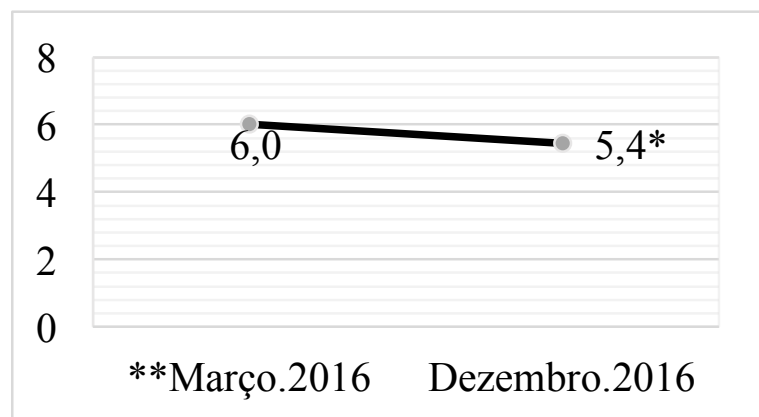

Nota: A duração do sono refere-se ao número de horas dormidas, em média, no mês anterior à aplicação do questionário.

* p<0,05; ** ANOVA para modelos mistos

Fonte: Silva RM. Alterações de saúde, resiliência e qualidade de vida de discentes de graduação em enfermagem no primeiro ano letivo. [Tese]. São Paulo: EEUSP; 2016. 
Uma vez que o IQSP possui escala reversa, o aumento dos escores indicam redução na duração e na qualidade subjetiva do sono entre os discentes de enfermagem no período avaliado. Em março, os alunos dormiam em média 6,00 horas por noite ( $\mathrm{Dp}=1,42)$, com queda estatisticamente significativa $(\mathrm{p}=0,009)$ para 5,40 horas de sono, em média, no mês de dezembro $(\mathrm{Dp}=1,27)$. Na Figura 15, demonstra-se a variação do nível de estresse psicoemocional, sintomas depressivos, qualidade do sono, qualidade de vida e resiliência em discentes de enfermagem.

Figura 15- Alteração dos níveis de estresse psicoemocional, sintomas depressivos, qualidade do sono, qualidade de vida e resiliência em discentes de enfermagem um ano após o ingresso no curso. São Paulo, 2016.

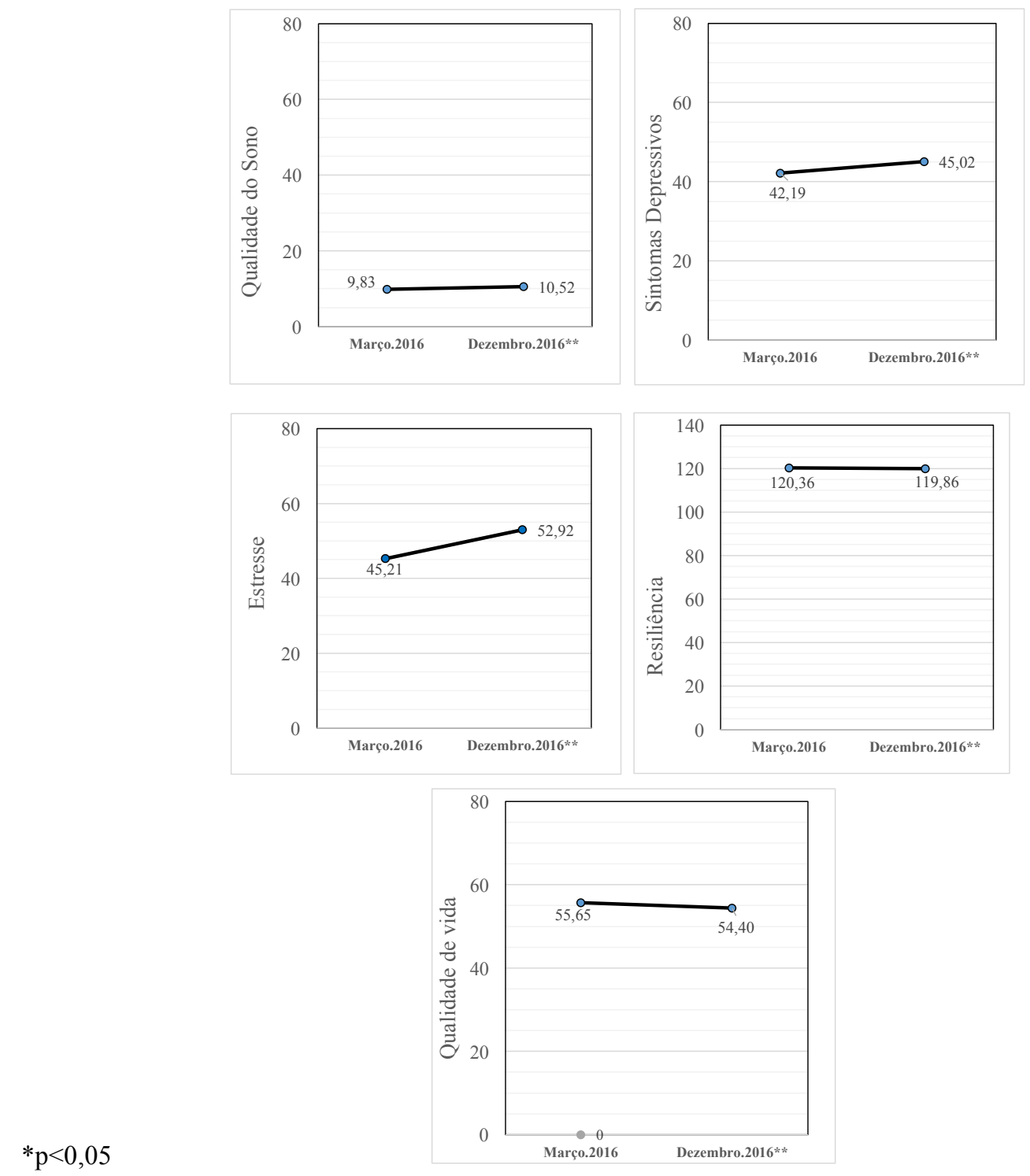

** ANOVA para modelos mistos.

Fonte: Silva RM. Alterações de saúde, resiliência e qualidade de vida de discentes de graduação em enfermagem no primeiro ano letivo. [Tese]. São Paulo: EEUSP; 2016. 
Na Figura 15, dos cinco constructos analisados, verifica-se o aumento estatisticamente significativo dos níveis de estresse psicoemocional geral e sintomas depressivos nos discentes de enfermagem ao longo do ano letivo de 2016. O aumento dos escores nos sintomas depressivos implica aumento na frequência com que os discentes experimentaram tais sintomas no período analisado. Para o estresse, o escore representa o aumento da intensidade do estresse psicoemocional vivenciado ao longo do ano letivo. Na Figura 16, apresenta-se a análise descritiva dos níveis de estresse nos dois momentos analisados- março e dezembro de 2016.

Figura 16- Análise descritiva dos níveis de estresse psicoemocional geral nos discentes de enfermagem em março e dezembro de 2016.

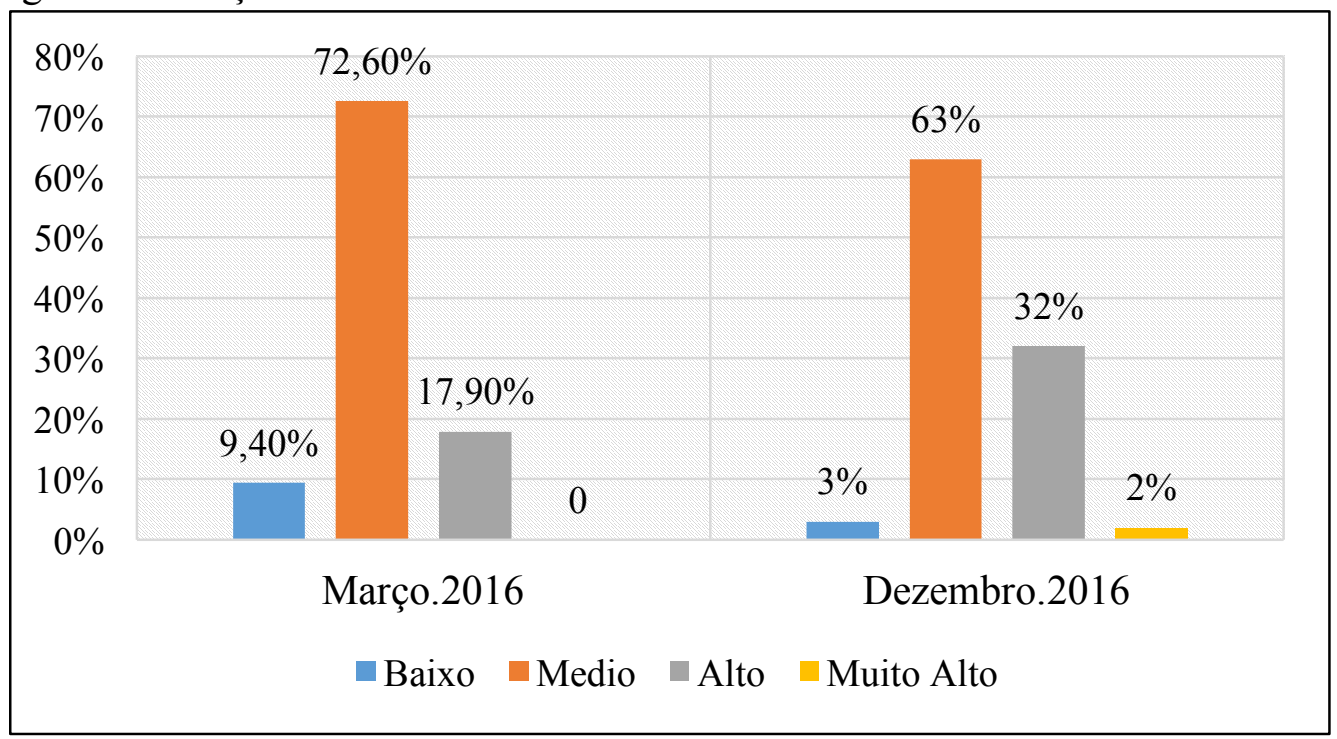

Fonte: Silva RM. Alterações de saúde, resiliência e qualidade de vida de discentes de graduação em enfermagem no primeiro ano letivo. [Tese]. São Paulo: EEUSP; 2016.

Na Figura 16, observa-se que, ao início do ano, 17,9\% dos discentes relataram alto estresse psicoemocional e nenhum muito alto estresse psicoemocional, porém esses valores aumentaram para $27,4 \%$ e $1,7 \%$ em dezembro.

\subsection{Efeito dos fenômenos de saúde sobre a qualidade de vida dos discentes de en- fermagem}

Para a análise do efeito dos fenômenos de saúde sobre a qualidade de vida dos discentes de enfermagem, incialmente, realizou-se a descrição dos modelos de mensuração que compuseram o modelo estrutural, seguido pelos índices de ajuste do modelo estrutural e achados da regressão linear. Posteriormente, o modelo final ajustado foi interpretado segundo às 
relações significativas encontradas. Na Figura 17, apresentam-se os modelos de Mensuração das variáveis latentes que compuseram o modelo estrutural inicial.

Figura 17- Modelos de Mensuração das variáveis latentes que compuseram o modelo estrutural inicial. São Paulo, 2016.

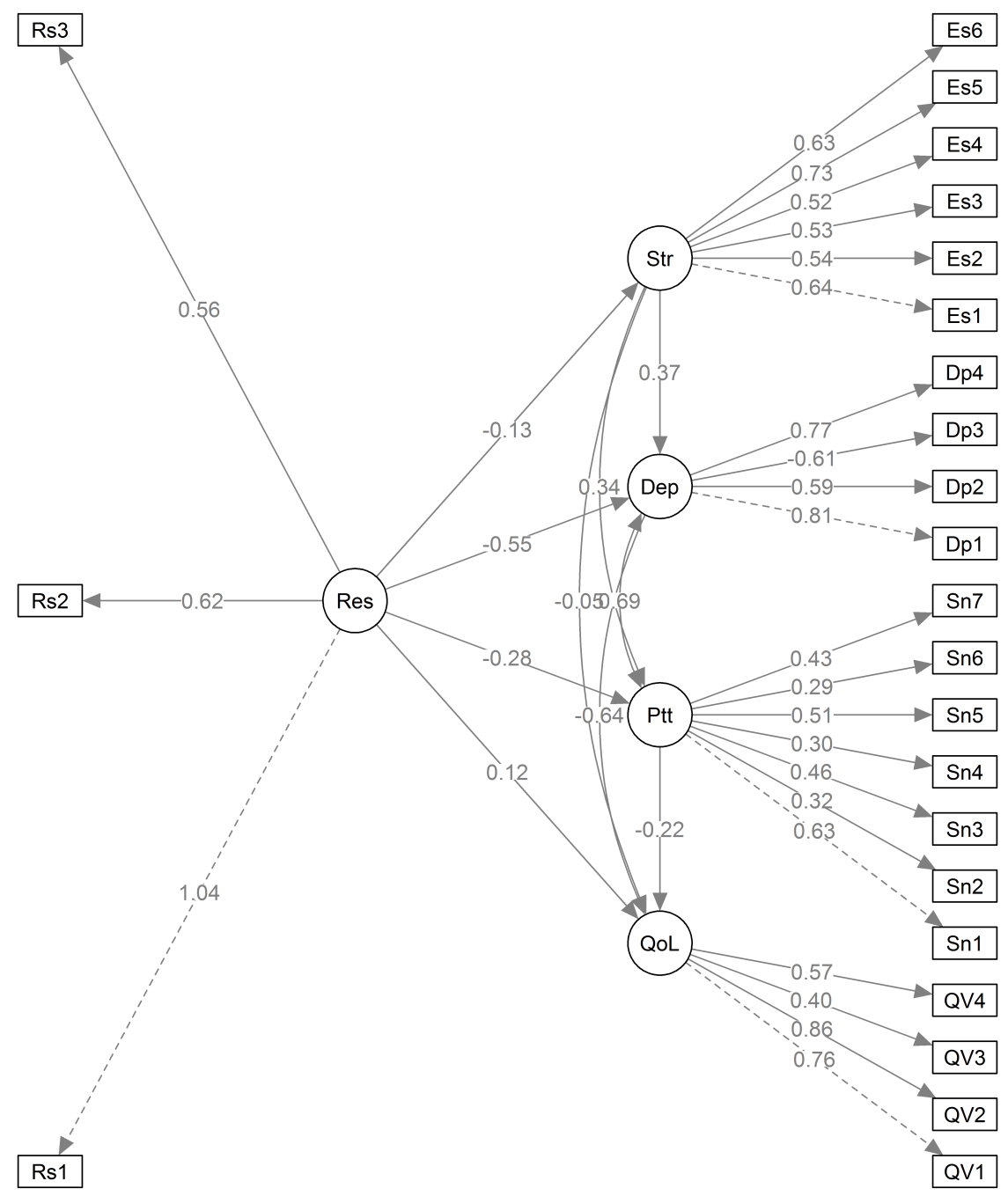

Legenda: Res-Resiliência; Str-Estresse psicoemocional (AEEE); Dep-Sintomas depressivos (CES-D); Ptt- Qualidade do sono (IQSP); e QOL-Qualidade de vida (WHOQoL-Bref).

Fonte: Silva RM. Alterações de saúde, resiliência e qualidade de vida de discentes de graduação em enfermagem no primeiro ano letivo [Tese]. São Paulo: EEUSP; 2016.

Quanto aos dados da Figura 17, verifica-se que os valores das cargas fatoriais ficaram muito abaixo do esperado nas relações entre resiliência e: qualidade de Vida (Carga Fatorial= 0,12); qualidade do sono (Carga Fatorial= -0,28); e estresse psicossocial (Carga Fatorial= 0,13). Na Tabela 10, descrevem-se os índices de Qualidade de Ajuste e má qualidade de ajuste do Modelo Estrutural hipotetizado inicial. 
Tabela 10- Índices de Ajuste e má qualidade de ajuste obtidos para o Modelo Estrutural hipotetizado inicial. São Paulo, 2016.

\begin{tabular}{lcc}
\hline Medidas Absolutas & $\begin{array}{c}\text { Valores Ob- } \\
\text { servados* }\end{array}$ & $\begin{array}{c}\text { Valores Espe- } \\
\text { rados }\end{array}$ \\
\hline$\chi 2$ & 418,1 & $>0,05$ \\
GL & 242 & - \\
$\chi 2$ normatizado $(\chi 2 / \mathrm{GL})$ & 1,72 & $<3,0$ \\
P valor & $<0,001$ & $<0,05$ \\
\hline Medidas Incrementais & & \\
\hline CFI & 0,94 & $>0,92$ \\
TLI & 0,94 & $>0,92$ \\
\hline Má Qualidade de Ajuste & & \\
\hline RMSEA & 0,06 & $\mathrm{r}<0,08$ \\
SRMR & 0,08 & $\mathrm{r}<0,09$ \\
\hline
\end{tabular}

*Estimador: Mínimos Quadrados Diagonalmente Ponderados (DWLS).

Fonte: Silva RM. Alterações de saúde, resiliência e qualidade de vida de discentes de graduação em enfermagem no primeiro ano letivo [Tese]. São Paulo: EEUSP; 2016.

Verifica-se, na Tabela 10, que as medidas absolutas, incrementais e de resíduos apresentaram valores dentro dos parâmetros estimados, o que confirma a adequação entre modelo observado e modelo esperado, com um índice aceitável de resíduos. Na análise de regressão, à exceção da relação do estresse psicoemocional, da qualidade do sono e da resiliência com a qualidade de vida $(p>0,05)$, as demais relações testadas entre os constructos foram estatisticamente significativas $(\mathrm{p}<0,05)$ (Figura 18).

Figura 18- Modelo estrutural inicial especificado em discentes de enfermagem. São Paulo, 2016.

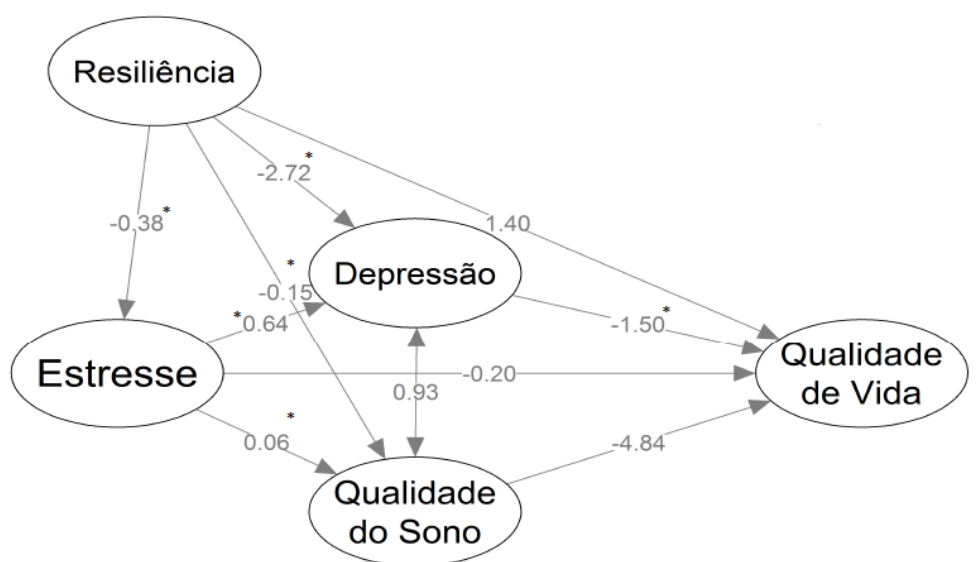

Nota: $\mathrm{R}^{2}$ Estresse $=0,018 ; \mathrm{R}^{2}$ Depressão $=0,490 ; \mathrm{R}_{\sim}^{2} \cdot \mathrm{Qualidade}$ do sono=0,214; $\mathrm{R}^{2}$ Qualidade de vida=0,840; Os valores entre as variáveis latentes referem-se aos valores de Beta.

*Correlação estatisticamente significativa $(\mathrm{p}<0,05)$.

Fonte: Silva RM. Alterações de saúde, resiliência e qualidade de vida de discentes de graduação em enfermagem no primeiro ano letivo [Tese]. São Paulo: EEUSP; 2016. 
Observa-se, na Figura 18, que os valores de Beta foram notavelmente baixos para as seguintes relações: estresse psicoemocional e qualidade de vida $(\beta=0,20)$; estresse psicoemocional e qualidade do Sono $(\beta=0,06)$; Resiliência e Qualidade do sono $(\beta=-0,15)$; resiliência e estresse psicoemocional $(\beta=-0,38)$. Com essa estrutura, os preditores conseguem explicar conjuntamente 84\% da Qualidade de Vida conforme indica o Coeficiente de Determinação $\left(\mathrm{R}^{2}\right)$. Entretanto, uma vez que a as cargas fatoriais dos domínios da Escala de Resiliência foram baixos e que o efeito observado da resiliência sobre o estresse psicoemocional e a qualidade do sono também foi baixo, um segundo modelo foi estimado e testado. Nesse, a resiliência foi estimada por meio dos seus itens, sem considerar os seus domínios. Na Figura 19, apresentam-se os Modelos de Mensuração e Estrutural finais.

Figura 19- Modelos de Mensuração e Estrutural finais. São Paulo, 2016.

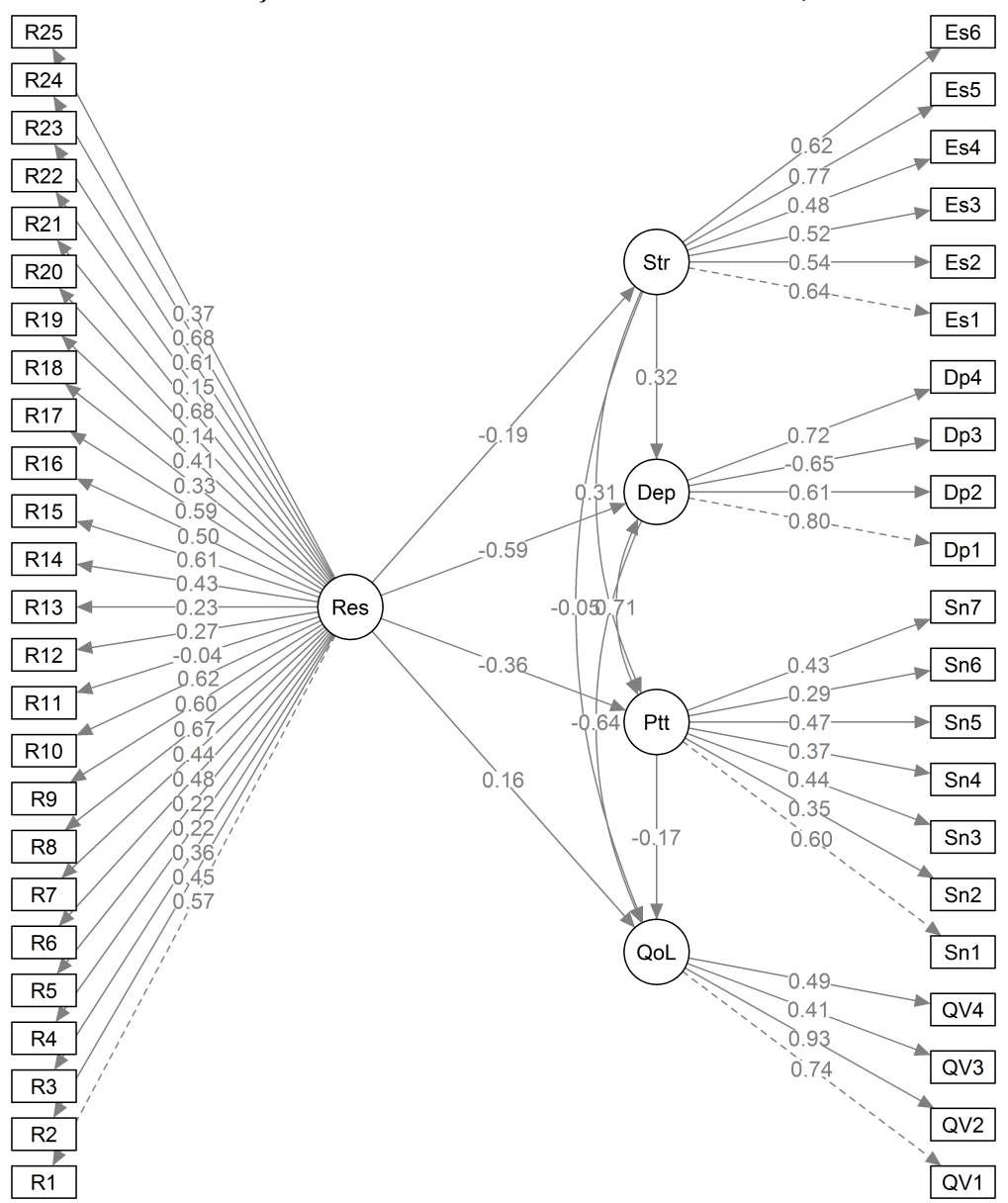

Fonte: Silva RM. Alterações de saúde, resiliência e qualidade de vida de discentes de graduação em enfermagem no primeiro ano letivo [Tese]. São Paulo: EEUSP; 2016.

Na Figura 19, verifica-se que as cargas fatoriais para o WHOQOL-Bref variaram de 0,41(Domínio Físico) a 0,93(Domínios Social). Dentre os domínios do AEEE, os fatores Am- 
biente $(0,48)$ e Formação Profissional $(0,77)$ apresentaram a menor e maior carga fatorial respectivamente. No CES-D, as cargas dos domínios variaram de 0,61 (Interpessoal) a 0,80 (Depressão); e de 0,30 (Uso de Medicações para Dormir) a 0,60 (Qualidade Subjetiva do Sono) no IQSP. Na Escala de Resiliência de Wagnild \& Young, o modelo de mensuração foi estimado de forma unifatorial, pois essa estrutura interna produziu o melhor ajuste possível ao modelo estrutural, com cargas fatoriais entre 0,04(Item 11) e 0,68(Item 21). Embora alguns itens/domínios tenham apresentado valores próximos aos limites do intervalo considerado adequado, eles foram mantidos pois produziram boa qualidade de ajuste ao Modelo estrutural. Assim, evidencia-se que os itens/domínios contribuem satisfatoriamente para explicar as variáveis latentes do segundo modelo analisado. Os resultados dos índices de ajuste e má qualidade de ajuste obtidos para esse segundo (e definitivo) modelo hipotetizado são apresentados na Tabela 11.

Tabela 11- Índices de Ajuste e má qualidade de ajuste obtidos para o Modelo Estrutural final. São Paulo, 2016.

\begin{tabular}{lcc}
\hline Medidas Absolutas & $\begin{array}{c}\text { Valores Ob- } \\
\text { servados* }\end{array}$ & $\begin{array}{c}\text { Valores Espe- } \\
\text { rados }\end{array}$ \\
\hline$\chi 2$ & 1474,9 & $>0,05$ \\
GL & 979 & - \\
$\chi 2$ normatizado $\left(\chi^{2} / \mathrm{GL}\right)$ & 1,5 & $<3,0$ \\
P valor & $<0,001$ & $<0,05$ \\
\hline Medidas Incrementais & & $>0,92$ \\
\hline CFI & 0,93 & $>0,92$ \\
TLI & 0,92 & \\
\hline Má Qualidade de Ajuste & & $\mathrm{r}<0,08$ \\
\hline RMSEA & 0,05 & $\mathrm{r}<0,09$ \\
\hline SRMR & 0,08 & \\
\hline
\end{tabular}

*Estimador: Mínimos Quadrados Diagonalmente Ponderados (DWLS).

Fonte: Silva RM. Alterações de saúde, resiliência e qualidade de vida de discentes de graduação em enfermagem no primeiro ano letivo [Tese]. São Paulo: EEUSP; 2016.

Verifica-se, na Tabela 11, que as medidas absolutas e incrementais apresentaram valores adequados, com nível de resíduos- diferença entre o modelo hipotético e observado no 
estudo- dentro dos parâmetros esperados. Tais achados evidenciam que o modelo teórico proposto foi confirmado pelos dados empíricos sessa pesquisa. Na análise de regressão linear, verifica-se que todas as relações testadas entre os constructos foram estatisticamente significativas $(\mathrm{p}<0,001)$, à exceção da relação do estresse psicoemocional, qualidade do sono e resiliência com a qualidade de vida $(p>0,05)$. Todavia, os valores de beta e os coeficientes de determinação foram superiores nessa segunda estimação do modelo para o constructo da resiliência, com índices de ajuste igualmente satisfatórios. Por isso, este segundo modelo foi selecionado como o definitivo para explicar as relações entre os fenômenos. Na Figura 20, apresenta-se o modelo estrutural final especificado em discentes de enfermagem.

Figura 20- Modelo estrutural final especificado em discentes de enfermagem. São Paulo, 2016.

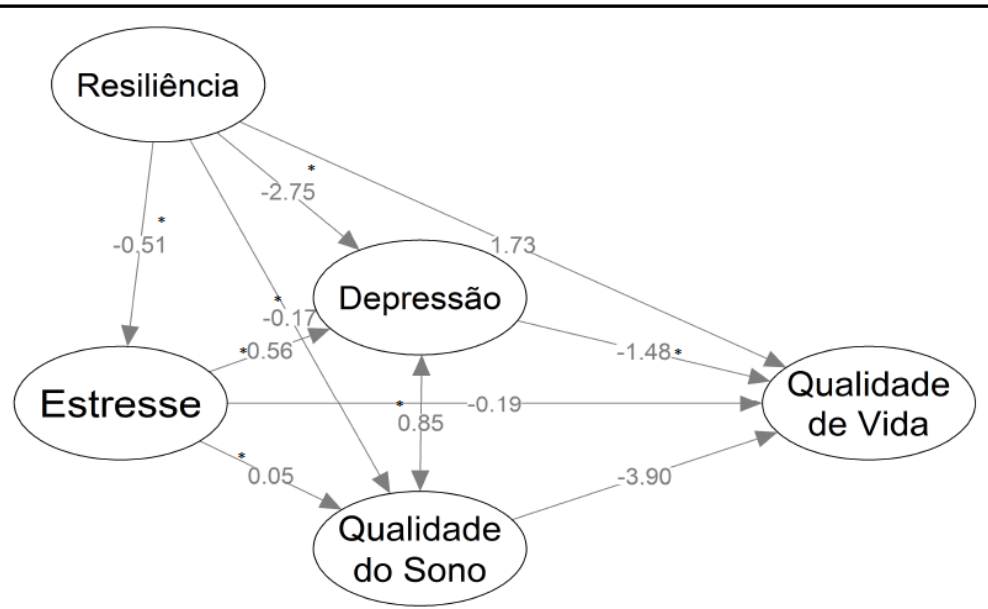

Nota: $\mathrm{R}^{2}$ Estresse $=0,035 ; \mathrm{R}^{2}$ Depressão= 0,$528 ; \mathrm{R}^{2}$ Qualidade do sono=0,266; $\mathrm{R}^{2}$ Qualidade de vida $=0,832$; Os valores entre as variáveis latentes referem-se aos valores de Beta.

*Correlação estatisticamente significativa $(\mathrm{p}<0,05)$.

\section{Hipóteses}

H1- O estresse psicoemocional leva à baixa qualidade do sono e aos sintomas depressivos em Discentes de Enfermagem;

$\mathrm{H} 2-\mathrm{O}$ estresse psicoemocional contribui diretamente para a baixa qualidade de vida entre os discentes de enfermagem;

H3- Os discentes com maior intensidade de sintomas depressivos possuem maior chance de apresentar baixa qualidade de vida;

H4- Os alunos com baixa qualidade do sono possuem maior chance de apresentar baixa qualidade de vida;

H5- A qualidade de sono pode impactar nas funções cognitivas e levar aos sintomas depressivos;

H6- O aumento da intensidade dos sintomas depressivos contribui para reduzir a qualidade do sono;

H7- A resiliência contribui diretamente para aumentar a qualidade de vida;

H8- A resiliência reduz os níveis de estresse psicoemocional e reduz a intensidade dos sintomas depressivos.

H9- Os sintomas depressivos mediam a relação entre o estresse psicoemocional e a qualidade de vida.

H10- A qualidade do sono media a relação entre o estresse psicoemocional e a qualidade de vida 
Fonte: Silva RM. Alterações de saúde, resiliência e qualidade de vida de discentes de graduação em enfermagem no primeiro ano letivo [Tese]. São Paulo: EEUSP; 2016.

Na Figura 20, ao se observar o coeficiente de determinação $\left(\mathrm{R}^{2}\right)$, ou seja, o quanto de informação de um dado desfecho seus preditores conseguem explicar, identifica-se que o estresse psicoemocional, a resiliência, os sintomas depressivos e a qualidade do sono explicam $83,20 \%$ da qualidade de vida. O estresse psicoemocional, a resiliência e sua correlação com os sintomas depressivos explicam $26,6 \%$ da qualidade do sono. Já o estresse psicoemocional, a resiliência e sua correlação com a qualidade do sono explicam 52,8\% dos sintomas depressivos. Isoladamente, a resiliência consegue explicar 3,5\% do estresse psicoemocional.

O estresse psicoemocional aumenta os níveis de sintomas depressivos $(\beta=0,56)$ e diminui a qualidade do sono $(\beta=0,05)$ na população, o que confirma a H1 dessa pesquisa. Destaca-se que embora o valor de Beta seja positivo, essa relação é negativa devido à interpretação inversa dos escores do IQSP. Já a relação direta entre estresse psicoemocional e qualidade de vida foi não significativa, o que refuta a H2. Embora os sintomas depressivos contribuam para redução da qualidade de vida $(\beta=-1,48)$, o que confirma a hipótese $H 3$, a qualidade do sono não apresentou efeito sobre esse desfecho, o que refuta a H4. Ainda, verifica-se que a qualidade do Sono $(\beta=0,85)$ impacta significativamente e inversamente nos escores dos sintomas depressivos e vice-versa, o que confirma as hipóteses H5 e H6. Assim, uma pior qualidade do sono implica maiores níveis de sintomas depressivos e vice-versa.

Sobre o impacto da resiliência, verifica-se que essa não possui efeito direto sobre qualidade de vida e, assim, nega-se a H7. Todavia, a resiliência minimiza os níveis de estresse psicoemocional $(\beta=-0,51)$ e sintomas depressivos $(\beta=-2,75)$, além de aumentar a qualidade do sono $(\beta=-0,17)$ o que leva ao aceite da H8. Após a verificação das hipóteses de relação direta do modelo teórico (H1 até H8), partiu-se para a análise das relações de mediação presentes no modelo especificado (H9 e H10) (Tabela 12).

Tabela 12- Regressão Linear para as relações de mediação e moderação presentes no modelo estrutural especificado em discentes de enfermagem. São Paulo, 2016.

\begin{tabular}{llll}
\hline $\begin{array}{l}\text { Tipo de } \\
\text { Relação }\end{array}$ & Hipóteses de Mediação & & \\
\hline & & & \\
& H9: Estresse Psicoemocional $\rightarrow$ Sintomas & $\boldsymbol{\beta}$ & P valor \\
& Depressivos $\rightarrow$ Qualidade de Vida & & \\
\hline
\end{tabular}




\begin{tabular}{llll}
\hline Direta & Estresse Psicoemocional $\rightarrow$ Qualidade de & $\beta_{\mathrm{d}^{*}=-0,19}$ & 0,493 \\
& Vida & & \\
Conjunta & Estresse Psicoemocional $\rightarrow$ Sintomas De- & $\beta_{1=0,56}$ & $<0,001$ \\
& pressivos & & \\
& Sintomas Depressivos $\rightarrow$ Qualidade de Vida & $\beta_{2=-1,48}$ & $<0,001$ \\
& Efeito Mediador $\left(\boldsymbol{\beta}_{1^{*}} \boldsymbol{\beta}_{2}\right)$ & $-0,83$ & \\
\hline \multirow{2}{*}{ Direta } & H10: Estresse Psicoemocional $\rightarrow$ Qualidade & $\boldsymbol{\beta}$ & P valor \\
& Estresse Psicoemocional $\rightarrow$ Qualidade de & $\mathrm{B}_{\mathrm{d}^{*}=-0,19}$ & 0,493 \\
& Vida & & \\
Conjunta & Estresse Psicoemocional $\rightarrow$ Qualidade do & $\beta_{1=0,05}$ & $<0,001$ \\
& Sono & & \\
& Qualidade do Sono $\rightarrow$ Qualidade de Vida & $\beta_{2=-3,90}$ & 0,415 \\
& Efeito Mediador $\left(\boldsymbol{\beta}_{1^{*}} \boldsymbol{\beta}_{2}\right)$ & $-0,195$ &
\end{tabular}

$* \boldsymbol{\beta d}=$ Efei-

preditor e desfecho na relação direta; $\boldsymbol{\beta}_{1}$ Efeito entre preditor e mediador; $\boldsymbol{\beta}_{2}=$ Efeito entre mediador e desfecho. Fonte: Silva RM. Alterações de saúde, resiliência e qualidade de vida de discentes de graduação em enfermagem no primeiro ano letivo. [Tese]. São Paulo: EEUSP; 2016.

Na Tabela 12, observa-se que não há relação direta entre estresse psicoemocional e qualidade de vida, o que exclui a possibilidade de mediação entre essas variáveis e refuta a H9. No entanto, uma vez que o estresse psicoemocional contribui significativamente para o aumento dos sintomas depressivos $\left(\beta_{1=} 0,56\right)$ e esses, por sua vez, para a queda da qualidade de vida $\left(\beta_{1=}-1,48\right)$, é possível afirmar que o estresse psicoemocional impacta na qualidade de vida de maneira indireta, ou seja, na presença de níveis elevados de sintomas depressivos. Sobre a última hipótese, além de não haver relação direta significativa entre preditor (Estresse psicoemocional) e desfecho, a variável mediadora (Qualidade do sono) e de desfecho (Qualidade de vida) também não se correlacionam significativamente, o que exclui a possibilidade de mediação e efeito indireto entre elas. 
9. DISCUSSÃO 


\section{DISCUSSÃO}

Para melhor compreensão, as discussões dos achados com a literatura estão apresentadas conforme cada etapa da pesquisa, a ser: calibração dos instrumentos (Fase 1); alterações na saúde, na resiliência e na qualidade de vida (Fase 2); e relações simultâneas de causalidade entre Estresse psicoemocional, sintomas depressivos, qualidade do sono e resiliência na explicação da qualidade de vida dos discentes de enfermagem (Fase 2).

\subsection{CALIBRAÇÃO DOS INSTRUMENTOS}

A estrutura interna de um instrumento é avaliada por meio de análise fatorial, ferramenta que permite esclarecer o número de fatores em um grupo de itens, revelar as associações entre os fatores de escalas multidimensionais e identificar quais itens estão relacionados a que fatores $^{(34)}$.

Nesse contexto, ao analisar o AEEE, observou-se que as cargas fatoriais de todos os itens dos domínios Ambiente e Comunicação Profissional foram satisfatórias. Já os itens 1 (Formação Profissional), 2 (Atividades Teóricas), 3 (Gerenciamento do Tempo), 10(Atividades Teóricas), 21 (Atividades Práticas) e 23 (Gerenciamento do Tempo) apresentaram cargas ligeiramente inferiores ao esperado. No estudo de validação desse instrumento, os itens 1,2 e 3 também apresentaram valores inferiores àqueles obtidos para os demais itens ${ }^{(2)}$. No entanto, para a confirmação de colinearidade ou baixo poder explicativo, é preciso que os outros parâmetros sejam avaliados ${ }^{(34,42)}$. Assim sendo, uma vez que a maioria das cargas fatoriais, os índices de ajuste e de resíduos e as correlações de Pearson foram satisfatórias, os itens em questão foram mantidos no instrumento, com a mesma estrutura validada pelos autores do instrumento.

O Center for Epidemiologic Studies Depression Scale (CES-D) apresentou cargas fatoriais satisfatórias; índices de ajuste e de resíduos dentro dos limites esperados e correlações significativas entre os fatores. Esses dados evidenciam respectivamente que os itens contribuem de forma satisfatória para explicar as variáveis latentes (domínios) da CES-D; que tais domínios (afeto positivo, aspectos somáticos, fatores interpessoais e depressão) explicam de forma interdependente o constructo principal $^{(34)}$, ou seja, os sintomas depressivos; e que a estrutura interna proposta se ajusta àquela observada no conjunto de dados, com presença de poucos resíduos, ou seja, diferença entre os valores observados e esperados para um dado modelo explicativo ${ }^{(34,36,88)}$. 
A Escala de Resiliência de Wagnild \& Young apresentou cargas fatoriais satisfatórias, exceto para os itens 3, 4 e 20 (Domínio Autoconfiança), 11 e 22 (Domínio Interdependência) e 14,16 e 18 (Domínio Ações), que apresentaram valores abaixo do esperado. Na tradução e validação desse instrumento para realidade brasileira, as cargas fatoriais encontradas para os itens $2,11,16,20$ e 22 também foram inferiores a $0,4^{(32)}$. Já para os itens 4,14 e 18, os resultados estiveram pouco acima do valor de corte, mas abaixo daqueles encontrados nos demais itens $^{(32)}$. Esses valores indicam baixo poder explicativo aos itens ${ }^{(34)}$, ou seja, eles contribuem pouco para a compreensão do domínio a que se vinculam e, por conseguinte, para o constructo principal. No entanto, uma vez que os resultados desse estudo se aproximam daqueles obtidos na validação do instrumento ${ }^{(34)}$ e que os demais parâmetros obtidos ${ }^{(34,36,42)}$ (medidas absolutas e de má qualidade de ajuste) foram satisfatórios, a estrutura original da Escala de Resiliência foi mantida.

$\mathrm{Na}$ análise do Instrumento de Avaliação da Qualidade de Vida (WHOQOL-Bref), verificou-se que, embora os itens 3, 4, 12, 14, 15 e 24 tenham apresentado valores próximos ao mínimo esperado, predominaram aqueles com cargas fatoriais satisfatórias, o que evidencia a capacidade de os itens explicarem os domínios do instrumento. Tais domínios se correlacionaram de forma significativa, embora a correlação entre os domínios físico e relações sociais (r= 0,46; $\mathrm{p}<0,001)$ tenha apresentado menor intensidade. Na validação do WHOQO-BREF em amostra brasileira, verificou-se que a correlação entre esses tais domínios também foi a menor da matriz $(\mathrm{r}=0,35 ; \mathrm{p}<0,05)^{(67)}$. Todavia, todas as correlações encontradas nessa pesquisa foram superiores àquelas verificadas no referido estudo de validação, inclusive entre os domínios supracitados (Físico X Psicológico: $r=0,62$; Físico X Relações Sociais: $r=0,25$; Físico $X$ Ambiente: $r=0,50$; Psicológico $X$ Relações Sociais: $r=0,49$; Psicológico $X$ Ambiente; $r=0,53$; Relações Sociais X Ambiente: $\mathrm{r}=0,53)^{(67)}$. Dessa forma, confirma-se o comportamento interdependente dos domínios do WHOQOL-BREF na explicação da qualidade de vida, cuja intensidade de correlação é superior na amostra de discentes de enfermagem quando comparada ao estudo original com pacientes e voluntários de um hospital brasileiro ${ }^{(67)}$.

Embora os valores das medidas absolutas de qualidade de ajuste e as medidas de má qualidade de ajuste (resíduos) tenham sido adequados para o WHOQOL-BREF, os valores de CFI e TLI ficaram próximos ao mínimo esperado. Sobre isso, destaca-se que o CFI baseia-se na estatística do Qui-quadrado que exige maiores valores amostrais para a análise fatorial confirmatória, sendo, assim, sensível ao tamanho amostral. Por isso, os demais indicadores foram avaliados conjuntamente ${ }^{(34,42)}$ e a estrutura originalmente validada foi mantida para tal instru- 
mento. Dessa forma, a validade de constructo, entendida pela capacidade de uma estrutura operacional verdadeiramente refletir o significado teórico de um conceito ${ }^{(89)}$, foi verificada nessa pesquisa, o que confirma a adequação da estrutura interna dos instrumentos para mensurar estresse psicoemocional, sintomas depressivos, resiliência e qualidade de vida em discentes universitários de enfermagem.

$\mathrm{Na}$ análise de confiabilidade por domínio, identificaram-se Alfas superiores a 0,7 e alguns próximos a este valor, fatos também observados nos estudos de validação dos instrumen$\operatorname{tos}^{(2,32,55,61,67)}$. No entanto, os fatores Gerenciamento do Tempo (AEEE) e Afeto (CES-D) apresentaram respetivamente valores de 0,554 e 0,475 , diferentemente dos estudos de validação que obtiveram resultados de 0,717 (Gerenciamento do Tempo) ${ }^{(2)}$ e 0,650(Afeto Positivo $)^{(17)}$. Sobre isso, autores afirmam que, em pesquisas de cunho social, resultados acima de 0,4 podem ser considerados satisfatórios para evidenciar a consistência interna de escalas de medida ${ }^{(90)}$.

$\mathrm{Na}$ análise da confiabilidade dos instrumentos, verificou-se que os valores de Alfa para o total de itens de cada instrumento foram respectivamente: 0,852 (AEEE); 0,746 (CES-D); 0,763(IQSP); 0,804(Escala de Resiliência); e 0,805(WHOQOL-BREF). Os valores encontrados nos estudos de validação dessas escalas junto a discentes universitários -0,890 (CESD) ${ }^{(17)}$ e 0,800 (Escala de Resiliência) ${ }^{(32)}$ e populações gerais - 0,820 (IQSP) ${ }^{(51)}$ e 0,90(WHOQOL-BREF) ${ }^{(67)}$ foram similares aos encontrados nesta investigação. Dessa forma, evidencia-se consistência interna satisfatória aos instrumentos dessa investigação, o que atesta sua capacidade de produzir resultados similares em diferentes aplicações ao longo do tempo entre discentes de enfermagem ${ }^{(34,89)}$.

\subsection{AVALIAÇÃO DAS ALTERAÇÕES NA SAÚDE, RESILIÊNCIA E QUALI- DADE DE VIDA}

Após o acompanhamento dos alunos por um ano após o ingresso no curso, verificou-se aumento significativo nos níveis de estresse psicoemocional em todos os domínios do AEEE: Realização de Atividades Práticas, Gerenciamento do Tempo, Comunicação Profissional, Ambiente, Formação Profissional e Atividades Teóricas. Em revisão sistemática conduzida em 2012, os estressores identificados em discentes de enfermagem de primeiro ano - por meio de diferentes instrumentos de medida- foram: o ingresso em um curso universitário; o notável volume de atividades em um período curto de tempo; manutenção de boas notas; avaliações e exames; gerenciar as questões financeiras; cometer erros com os pacientes; e aprender proce- 
dimentos clínicos ${ }^{(91)}$. Em pesquisa longitudinal com 853 discentes de enfermagem da Escócia, após acompanhamento desde do ingresso até o final do primeiro ano, verificou-se aumento no níveis de estresse psicoemocional relacionado à sobrecarga acadêmica, aos problemas pessoais, ao relacionamento interpessoal e às preocupações com aspectos clínicos ${ }^{(92)}$. Tais estressores perpassam os fatores de estresse do AEEE, pois as questões relacionadas a avaliações, testes e notas são descritas no fator Atividades Teóricas; os aspectos financeiros e as transformações vivenciadas quando do ingresso no curso são abordados no fator Ambiente; o Gerenciamento do Tempo envolve questões relativas à dificuldade de administrar a demanda acadêmica para que seja possível atender as necessidades sociais, familiares e pessoais; e as preocupações com aspectos clínicos, como procedimentos e manejo do paciente, relacionamse à Realização de Atividades Práticas ${ }^{(2-3)}$. Dessa maneira, observa-se que estudos anteriores com alunos ingressantes confirmam a presença dos estressores aqui encontrados, bem como o aumento da sua intensidade ao longo do primeiro ano. Por essa razão, pesquisadores recomendam melhorias no escopo dos currículos de enfermagem, com base nos estressores evidenciados na literatura, o que inclui: considerar o tempo necessário para a realização das atividades propostas a fim de evitar sobrecarga; e utilizar formas alternativas de avaliação que vão além de testes de aquisição de habilidades e conhecimentos esperados ${ }^{(91)}$. O sucesso desse tipo de ação foi confirmado por pesquisa realizada em 2000 junto a discentes de enfermagem matriculados em dois sistemas curriculares da Escócia (o tradicional e o inovador), o que demonstra que os discentes matriculados no curso com currículo novo (centrado no aluno e na resolução de problemas) levou a um menor nível de estresse psicoemocional e ao uso de estratégias de enfretamento mais resolutivas ${ }^{(92)}$.

Uma vez que o IQSP possui escala reversa, o aumento dos escores indicam redução na duração e na qualidade subjetiva do sono entre os discentes de enfermagem no período avaliado. Em março, os alunos dormiam em média 6,00 horas por noite $(\mathrm{Dp}=1,42)$, com queda para 5,41 horas de sono, em média, no mês de dezembro ( $\mathrm{Dp}=1,27)$. Da mesma forma, houve queda do número de alunos que referiram "muito boa" qualidade de sono (De $41 \%$ em março para $26 \%$ em dezembro) e aumento daqueles que percebiam sua qualidade do sono como ruim (De 7,7\% em Março para 15\% em dezembro. Após acompanhar os alunos ingressantes no curso de graduação em enfermagem de Campinas-SP, o pesquisadores verificaram predomínio de má qualidade de sono e redução da duração do sono $(p=0,002)^{(93)}$. Em pesquisa transversal realizada com 93 discentes de enfermagem de Taiwan, identificou-se que a duração média do sono foi de 6,68 horas $(\mathrm{DP}=1,27)$ e a qualidade subjetiva do sono foi percebida 
como ruim ou muito ruim por $34,4 \%$ dos indivíduos ${ }^{(94)}$. Observa-se que os alunos dormem menos do que o tempo considerado suficiente, ou seja, 7 horas por noite ${ }^{(95)}$, com intensificação dessa situação ao longo do ano entre os alunos Brasileiros, o que explica a qualidade subjetiva do sono ser avaliada como ruim ou muito ruim. Um sono insuficiente torna o organismo incapaz de regular ou (re)estabelecer adequadamente funções essenciais, tais como: memória, termorregulação, energia, metabolismo cerebral, níveis de linfócitos e colesterol ${ }^{(96-98)}$. Isso pode causar déficit cognitivo e alterações de humor; maior vulnerabilidade para doenças, especialmente as crônicas; ganho de peso; e redução do desempenho acadêmico ${ }^{(94,97)}$. Sobre isso, entre 535 discentes de ensino médio de Los Angeles, identificou-se que, independentemente do tempo de estudo diário, os discentes que se privavam de dormir para estudar (mais que o usual) tinha mais dificuldade para entender os conteúdos ensinados em aula e necessitam se esforçar mais para realizar um teste ou tarefa escolar ${ }^{(99)}$. Como efeitos físicos da privação de sono, entre aproximadamente 19 mil calouros de 11 universidades de Taiwan, foram encontrados: cefaléia, dor de estômago, sensação de compressão no peito, aumento dos níveis de ácido úrico, enzimas hepáticas, hemoglobinas e colesterol ${ }^{(96)}$. Nesse sentido, tendo em vista o impacto negativo do sono sobre o funcionamento orgânico e psíquico, é preciso desenvolver e aplicar intervenções que permitam ao aluno manter um padrão de sono adequado às necessidades individuais. A higiene do sono, que tem por base a mudança de hábitos alimentares e comportamentais, tem-se destacado como uma medida capaz de melhorar a qualidade subjetiva do sono em discentes universitários, sendo capaz de prevenir desfechos de longo prazo, como a elevação dos níveis de estresse e os sintomas depressivos ${ }^{(100)}$.

Sobre isso, destaca-se o aumento significativo dos níveis de estresse geral e dos sintomas depressivos, inclusive no domínio somática/iniciativa (CES-D), nos discentes de enfermagem ao longo do ano letivo de 2016. O alto estresse foi identificado, ao início do ano, em $17,9 \%$ dos discentes e o muito alto estresse em nenhum deles, porém esses valores aumentaram para 27,4\% e 1,7\% em dezembro. Quanto aos sintomas depressivos, a elevação dos escores evidenciou o aumento na frequência com que os discentes experimentaram tais sintomas no período analisado, especialmente aqueles relacionados à dificuldade de se engajar e manter atividades cotidianas (Domínio somática/Iniciativa) ${ }^{(17)}$. Em pesquisa longitudinal com 174 discentes ingressantes em um curso de medicina da Malásia, foi verificado que os escores de estresse e sintomas depressivos aumentaram significantemente ao longo dos cinco momentos de avaliação- início do ano, 2 meses, 4 meses, 6 meses e ao final do ano- de forma que as médias de estresse aumentaram de 8,52 para 11,38; e as de sintomas depressivos de 2,62 para 
$8,38^{(13)}$. Estudo conduzido com 187 acadêmicos de medicina do primeiro ano da Índia verificou aumento dos escores de estresse, que passaram de 9,19 para 12,69, e de sintomas depressivos, que variaram de 14,02 a 17,78, desde o ingresso no curso até o final do ano ${ }^{(101)}$. Além disso, ao acompanhar uma coorte de discentes de enfermagem na Escócia, verificou-se que, desde o ingresso $(n=168)$, até o final do primeiro ano de curso $(n=124)$, os alunos apresentaram elevação do nível de estresse geral, com médias que variaram de $8,9(\mathrm{Dp}=4,3)$ para $12,1(\mathrm{Dp}=5,4)^{(102)}$. O estresse impacta negativamente na saúde física e mental do discente e pode levar à Síndrome de Burnout, à baixa qualidade do sono, ao ganho de peso, ao absenteísmo por doença e à desistência do curso ${ }^{(55,92)}$. Nesse sentido, além da revisão da estrutura curricular tradicional, sugere-se que os gestores das instituições de ensino considerem a possibilidade de avaliações regulares dos discentes para identificação precoce de desordens psicológicas, especialmente aquelas decorrentes do processo de formação ${ }^{(101-102)}$. A partir dessas informações, seria possível desenvolver e aplicar intervenções focadas na necessidade do aluno, tais como o aconselhamento individual, o fortalecimento de estratégias de enfrentamento dos estressores e a promoção da personalidade resiliente e hardiness. Nesse sentido, revisão sistemática conduzida em 2014, com seleção de intervenções cognitivo-comportamentais, como a promoção de personalidade hardiness e resiliente, evidenciou a efetividade das mesmas para redução do estresse, ansiedade e sintomas depressivos ${ }^{(103)}$. Contudo, os autores apontam a necessidade de amostras heterogêneas e de superação das limitações metodológicas dos estudos experimentais incluídos ${ }^{(103)}$.

Além disso, em estudo recente, embora se tenha confirmado o papel protetor da personalidade em relação ao estresse e aos sintomas depressivos, os pesquisadores evidenciam a necessidade de análises mais complexas e correlações mais fortes para que os achados sejam convertidos à prática ${ }^{(102)}$. Dessa forma, seria possível o planejamento e aplicação de intervenções que minimizem as alterações de saúde nos discentes, com a prevenção de processos crônicos, como o Burnout ${ }^{(101)}$. Para atender essa lacuna, utilizou-se, nessa pesquisa, a modelagem de equações estruturais que permitirá compreender e confirmar o papel da personalidade resiliente nas relações entre estresse e desfechos negativos de saúde nos discentes de enfermagem. 


\subsection{EFEITO DOS FENÔMENOS DE SAÚDE SOBRE A QUALIDADE DE VI- DA DOS DISCENTES DE ENFERMAGEM}

Verifica-se que as medidas absolutas e incrementais apresentaram valores adequados, com nível de resíduos dentro dos parâmetros esperados, de forma que o estresse psicoemocional, a resiliência, os sintomas depressivos e a qualidade do sono explicaram $83,20 \%$ da qualidade de vida. Esses achados evidenciam que o modelo proposto com base em pesquisas anteriores e no referencial teórico foi confirmado pelos dados observados, com uma diferença aceitável entre os modelos (observado e esperado) ${ }^{(34)}$. Ainda, os preditores explicam quase que integralmente a variância do desfecho em questão ${ }^{(34,37)}$ nos discentes de enfermagem, com valores superiores àqueles encontrados em outros modelos testados em discentes universitário com variáveis similares ${ }^{(16,30)}$.

Verificou-se que o estresse psicoemocional aumenta os níveis de sintomas depressivos e diminui a qualidade do sono dos discentes de enfermagem. Em estudo transversal com 88 discentes de enfermagem do último ano de Ribeirão Preto, os dados revelaram relação do estresse com a presença de sinais indicativos de depressão, especialmente de depressão grave (Pearson: $\mathrm{r}-0,755$ e $\mathrm{p}<0,01)^{(14)}$. Pesquisa realizada com 1125 discentes de uma universidade privada no centro-oeste dos Estados Unidos identificou que o estresse acadêmico impacta negativamente na qualidade do sono $(\beta=0,024$ e $p<0,001)$, sendo o estresse e a tensão emocional responsáveis por $24 \%$ da variância da qualidade do sono ${ }^{(15)}$. Nesse contexto, verifica-se que o aluno percebe o ambiente acadêmico como um estressor e que este impacta na sua qualidade do sono e na ocorrência de sintomas depressivos. Embora elementos como ruídos externos, especialmente em grandes centros urbanos, e o uso de mídias eletrônicas exerçam papel importante na qualidade do sono e em estados depressivos, o estresse - medido por meio de instrumentos validados ou questões abertas- tem se destacado enquanto preditor desses fenômenos ${ }^{(9,15)}$ Isso pode decorrer da transição do indivíduo para um novo espaço de formação, com alto grau de exigência e de responsabilidades, além de carga horária de estudos elevada, o que limita as atividades de cunho social, pessoal e familiar. Ainda, na realidade dessa investigação, muito alunos mudam-se de suas cidades de origem para São Paulo (capital), o que suscita a necessidade de enfrentar uma cidade grande e, muitas vezes, trabalhar e assumir responsabilidades financeiras ${ }^{(2,14,55)}$. Todos esses aspectos contribuem para a sobrecarga dos recursos de enfrentamento dos discentes, o que, por conseguinte, reduz a qualidade do sono e aumenta a possibilidade de sintomas depressivos. 
Ao analisar os fenômenos de saúde que predizem a qualidade de vida, observou-se que apenas os sintomas depressivos contribuem diretamente para redução da qualidade de vida. Todavia, o estresse psicoemocional é capaz de reduzir a qualidade de vida na presença de níveis elevados de sintomas depressivos, ou seja, de forma indireta. Após aplicação do ShortForm Health Survey (SF-36) e do Inventário de Depressão de Beck (IDB) em 256 discentes de enfermagem de uma universidade federal mineira, foi identificado que alunos com maior intensidade de sintomas depressivos apresentaram menor qualidade de vida relacionada à capacidade funcional, vitalidade e aspectos sociais $^{(79)}$. Em pesquisa com 130 discentes Nepaleses matriculados em cursos de graduação e pós-graduação da Coréia Do Sul, foi observado correlação significativa entre estresse percebido e qualidade de vida ${ }^{(16)}$. Contudo, quando analisado junto a outros preditores (estresse aculturativo, gênero, relação com o supervisor, estado civil), o estresse apresentou pouco impacto sobre a qualidade de vida ${ }^{(16)}$. Uma vez que os alunos, ao ingressarem no curso, vivenciam uma série de mudanças em sua rotina diária, especialmente a sobrecarga de atividades e aquela de cunho emocional (decorrente do trato com pacientes, novos colegas e docentes), eles ficam vulneráveis ao isolamento social, à experiências desagradáveis no cotidiano e à baixa-autoestima, elementos importantes para a ocorrência de sintomas depressivos ${ }^{(14,79)}$. Nesse sentido, é essencial que programas de intervenção- a exemplo das técnicas de meditação, hipnose, relaxamento muscular ou grupos de suportecom aplicação em plataformas online ou presencialmente, sejam adaptados à realidade do discentes de enfermagem e realizados a fim de minimizar o estresse e sintomas depressivos nesta população ${ }^{(14 ; 103-104)}$. Assim, ao reduzir o estresse, espera-se menor risco de sintomas depressivos e, portanto, melhora da qualidade de vida.

Verificou-se que a baixa qualidade do sono leva a maiores níveis de sintomas depressivos. A relação oposta também foi significativa, ou seja, alunos com maiores níveis de sintomas depressivos apresentam queda na qualidade do sono. Em estudo longitudinal com 35 discentes universitários de Austin (Texas), conduzido por meio da modelagem de equações estruturais, verificou-se que a menor qualidade do sono (mensurada por actígrafo e Índice de Qualidade do Sono de Pittsburgh) levou ao aumento dos sintomas depressivos ${ }^{(25)}$.Por outro lado, houve correlação estatisticamente significativa entre os sintomas depressivos e na qualidade do sono no segundo período de acompanhamento $(\mathrm{p}<0,05 ; \mathrm{r}=0,43)^{(25)}$. Essa mesma correlação foi identificada em investigação com 49 universitários de uma instituição privada da grande São Paulo $(p=0,027 ; r=0,278)^{(26)}$. Isso sugere que os distúrbios do sono não são apenas um desfecho dos sintomas depressivos, mas também podem predizer tais sintomas, um 
fato confirmado em estudos com adultos jovens ${ }^{(25,105)}$. Os pesquisadores explicam que os universitários, frequentemente, abdicam do tempo de sono e de atividades de lazer para atender a tarefas acadêmicas (trabalhos ou realização de pesquisas na internet) e fazem uso noturno do computador e outras mídias eletrônicas. Isso torna os horários do sono irregulares e o tempo de sono insuficiente, o que reduz a qualidade do sono, o qual aumenta a chance de sintomas depressivos nessa população ${ }^{(26,106)}$. Por outro lado, essa relação pode se apresentar de forma inversa, sendo as alterações biológicas, cognitivas e afetivas do quadro depressivos responsáveis por alterações no sono ${ }^{(25,105)}$. Estudo conduzido em 2008 demonstrou essa relação ao demonstrar que alterações encontradas no eletroencefalograma de indivíduos com quadro depressivo permanecem elevados durante e logo após a remissão do quadro depressivo, que sugere o uso dessas alterações do sono como um biomarcador de depressão ${ }^{(107)}$.

Embora os sintomas depressivos e o estresse (mesmo que de forma indireta), levem à redução da qualidade de vida, a resiliência pode auxiliar no controle desses eventos negativos e, por isso, é vista como um fator protetor da saúde ${ }^{(29-30)}$. Esse preceito foi confirmado nessa pesquisa, pois se verificou que a resiliência é capaz de minimizar os níveis de estresse psicoemocional e a intensidade dos sintomas depressivos, além de aumentar a qualidade do sono dos discentes de enfermagem. Em estudo longitudinal com 1321 discentes de medicina de cinco universidade norte-americanas, verificou-se que discentes resilientes são propensos a experienciar menor intensidade de sintomas depressivos, apresentam menores níveis de estresse e melhor qualidade de vida ${ }^{(29)}$. Embora eventos negativos, como relações interpessoais, exigências do estudo e mudança de hábitos para adaptação às exigências acadêmica, levem à problemas de saúde mental, o que inclui sintomas depressivos, ansiedade, hostilidade e psicoses, pesquisadores confirmaram em amostra de 1998 discentes de medicina chineses que a resiliência minimizou o efeito dos eventos negativos de vida na saúde mental dos discentes ${ }^{(30)}$. Ao perceber os potenciais estressores como desafios necessários e importantes ao desenvolvimento e aprendizado, os discentes passam a compreender os estressores de maneira positiva e adotam comportamentos e atitudes necessários à adaptação ao ambiente acadêmico ${ }^{(30-31)}$. Assim, a resiliência contribui para reduzir o estresse psicoemocional e seus desfechos (aumento da intensidade dos sintomas depressivos e baixa qualidade do sono), o que melhora o desempenho e a condição de saúde geral dos discentes ${ }^{(30-31)}$. Por isso, sugere-se o desenvolvimento e aplicação de programas de treinamento das habilidades emocionais, mentais e comportamentais que fortalecem a resiliência em discentes de enfermagem, os quais já tem sido aplicados em estudados de ensino médio ${ }^{(108)}$, mas ainda precisam ser melhor explorados 
quanto aos fatores que influenciam a resiliência no contexto específico da formação universitária $^{(30,108-109)}$.

De maneira geral, pode-se dizer que o modelo hipotetizado foi confirmado pelos dados observados, frente aos bons índices de ajuste, de maneira que: $\mathrm{O}$ estresse psicoemocional reduz a qualidade do sono e aumenta a intensidade de sintomas depressivos, os quais podem reduzir diretamente a qualidade de vida dos discentes de enfermagem. Tais sintomas também permitem um efeito indireto do estresse psicoemocional sobre a qualidade de vida. Por outro lado, a resiliência minimiza os níveis de estresse psicoemocional, melhora a qualidade do Sono e minimiza a intensidade dos sintomas depressivos na população de estudo. Nesse sentido, é preciso dar atenção às queixas de estresse psicoemocional, sono e comportamentos depressivos apresentados por essa população para que haja possibilidade de prevenção e diagnóstico precoce ainda durante a formação ${ }^{(26)}$. Para isso, é importante que as instituições de ensino ofertem espaços de atenção multiprofissional à saúde dos discentes, como já se observam em países desenvolvidos, onde se possam prevenir doenças e promover saúde por meio de aconselhamento, psicoterapia, técnicas de relaxamentos e outras intervenções, como a higiene do sono e os programas de fortalecimento da resiliência ${ }^{(103,108-109)}$. Dessa forma, ao se tornarem capazes de lidar com os estressores e de utilizar estratégias de controle do estresse psicoemocional, os discentes, enquanto futuros profissionais, poderão estender esses conhecimentos e seus benefícios aos profissionais de saúde e aos pacientes em situações difíceis. Em suma, ao serem capazes de cuidar si, esses indivíduos estarão mais fortalecidos e aptos para o cuidado do outro. 
10. CONCLUSÃO 


\section{CONCLUSÃO}

Verificou-se validade de constructo e confiabilidade satisfatórias para a explicação dos fenômenos investigados em discentes de enfermagem. Verificou-se que após um ano de ingresso no curso ocorre: elevação do nível de estresse psicoemocional; redução da qualidade do subjetiva do sono e aumento da intensidade dos sintomas depressivos (escore geral e do domínio Somática Iniciativa), porém sem alterações significativas nos escores de qualidade de vida, qualidade do sono (geral) e resiliência. Esses achados confirmam parcialmente a hipótese inicial do estudo, ou seja, de que haveria: aumento dos níveis de estresse psicoemocional, sintomas de depressivos e resiliência, com redução da qualidade do sono e qualidade de vida. A partir da Modelagem de Equações, observou-se que o estresse psicoemocional reduz a qualidade do sono e aumenta a intensidade de sintomas depressivos, os quais podem reduzir diretamente a qualidade de vida dos discentes de enfermagem. Tais sintomas também permitem um efeito indireto do estresse psicoemocional sobre a qualidade de vida. Por outro lado, a resiliência minimiza os níveis de estresse psicoemocional, melhora a qualidade do Sono e minimiza a intensidade dos sintomas depressivos na população de estudo. A partir desses resultados, confirmam-se todas as hipóteses levantadas para o modelo, a exceção de que: o estresse psicoemocional e a qualidade do sono impactam diretamente na redução da qualidade de vida; e de que a qualidade do sono media a relação entre estresse psicoemocional e qualidade de vida.

Confirmar-se que o ambiente de formação em enfermagem apresenta potencial para doenças e sofrimento, com impacto, em segunda instância, à qualidade de vida dos discentes. Ainda, evidenciou-se o estresse psicoemocional como preditor das alterações de saúde e a resiliência como um fator protetor contra o estresse psicoemocional e seus desfechos nos discentes de enfermagem. Por isso, é importante que as instituições formadoras sejam foco de análise e ações que permitam um ambiente saudável de formação dentro dos seus espaços e possibilidades. Para isso, a carga de atividades teóricas, as dificuldades com o manejo de tempo entre demandas acadêmicas e pessoais, além das limitações em relação à comunicação profissional, são estressores que podem ser minimizados por meio de ações institucionais, tais como a revisão de elementos curriculares. Ainda, devido à capacidade minorar os efeitos deletérios do estresse psicoemocional, melhorar a qualidade do sono e reduzir a intensidade dos sintomas depressivos a que estão expostos os discentes, os programas de treinamento da personalidade resiliente poderiam ser promovidos e aplicados no ambiente institucional. Por úl- 
timo, destaca-se a possibilidade da criação de espaços intramuros, com equipe multiprofissional, para a prevenção de doenças e promoção da saúde, voltado exclusivamente as demandas dos graduandos- experiência já realizada com sucessos em alguns países desenvolvidos. Assim, será possível uma formação com melhor saúde geral e qualidade de vida aos discentes de enfermagem.

Como limitações desse estudo, destacam-se a descrição não detalhada dos procedimentos em análises de validade de constructo e de confiabilidade dos instrumentos utilizados nessa pesquisa; e a escassez de estudos longitudinais com discentes de enfermagem, o que dificultou a comparação dos achados dessa pesquisa com outras envolvendo alunos da mesma área. Além disso, a presença de índices de ajustes fora dos parâmetros desejados na Escala de Resiliência de Wagnild \& Young demandou a reespecificação do modelo multifatorial para unifatorial durante na análise dos comportamentos dos fenômenos, o que evidencia a necessidade futura de revisão de sua estrutura interna para discentes de enfermagem com amostras maiores. Por fim, o seguimento de um ano pode ter sido insuficiente para identificar alterações significativas na qualidade de sono, resiliência e qualidade de vida. 
11. RECOMENDAÇÕES 


\section{RECOMENDAÇÕES}

Com base nos resultados dessa investigação e em suas limitações, recomenda-se:

- novas aplicações da análise fatorial em populações com amostras mais expressivas a fim de melhorar os índices alcançados na Escala de Resiliência de Wagnild \& Young.

- o uso mais frequente desse método para a análise de validade de constructo dos instrumentos já validados, especialmente quando da aplicação em populações distintas daquelas utilizadas na versão original e(ou) quando sua data de validação é superior a dois anos.

- o estudo aprofundado da resiliência no campo da formação em saúde para melhor compreensão dos fatores relacionados, o que fornecerá subsídios para a criação de intervenções que promovam a resiliência neste contexto.

- O acompanhamento dos discentes de enfermagem por período superior a um ano em relação a qualidade do sono, qualidade de vida e resiliência, pois esses parecem fenômenos mais estáveis e que, portanto, necessitam de um maior período para se alterarem de forma significativa nessa população.

- A analise de viabilidade e implementação de novas propostas curriculares a fim de reduzir a sobrecarga acadêmica, e, assim, melhorar a saúde dos discentes.

- Implementar estratégias de promoção da personalidade resiliência em discentes de enfermagem, visto sua capacidade para reduzir o estresse psicoemocional, a intensidade dos sintomas depressivos e melhorar a qualidade do sono.

- Avaliar a viabilidade da criação de espaços nas escolas de enfermagem para atendimento multidisciplinar aos discentes de enfermagem a fim de prevenir doenças e promover a saúde dentro dos espaços formativos.

- A implementação de espaços de descanso, com computadores, sofás, camas e vídeo games para que os discentes possam dormir e relaxar durante o período integral que passam na instituição. 


\section{REFERÊNCIAS}

1.Costa ALS. Estresse em discentes de enfermagem: construção dos fatores determinantes. REME rev. min. enferm. 2007; 11(4): 414-9.

2. Costa ALS, Polak C. Construção e validação de instrumento para avaliação de estresse em estudantes de enfermagem (AEEE). Rev. Esc. Enferm. USP. 2009; 43(N.esp.):1017-26.

3. Bayram N, Bilgel N. The prevalence and socio-demographic correlations of depression, anxiety and stress among a group of university students. Soc Psychiatry Psychiatr Epidemiol. 2008 Aug; 43(8):667-72.

4. Montgomery P, Mossey S, Killam L. Views of second year nursing students on impediments to safety in the clinical setting: Q-methodology. J Nurs Educ Pract. 2013; 3(8):1-12.

5. Häfner A, Stock A. Time management training and perceived control of time at work. J Psychol. 2010 Sep-Oct;144(5):429-47.

6. Häfner A, Stock A, Pinneker L, Ströhle S. Stress prevention through a time management training intervention: an experimental study. Educ Psychol. 2014; 34(13): 403-16.

7. Bublitz S, Freitas EO, Kirchhof RS, Lopes LFD, Guido LA. Estressores entre acadêmicos de enfermagem e uma universidade pública. Rev. enferm. UERJ. 2012 dez; 20(N.esp.2):73945 .

8. Labrague LJ. Stress, Stressors, and Stress Responses of Student Nurses in a Government Nursing School. Health Sci J. 2013; 7(4): 424-35.

9. Wong Wai Yi W. The Relationship between Time Management, Perceived Stress, Sleep Quality and Academic Performance among University Students [monografia]. Hong Kong: Hong Kong Baptist University; 2008.

10. Lazarus RS, Folkman S. Stress, appraisal, and coping. New York: Springer; 1984.

11. Basso Musso L, Vargas BA, Torres MB, Canto MJM, Meléndez CG, Balloqui MFK. Fatores derivados dos laboratórios intra-hospitalares que provocam estresse nos estudantes de enfermagem. Rev latinoam enferm. 2008; 16(5):805-11.

12. Silva RM, Goulart CT, Lopes LFD, Costa ALS, Guido LA. Avaliação de estresse em estudantes de enfermagem - proposta de padronização da análise. In: Rossi AM, Meurs JA, Perrewé PL, (organizadores). Stress e qualidade de vida no trabalho: melhorando a saúde e bemestar dos funcionários Porto Alegre: Atlas; 2013. p.55-67.

13. Yusoff MS, Abdul Rahim AF, Baba AA, Ismail SB, Mat Pa MN, Esa AR. Prevalence and associated factors of stress, anxiety and depression among prospective medical students. Asian J Psychiatr. 2013 Apr;6(2):128-33.

14. Moreira DP, Furegato ARF. Estresse e depressão entre alunos do último período de dois cursos de enfermagem. Rev latinoam enferm. 2013; 21(n.spe):155-62. 
15. Lund HG, Reider BD, Whiting AB, Prichard JR. Sleep patterns and predictors of disturbed sleep in a large population of college students. J Adolesc Health. 2010 Feb; 46(2):12432 .

16. Bhandari P. Stress and health related quality of life of Nepalese students studying in South Korea: a cross sectional study. Health Qual Life Outcomes. 2012 Mar 13;10:26.

17. Filho NK, Teixeira MAP. A estrutura fatorial da Escala CES-D em estudantes universitários brasileiros. Aval psicol. 2011;10(1):91-7.

18. Matos ACS, Oliveira IR. Terapia cognitivo-comportamental da depressão: relato de caso. Rev Ciênc Méd Biol. 2013; 12(n.spe): 512-9.

19. Garlow SJ, Rosenberg J, Moore JD, Haas AP, Koestner B, Hendin H, et al. Depression, desperation, and suicidal ideation in college students: results from the American Foundation for Suicide Prevention College Screening Project at Emory University. Depress Anxiety. 2008;25(6):482-8.

20. Guo L, Deng J, He Y, Deng X, Huang J, Huang G, et al. Prevalence and correlates of sleep disturbance and depressive symptoms among Chinese adolescents: a cross-sectional survey study. BMJ Open. 2014;4(7):1-9.

21. Sawatzky RG, Ratner PA, Richardson CG, Washburn C, Sudmant W, Mirwaldt P. Stress and depression in students: the mediating role of stress management self-efficacy. Nurs Res. 2012 Jan-Feb; 61(1):13-21

22. Menon B, Karishma HP, Mamatha IV. Sleep quality and health complaints among nursing students. Ann Indian Acad Neurol. 2015; 18(3): 363-4.

23. Hicks RA, Fernandez C, Pellegrini RJ. Striking changes in the sleep satisfaction of university students over the last two decades. Percept Mot Skills. 2001 Dec;93(3):660.

24. Taylor DJ1, Bramoweth AD, Grieser EA, Tatum JI, Roane BM. Epidemiology of insomnia in college students: relationship with mental health, quality of life, and substance use difficulties. Behav Ther. 2013 Sep;44(3):339-48.

25. Vanderlind WM, Beevers CG, Sherman SM, Trujillo LT, McGeary JE, Matthews MD, et al. Sleep and sadness: exploring the relation among sleep, cognitive control, and depressive symptoms in young adults. Sleep Med. 2014 Jan;15(1):144-9.

26. Coelho AT, Lorenzini LM, Suda EY, Rossini S, Reimão R. Sleep Quality, Depression and Anxiety in College Students of Last Semesters in Health Area's Courses Neurobiologia. 2010; 73 (1): 35-9.

27. The WHOQOL group. The World Health Organization Quality of Life assessment (WHOQOL): position paper from the World Health Organization.Soc Sci Med. 1995 Nov;41(10):1403-9. 
28. Fiedler PT. Avaliação da qualidade de vida do estudante de medicina e da influência exercida pela formação acadêmica[Internet]. São Paulo: Faculdade de Medicina, Universidade de São Paulo; 2008 [citado 2014 Jan. 11]. Disponível em: http://www.teses.usp.br/teses/disponiveis/5/5137/tde-10072008-161825/pt-br.php

29- Dyrbye LN, Power DV, Massie FS, Eacker A, Harper W, Thomas MR, Szydlo DW, Sloan JA, Shanafelt TD. Factors associated with resilience to and recovery from burnout: a prospective, multi-institutional study of US medical students. Med Educ. 2010 Oct;44(10):1016-26.

30- Peng L1, Zhang J, Li M, Li P, Zhang Y, Zuo X, Miao Y, Xu Y. Negative life events and mental health of Chinese medical students: the effect of resilience, personality and social support. Psychiatry Res. 2012 Mar 30;196(1):138-41.

31. Wagnild GM, Young HM. Development and psychometric evaluation of resilience scale. J Nurs Meas. 1993; 1:165-78.

32. Pesce RP, Assis SG, Avanci JQ, Santos NC, Malaquias JV, Carvalhaes R. Adaptação transcultural, confiabilidade e validade da escala de resiliência. Cad Saúde Pública. 2005; 21(2):436-48.

33. Godoy KAB, Joly MCRA, Piovezan NM, Dias AS, Silva DV. Avaliação da resiliência em escolares do ensino médio. Mudanças. 2010; 18 (1-2) 79-90.

34. Hair Jr JF, Anderson RE, Tatham RL, Black WC. Análise multivariada de dados. 5 a . ed. Porto Alegre: Bookman; 2005.

35. Campos, JADB, Jordani PC, Zucoloto MC, Bonafé FSS, Maroco J. Síndrome de Burnout em graduandos de Odontologia. Rev bras epidemio. 2012; 15(1): 155-65.

36.Schumacker RE, Lomax RG. A Beginner's Guide to Structural Equation. $3^{\mathrm{a}}$ ed. Ohio $(\mathrm{OH})$ : Routledge; 2010.

37. Vieira VA. Moderação, mediação, moderadora-mediadora e efeitos indiretos em modelagem de equações estruturais: uma aplicação no modelo de desconfirmação de expectativas. R.Adm., São Paulo, v.44, n.1, p.17-33, jan./fev./mar. 2009

38. Mackinnon DP, Lockwood CM, Hoffman JM, West SG, Sheets V. A comparison of methods to test mediation and other intervening variable effects. Psychol Methods. 2002 Mar;7(1):83-104.

39. Abbad G, Torres CV. Regressão múltipla stepwise e hierárquica em Psicologia Organizacional: aplicações, problemas e soluções. Estud psicol (Natal). 2002; 7(n.spe):19-29.

40. Campana N, Tavares MC, Silva D. Modelagem de Equações Estruturais: Apresentação de uma abordagem estatística multivariada para pesquisas em Educação Física. Motri. 2009; 5 (4), 59-80

41. Farias SA, Santos RC. Modelagem de Equações Estruturais e Satisfação do Consumidor: uma Investigação Teórica e Prática Consumidor: uma Investigação Teórica e Prática. Rev 
adm contemp. 2000; 4 (3):107-32.

42. Brown T. Confirmatory Factor Analysis for Applied Research. New York: The Guiford Press; 2006.

43. David B. Flora and Patrick J. Curran. An Empirical Evaluation of Alternative Methods of Estimation for Confirmatory Factor Analysis With Ordinal Data. Psychol Methods. 2004; 9(4): 466-91.

44. Mueller RO. Structural equation modeling: Back to basics. Struct Equ Modeling. 1997; 4(4):353-69.

45. Kawakame PMG, Miyadahira AMK . Qualidade de vida de estudantes de graduação em enfermagem. Rev Esc Enferm USP 2005; 39(2):164-72.

46. Bianchi ERF. Conceito de stress- Evolução Histórica. Nursing. 2001; 4(39): 16-19.

47. Benevides-pereira AMT. O Estado da Arte do Burnout no Brasil. Revista Eletrônica InterAção Psy, 2003; 1(1) 4-11.

48. Guido LA. Stress e Coping entre enfermeiros de centro cirúrgico e recuperação anestésica[Internet]. São Paulo: Escola de Enfermagem, Universidade de São Paulo; 2003 [citado 2015 Jan. 1]. Disponível em: http://www.teses.usp.br/teses/disponiveis/83/83131/tde22122003-160217/pt-br.php

49. Miranda AS. Estresse Ocupacional- inimigo invisível do enfermeiro? Ribeirão Preto: Escola de Enfermagem de Ribeirão Preto, Universidade de São Paulo; 1998.

50. Guerrer FJL, Bianchi ERF. Caracterização do estresse nos enfermeiros de unidades de terapia intensiva. Rev Esc Enferm USP. 2008; 42(2):355-62.

51. Bertolazi AN. Tradução, adaptação cultural e validação de dois instrumentos de avaliação do sono: escala de sonolência de Epworth e índice de qualidade de sono de Pittsburgh[Internet]. Porto Alegre: Escola de Medicina, Universidade Federal do Rio Grande do Sul; 2008[citado 2014 Jan. 11]. Disponível em: http://www.lume.ufrgs.br/handle/10183/14041?show=full

52. Cardoso HC, Bueno FCC, Mata, JC, Alves, APR, Jochims, I, Filho, IHRV, et al. Avaliação da qualidade do sono em estudantes de Medicina. Rev bras educ Med. 2009; 33 (3) : $349-55$.

53. Araújo MFM, Lima ACS, Alencar AMPG, Araújo TM, Fragoaso LVC, Damasceno MMC. Avaliação da qualidade do sono de estudantes universitários de Fortaleza-CE. Texto \& contexto enferm. 2013; 22(2): 352-60.

54. Buysse DJ, Reynolds CF, Monk TH, Berman SR, Kupfer DJ. He Pittsburgh Sleep Quality Index: a new instrument for psychiatric practice and research. Psychiatr Res. 1989; 28: 193213. 
55. Benavente SBT, Silva RM, Higashi AB, Guido LA, Costa ALS. Influência de fatores de estresse e características sociodemográficas na qualidade do sono de estudantes de enfermagem. Rev Esc Enferm USP. 2014; 48(3):514-20

56. Cavagione LC. Influência do Plantão de 24 horas sobre a pressão arterial e o perfil de risco cardiovascular em profissionais da área da saúde que atuam em serviços de atendimento pré-hospitalar [Internet]. São Paulo: Escola de Enfermagem, Universidade de São Paulo; 2010[citado 2014 Jan. 11]. Disponível em: http://www.teses.usp.br/teses/disponiveis/7/7139/tde-23122010-094708/en.php

57. Knapp, P. Terapia Cognitivo-Comportamental na Prática Psiquiátrica. Porto Alegre: Artmed; 2004.

58. Del Porto JA. Conceito e diagnóstico. Rev Bras Psiquiatr. 1999; 21(Suppl 1): 06-11. Seidl EMF; Zannon C.MLC. Qualidade de Vida e Saúde: Aspectos Conceituais e Metodológicos. Cad Saúde Pública. 2004; 20 (2): 580-8.

59. Sakae TM, Padão DL, Jornada LK. Sintomas depressivos em estudantes da área da saúde em uma Universidade no Sul de Santa Catarina - UNISUL. Rev AMRIGS. 2010; 54 (1): 3843.

60. Vallil NG, Júnior RD, Gobbo R, Novo NF, Hübner CK. Prevalência de sintomas depressivos em estudantes de Medicina. Rev Bras Clin Med. 2011;9(1):36-41.

61. Radloff LS. The CES-D Scale: a self-report depression scale for research in the general population. Appl psychol meas [Internet]. 1977 [cited 2014 Mar. 12]; 1(3): 385-401. Available from:

https://conservancy.umn.edu/bitstream/handle/11299/98561/v01n3p385.pdf?sequence=1

62. Beck AT, Ward CH, Mendelson M, Mock J, Erbaugh J. An inventory for measuring depression. Arch Gen Psychiatry. 1961 Jun;4:561-71.

63. Yesavage JA, Brink TL, Rose TL, Lum O, Huang V, Adey M, Leirer VO. Development and validation of a geriatric depression screening scale: a preliminary report. J Psychiatr Res. 1983;17(1):37-49.

64. Silveira DX, Jorge MR. Escala de rastreamento populacional para depressão CES-D em populações clínicas e não clínicas de adolescentes e adultos jovens. In: Gorestain $\mathrm{C}$, Andrade LHSG, Zuarde AW, (editores). Escalas de avaliação clínica em psiquiatria e farmacologia. São Paulo: Lemos Editorial; 2000.

65. Oliveira RA, Ciampone MHT. Qualidade de vida de estudantes de enfermagem: a construção de um processo e intervenções. Rev Esc Enferm USP 2008; 42(1):57-65

66. Seidl EMF; Zannon C.MLC. Qualidade de Vida e Saúde: Aspectos Conceituais e Metodológicos. Cad Saúde Pública. 2004; 20 (2): 580-8. 
67. Fleck MPA, Louzada S, Xavier M, Chachamovich E, Vieira G, Santos L, et al. Aplicação da versão em português do instrumento abreviado de avaliação da qualidade de vida "WHOQOL-Bref". Rev Saúde Pública. 2000;34(2):178-83.

68. Stumm EMF.; Ribeiro G, Kirchner RM, Loro MM, Schmidt CL. Avaliação da Saúde e Qualidade de Vida: Profissionais de um Samu. Cogitare Enferm 2009; 14(4):620-7.

69. Rufino Netto A. Qualidade de Vida: Compromisso Histórico da Epidemiologia. Belo Horizonte: Coopmed/Abrasco; 1994.

70. Andrades Barrientos L, Valenzuela Suazo S. Fatores Associados à Qualidade de Vida de Enfermeiras hospitalares chilenas. Rev Latinoam Enferm. 2007; 15(3): 480-6.

71. The WHOQOL Group. Development of the World Health Organization WHOQOL-BREF quality of life assessment. Psychol Med.1998;28(3):551-8.

72. Pessoa RC. Análise da resiliência, bem-estar subjetivo e rendimento acadêmico de estudantes universitários da Amazônia[Internet]. Manaus: Faculdade de Psicologia, Universidade Federal do Amazonas; 2014 [citado 2014 Jan. 11]. Disponível em: http://tede.ufam.edu.br/bitstream/tede/996/1/ROCKSON\%20COSTA\%20PESSOA.pdf

73. Brandão JM, Mahfoud M, Gianordoli-Nascimento IF. A construção do conceito de resiliência em psicologia: discutindo as origens. Paidéia (Ribeirão Preto). 2011; 21(49), 263-71.

74. Assis SG, Pesce RP, Avanci JQ. Resiliência: enfatizando a proteção dos adolescentes. Porto Alegre: Artmed; 2006.

75. Angst R. Psicologia e resiliência: uma revisão de literatura. Psicol. argum. 2009; 27(58): 253-60.

76. Salgado Lévano AC. Felicidad, resiliencia y optimismo en estudiantes de colegios nacionales de la ciudad de Lima. Liberabit. 2009; 15(2): 133-41.

77. Moser AM, Amorim C, Angst R. Burnout e resiliência em estudantes de pedagogia de Curitiba/PR. PsicoFAE, 2013; 2(2): 49-58.

78. Prieto-Miranda SE, Rodríguez-Gallardo GB, Jiménez-Bernardino CA, Guerrero-Quintero LG. Burnout and quality of life in medical residents. Rev Med Inst Mex Seguro Soc. 2013 Sep-Oct; 51(5):574-9.

79. Souza IM, Paro HB, Morales RR, Pinto Rde M, da Silva CH. Health-related quality of life and depressive symptoms in undergraduate nursing students. Rev latinoam enferm. 2012 JulAug;20(4):736-43.

80. Mathews D. Assessing Sleep Quality in Young Adult College Students, Aged 18 - 24 in Relation to Quality of Life and Anthropometrics [Dissertation]. Bangor: Graduate Program in Food Science and Human Nutrition, The University of Maine; 2010. 
81. Jeon HJ, Bang YR, Park HY, Kim SA, Yoon IY. Differential effects of circadian typology on sleep-related symptoms, physical fatigue and psychological well-being in relation to resilience. Chronobiol Int. 2017;34(6):677-86.

82. Sousa VD, Driessnack M, Mendes IAC. An overview of research designs relevant to nursing. part 1: quantitative research designs. Rev latinoam enferm. 2007; 15(3):502-7.

83. Referência suprimida para não identificação do local de pesquisa.

84. Laros JA. O uso da análise fatorial: algumas diretrizes para pesquisadores. In: Pasquali L, organizadores. Análise fatorial para pesquisadores. Brasília: LabPAM Saber e Tecnologia; 2012. p.141-60.

85- Hulley SB, Cummings SR, Browner WS, Grady DG, Newman TB. Delineando a pesquisa clínica. $3^{\mathrm{a}}$ ed. Porto Alegre: Artmed; 2008.

86. Referência suprimida para não identificação do local de pesquisa.

87. Wagnild GM, Collins JA. Assessing resilience. J Psychosoc Nurs Ment Health Serv. 2009 Dec;47(12):28-33.

88. Pilati R, Laros JA. Modelos de Equações Estruturais em Psicologia: Conceitos e Aplicações. Psicol teor pesqui. 2007; 23(2): 205-16.

89. Martins GA. Sobre confiabilidade e validade. RBGN. 2006; 8(20):1-12.

90. Bailar J, Mosteller F. Medical users of statistics. Boston: Nejm Books;1992.

91. Pulido-Martos M, Augusto-Landa JM, Lopez-Zafra E. Sources of stress in nursing students: a systematic review of quantitative studies. Int Nurs Rev. 2012; 59(1): 15-25

92. Jones MC, Johnston W. Is the introduction of a studentcentred, problem-based curriculum associated with improvements in student nurse well-being and performance? An observational study of effect. Int J Nurs Stud. 2006; 43(8):941-52

93. Furlani R, Ceolim MF. Padrões de sono de estudantes ingressantes na Graduação em Enfermagem. Rev Bras Enferm 2005; 58(3):320-4.

94. Huang CF, Yang LY, Wu LM, Liu Y, Chen HM. Determinants of daytime sleepiness in first-year nursing students: a questionnaire survey. Nurse Educ Today. 2014 Jun;34(6):104853.

95. Cappuccio FP, D’Elia L, Strazzullo P, Miller MA. Sleep duration and all-cause mortality: a systematic review and meta-analysis of prospective studies. Sleep. 2010;33(5):585-92

96. Lee CW, Huang YT, Yen CW. The analysis of health problems and health defects of college freshmen in Taiwan. Chin J Sch Health. 2008; 12 (53): 1-15. 
97. Araújo MFM, Lima ACS, Alencar AMPG, Araújo TM, Fragoaso LVC, Damasceno MMC. Avaliação da qualidade do sono de estudantes universitários de Fortaleza-CE. Texto \& contexto enferm. 2013; 22(2): 352-60.

98.Winston TN. Handbook on Burnout and Sleep Deprivation. New York: NOVA; 2015.

99. Gillen-O'Neel C, Huynh VW, Fuligni AJ. To study or to sleep? The academic costs of extra studying at the expense of sleep. Child Dev. 2013;84(1):133-42.

100. Brick CA, Seely DL, Palermo TM. Association between sleep hygiene and sleep quality in medical students. Behav Sleep Med. 2010;8(2):113-21.

101. Goel AD, Akarte SV, Agrawal SP, Yadav V. Longitudinal assessment of depression, stress, and burnout in medical students. J Neurosci Rural Pract. 2016 Oct-Dec;7(4):493-8.

102. Deary IJ, Watson R, Hogston R. A longitudinal cohort study of burnout and attrition in nursing students. J Adv Nurs. 2003 Jul;43(1):71-81.

103. Davies EB, Morriss R, Glazebrook C. Computer-delivered and web-based interventions to improve depression, anxiety, and psychological well-being of university students: a systematic review and meta-analysis. J Med Internet Res. 2014;16(5):e130.

104. Li, MH. Helping college students: Identifying predictors of active coping in different stressful situations. J Psych, Psychol, Ment Health. 2008; 2(1):1-15.

105. Chen MC, Burley HW, Gotlib IH. Reduced sleep quality in healthy girls at risk for depression. J Sleep Res 2012; 21:68-72.

106. Mesquita G, Reimão R. Nightly use of computer by adolescents: its effect on quality of sleep. Arq Neuropsiquiatr 2007; 65(2-B):428-32.

107. Rao U, Poland RE. Electroencephalographic sleep and hypothalamic-pituitary-adrenal changes from episode to recovery in depressed adolescents. J Am Acad Child Adolesc Psychiatry. 2008; 18:607-613.

108. Rebecca KH, Daly J, Freund M, Bowman J, Hazell T and Wiggers J. A school-based resilience intervention to decrease tobacco, alcohol and marijuana use in high school student. BMC Public Health. 2011; 11: 722.

109. Ungar M, Russell P, Connelly G. School-Based Interventions to Enhance the Resilience of Students. J Educ Develop Psychol. 2014; 4(1):1-18. 
APÊNDICES 


\section{APÊNDICE A- FORMULÁRIO PARA CARACTERIZAÇÃO SOCIODEMO- GRÁFICA E ACADÊMICA DOS DISCENTES.}

Iniciais do Nome:

E-mail:

Telefone:

\section{VARIÁVEIS SOCIODEMOGRÁFICAS}

1. Data de nascimento:

2. Sexo: ( ) Feminino

( ) Masculino

3. Situação conjugal:( ) Casado ( ) Divorciado ( ) Separado ( ) Solteiro/com companheiro* ( ) Solteiro/sem companheiro ( ) Viúvo Outro. Qual?

*Equivale à União Estável.

4. Possui filhos: ( )Sim ( )Não Quantos?

5. Reside em São Paulo( )Sim ( )Não

6. Reside com:( )família ( )amigo-colega ( )sozinho ( ) Outro. Qual?

7. Reside em:

( ) República

( ) Casa universitária

( ) Apartamento/Casa própria

( ) Apartamento/Casa Alugada.

( ) Outro. Qual?

8. Frequentou o ensino médio na sua maior parte em:

( )Escola Pública

( )Escola Privadas

9. Como você ingressou no Curso de Graduação da USP? ( )Vestibular ( )ENEM(SISU) ( ) Outro. Qual?

10. Etnia:

( ) Europeu

( ) Sul-asiáticos

( ) Chineses

( ) Japoneses

( ) Centro e sul-americanos

( ) Africanos

( ) Mediterrâneo Oriental

( ) Oriente Médio (Árabes)

11. Pratica algum esporte? ( )Sim ( )Não Qual?

12. Atividade de lazer? ( )Sim ( )Não Qual?

13. Qual(is) a(s) sua(s) fonte(s) de renda?(Você pode assinalar mais de uma opção)

( ) Bolsa Acadêmica (PET/Ensino/Extensão)

( ) Bolsa de Assistência (Auxílio financeiro). Qual?

( ) Estágio Remunerado.

( ) Recurso da família

( ) Trabalho Fixo

( ) Trabalho Ocasional (Freelancer)

( ) Outro. Qual? 
14. Se você for dependente financeiro(recurso da família), quem é responsável pela sua manutenção? (Você pode assinalar mais de uma opção)
( )Pai
( ) Mãe
( ) Irmão
( ) Padrasto
( ) Madrasta
( ) Padrinho
( ) Madrinha
( ) Irmão
( ) Irmã ( ) Outro. Qual?

15.Qual a renda mensal total recebida?

( ) Nenhuma renda

( ) Até 1 salário mínimo (até $\mathbf{R} \$ \mathbf{7 8 8 , 0 0}$ inclusive)

( ) Entre 1 e 2 salários mínimos (R\$ 789,00 a $R \$ 1576,00$ inclusive)

( ) Entre 2 e 5 salários mínimos (R\$ 1577,00 a R\$ 3.940,00 inclusive)

( ) Entre 5 e 10 salários mínimos (R\$ 3.941,00 a R\$ 7.880,00 inclusive)

( ) Entre 10 e 30 salários mínimos ( $R \$ 7.881,00$ a $R \$ 23.640,00$ inclusive)

( ) Mais de 30 salários mínimos (mais de $\mathbf{R} \$ 23.640,00$ )

16.Qual a sua despesa mensal em salários mínimos?

( ) Nenhuma renda

( ) Até 1 salário mínimo (até $\mathbf{R} \$ \mathbf{7 8 8 , 0 0}$ inclusive)

( ) Entre 1 e 2 salários mínimos ( $R \$ 789,00$ a $R \$ 1576,00$ inclusive)

( ) Entre 2 e 5 salários mínimos (R\$ 1577,00 a R\$ 3.940,00 inclusive)

( ) Entre 5 e 10 salários mínimos (R\$ 3.941,00 a $R \$$ 7.880,00 inclusive)

( ) Entre 10 e 30 salários mínimos ( $\mathbf{\$} \mathbf{7 . 8 8 1 , 0 0}$ a $\mathbf{R} \$ \mathbf{2 3 . 6 4 0 , 0 0}$ inclusive)

( ) Mais de 30 salários mínimos (mais de R\$ 23.640,00)

17. Você considera a sua renda mensal suficiente para a sua manutenção?

( ) Sim ( ) Não

18. Toma algum contraceptivo oral ou injetável?

( )Sim ( )Não ( )Parei ( ) Não se aplica

19.Toma algum fármaco ou substância (chá, café, energético, etc) para inibir o sono? Sim( ) Não( ) Parei ( ) Se sim, qual?

20.Toma algum fármaco ou substância (chá, bebidas, etc) para conseguir dormir?

Sim( ) Não( ) Parei ( ) Se sim, qual?

21. Tem hábito de fumar?

( )Sim, fumo. Especifique o tipo e o tempo(em anos)

( ) Não, parei. Há quanto tempo?(em anos)

( ) Não, nunca fumei.

22.Quanto cigarros você fuma por dia? (Responder em caso afirmativo para a questão anterior)

( ) 1 a 5 cigarros

( ) 6 a 10 cigarros

( ) 11 a 15 cigarros

( ) 20 cigarros ou mais

23.Tem hábito de consumir bebida alcoólica?

( )Sim, bebo. Especifique o tipo e o tempo(em anos)

( ) Não, parei. Há quanto tempo?(em anos)

( ) Não, nunca bebi.

24. Se sim para a questão anterior, com que frequência você ingeri bebidas alcoólicas?

( ) Diariamente

( ) Semanalmente

( ) Mensalmente 


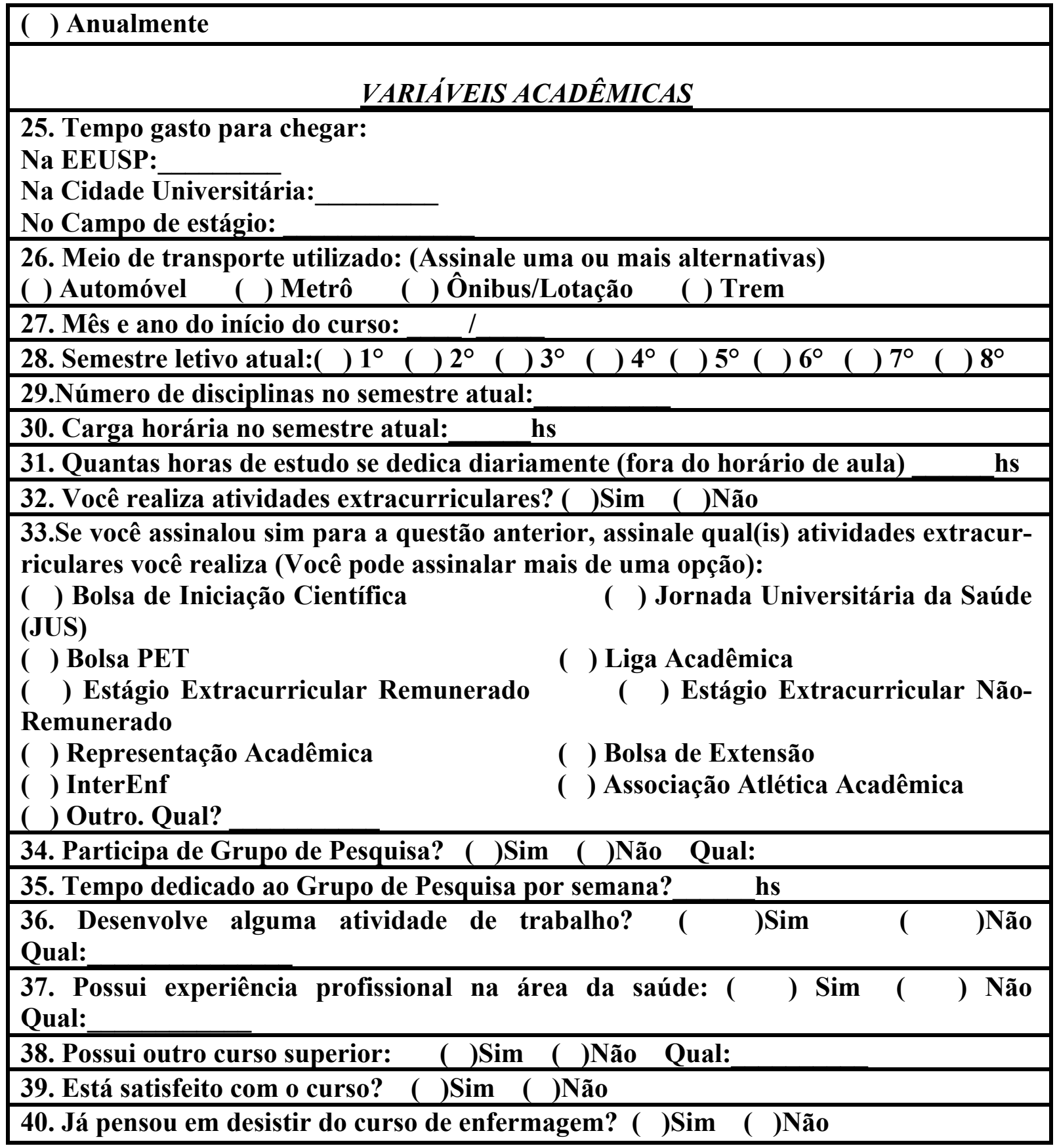




\section{ANEXO 1- INSTRUMENTO PARA AVALIAÇÃO DE ESTRESSE EM DIS- CENTES DE ENFERMAGEM (AEEE)}

Leia atentamente cada item abaixo e marque com um "X" o número correspondente com a intensidade de estresse que a situação lhe provoca, conforme a legenda a seguir:

\begin{tabular}{|c|c|c|c|}
\hline $\mathbf{0}$ & $\mathbf{1}$ & $\mathbf{2}$ & $\mathbf{3}$ \\
\hline $\begin{array}{c}\text { Não vivencio a } \\
\text { situação }\end{array}$ & $\begin{array}{c}\text { Não me sinto es- } \\
\text { tressado com a si- } \\
\text { tuação }\end{array}$ & $\begin{array}{c}\text { Me sinto pouco } \\
\text { estressado com a } \\
\text { situação }\end{array}$ & $\begin{array}{c}\text { Me sinto muito estres- } \\
\text { sado com a situação }\end{array}$ \\
\hline
\end{tabular}

\begin{tabular}{|c|c|c|c|c|c|}
\hline 1 & Ter preocupação com o futuro profissional & ( & 1 & 2 & 3 \\
\hline 2 & A obrigatoriedade em realizar os trabalhos extraclasse & $\mathbf{0}$ & 1 & 2 & 3 \\
\hline 3 & Estar fora do convívio social traz sentimentos de solidão & $\mathbf{0}$ & 1 & 2 & 3 \\
\hline 4 & Realizar os procedimentos assistenciais de modo geral & $\mathbf{0}$ & 1 & 2 & 3 \\
\hline 5 & As novas situações que poderá vivenciar na prática clínica & $\mathbf{0}$ & 1 & 2 & 3 \\
\hline 6 & Comunicação com os demais profissionais da unidade de estágio & $\mathbf{0}$ & 1 & 2 & 3 \\
\hline 7 & O ambiente da unidade clínica de estágio & $\mathbf{0}$ & 1 & 2 & 3 \\
\hline 8 & $\begin{array}{l}\text { Comunicação com os profissionais de outros setores no local de está- } \\
\text { gio }\end{array}$ & $\mathbf{0}$ & 1 & 2 & 3 \\
\hline 9 & Ter medo de cometer erros durante a assistência ao paciente & $\mathbf{0}$ & 1 & 2 & 3 \\
\hline 10 & A forma adotada para avaliar o conteúdo teórico & $\mathbf{0}$ & 1 & 2 & 3 \\
\hline 11 & Distância entre a faculdade e o local de moradia & $\mathbf{0}$ & 1 & 2 & 3 \\
\hline 12 & Executar determinados procedimentos assistenciais & $\mathbf{0}$ & 1 & 2 & 3 \\
\hline 13 & Sentir insegurança ou medo ao fazer as provas teóricas & $\mathbf{0}$ & 1 & 2 & 3 \\
\hline 14 & O grau de dificuldade para a execução dos trabalhos extraclasse & $\mathbf{0}$ & 1 & 2 & 3 \\
\hline 15 & $\begin{array}{l}\text { A semelhança entre as situações que vivencia no estágio e aquelas que } \\
\text { poderá vivenciar na vida profissional }\end{array}$ & $\mathbf{0}$ & 1 & 2 & 3 \\
\hline 16 & $\begin{array}{l}\text { Perceber as dificuldades que envolvem o relacionamento com outros } \\
\text { profissionais da área }\end{array}$ & $\mathbf{0}$ & 1 & 2 & 3 \\
\hline 17 & Pensar nas situações que poderá vivenciar quando for enfermeiro & $\mathbf{0}$ & 1 & 2 & 3 \\
\hline 18 & Tempo reduzido para estar com os familiares & $\mathbf{0}$ & 1 & 2 & 3 \\
\hline 19 & $\begin{array}{l}\text { Perceber a responsabilidade profissional quando está atuando no cam- } \\
\text { po de estágio }\end{array}$ & $\mathbf{0}$ & 1 & 2 & 3 \\
\hline 20 & Observar atitudes conflitantes em outros profissionais & $\mathbf{0}$ & 1 & 2 & 3 \\
\hline 21 & Sentir que adquiriu pouco conhecimento para fazer a prova prática & $\mathbf{0}$ & 1 & 2 & 3 \\
\hline 22 & Transporte público utilizado para chegar à faculdade & $\mathbf{0}$ & 1 & 2 & 3 \\
\hline 23 & Tempo exigido pelo professor para a entrega das atividades extraclasse & $\mathbf{0}$ & 1 & 2 & 3 \\
\hline 24 & Distância entre a maioria dos campos de estágio e o local de moradia & $\mathbf{0}$ & 1 & 2 & 3 \\
\hline 25 & $\begin{array}{l}\text { Vivenciar as atividades, como enfermeiro em formação, no campo de } \\
\text { estágio }\end{array}$ & $\mathbf{0}$ & 1 & 2 & 3 \\
\hline 26 & Faltar tempo para o lazer & $\mathbf{0}$ & 1 & 2 & 3 \\
\hline 27 & $\begin{array}{l}\text { Perceber a relação entre o conhecimento teórico adquirido no curso e o } \\
\text { futuro desempenho profissional }\end{array}$ & $\mathbf{0}$ & 1 & 2 & 3 \\
\hline 28 & Assimilar o conteúdo teórico-prático oferecido em sala de aula & $\mathbf{0}$ & 1 & 2 & 3 \\
\hline 29 & Transporte público utilizado para chegar ao local do estágio & $\mathbf{0}$ & 1 & 2 & 3 \\
\hline 30 & Faltar tempo para momentos de descanso & $\mathbf{0}$ & 1 & 2 & 3 \\
\hline
\end{tabular}


ANEXO 2- CENTER FOR EPIDEMIOLOGIC STUDIES DEPRESSION SCALE (CES-D)

\section{Instruções:}

Segue abaixo uma lista de tipos de sentimentos e comportamentos. Solicitamos que você assinale a frequência com que tenha se sentido dessa maneira durante a semana passada

\begin{tabular}{|l|l|l|l|l|}
\hline & $\begin{array}{c}\text { Raramente } \\
\text { (menos que } \\
\mathbf{1} \text { dia) }\end{array}$ & $\begin{array}{c}\text { Durante } \\
\text { pouco } \\
\text { tempo } \\
\mathbf{1} \text { ou 2 } \\
\text { dias) }\end{array}$ & $\begin{array}{c}\text { Durante } \\
\text { um tem- } \\
\text { po mode- } \\
\text { rado } \\
\text { (de 3 a 4 } \\
\text { dias) }\end{array}$ & $\begin{array}{c}\text { Durante a } \\
\text { maior } \\
\text { parte do } \\
\text { tempo } \\
\text { (de 5 a 7 } \\
\text { dias) }\end{array}$ \\
\hline $\begin{array}{l}\text { 01. Senti-me incomodado com coisas que habitu- } \\
\text { almente não me incomodam }\end{array}$ & & & & \\
\hline 02. Não tive vontade de comer, tive pouco apetite & & & & \\
\hline $\begin{array}{l}\text { 03. Senti não conseguir melhorar meu estado de } \\
\text { ânimo mesmo com a ajuda de familiares e amigos }\end{array}$ & & & & \\
\hline $\begin{array}{l}\text { 04. Senti-me, comparando-me às outras pessoas, } \\
\text { tendo tanto valor quanto a amioria delas }\end{array}$ & & & & \\
\hline $\begin{array}{l}\text { 05. Senti dificuldade em me concentrar no que } \\
\text { estava fazendo }\end{array}$ & & & & \\
\hline 06. Senti-me deprimido & & & & \\
\hline $\begin{array}{l}\text { 07. Senti que tive de fazer esforço para dar conta } \\
\text { das minhas tarefas habituais }\end{array}$ & & & & \\
\hline 08. Senti-me otimista com relação ao futuro & & & & \\
\hline 09. Considerei que a minha vida tinha sido um \\
fracasso
\end{tabular}




\section{ANEXO 3 - ÍNDICE DE QUALIDADE DO SONO DE PITTSBURGH (IQSP)}

1) Durante os meses passados, à que horas você foi deitar à noite na maioria das vezes? HORÁRIO DE DEITAR:

2) Durante o mês passado, quanto tempo (em minutos) você demorou em pegar no sono, na maioria das vezes?

QUANTOS MINUTOS DEMOROU A PEGAR NO SONO:

3) Durante os meses passados, a que horas você acordou de manhã, na maioria das vezes?

HORÁRIO DE ACORDAR:

4) Durante o mês passado, quantas horas de sono por noite você dormiu? (pode ser diferente do número de horas que você ficou na cama)

HORAS DE SONO POR NOITE:

Para cada uma das questões seguinte escolha uma única resposta, que você ache mais correta. Por favor, responda a todas as questões.

5) Durante o mês passado, quantas vezes você teve problemas para dormir por causa de:

a) Demorar mais de 30 minutos para pegar no sono
()nenhuma vez
( )menos de uma vez por semana

( )uma ou duas vezes por semana

( )três vezes por semana ou mais

b) Acordar no meio da noite ou de manhã muito cedo

( )nenhuma vez ( )menos de uma vez por semana

( )uma ou duas vezes por semana ( )três vezes por semana ou mais

c) Levantar-se para ir ao banheiro

()nenhuma vez

( )menos de uma vez por semana

( )uma ou duas vezes por semana ( )três vezes por semana ou mais

d) Ter dificuldade para respirar
( )nenhuma vez
( )menos de uma vez por semana

( )uma ou duas vezes por semana ( )três vezes por semana ou mais

e) Tossir ou roncar muito alto
()nenhuma vez
( )menos de uma vez por semana
( )uma ou duas vezes por semana ( )três vezes por semana ou mais

\section{f) Sentir muito frio}
()nenhuma vez
( )menos de uma vez por semana
( )uma ou duas vezes por semana ( )três vezes por semana ou mais
g) Sentir muito calor
( )nenhuma vez
( )menos de uma vez por semana
( )uma ou duas vezes por semana ( )três vezes por semana ou mais
h)Ter sonhos ruins ou pesadelos 
( )nenhuma vez ()menos de uma vez por semana

( )uma ou duas vezes por semana ()três vezes por semana ou mais

\section{i) Sentir dores}

()nenhuma vez ()menos de uma vez por semana

( )uma ou duas vezes por semana ( )três vezes por semana ou mais

j)Outra razão, por favor, descreva:

Quantas vezes você teve problemas para dormir por esta razão durante o mês passado?

()nenhuma vez ()menos de uma vez por semana

( )uma ou duas vezes por semana ()três vezes por semana ou mais

6) Durante o mês passado, como você classificaria a qualidade do seu sono?

()Muito boa ()Boa ( )ruim ( )muito ruim

7) Durante o mês passado, você tomou algum remédio para dormir, receitado pelo médico, ou indicado por outra pessoa(farmacêutico, amigo, familiar) ou mesmo por sua conta?

( )nenhuma vez ( )menos de uma vez por semana

( )uma ou duas vezes por semana ()três vezes por semana ou mais

Qual(is)?

8) Durante o mês passado, se você teve problemas para ficar acordado enquanto estava dirigindo, fazendo suas refeições ouparticipando de qualquer outra atividade social, quantas vezes isso aconteceu?
( )nenhuma vez
()menos de uma vez por semana
( )uma ou duas vezes por semana
( )três vezes por semana ou mais

9) Durante o mês passado, você sentiu indisposição ou falta de entusiasmo para realizar suas atividades diárias?

( )Nenhuma indisposição nem falta de entusiasmo

( )indisposição e falta de entusiasmo pequenas

( )Indisposição e falta de entusiasmo moderadas

( ) muita indisposição e falta de entusiasmo

Comentários do entrevistado 


\section{ANEXO 4- ESCALA DE RESILIÊNCIA DE WAGNILD \& YOUNG}

\section{Marque o quanto você concorda ou discorda com as seguintes afirmações:}

\begin{tabular}{rcccccc} 
DISCORDO & & \multicolumn{1}{c}{ NEM CON- } & \multicolumn{2}{c}{ CONCORDO } \\
TORDO & & & & \\
CORlmente & Muito & Pouco & $\begin{array}{c}\text { NEM DIS- } \\
\text { CORDO }\end{array}$ & Pouco & Muito & Totalmente
\end{tabular}

1. Quando eu faço planos, eu levo eles até o fim

$1 \quad 2$

\section{4}

5

6

7

2. Eu costumo lidar com os problemas de uma for-

23

4 7 ma ou de outra

3. Eu sou capaz de depender de mim mais do que qualquer outra pessoa.

4. Manter interesse nas coisas é importante para mim.

5. Eu posso estar por minha conta se eu precisar. 1 234567

6. Eu sinto orgulho de ter realizado coisas em minha vida

7. Eu costumo aceitar as coisas sem muita preocupação

8. Eu sou amigo de mim mesmo.

9. Eu sinto que posso lidar com várias coisas ao mesmo tempo

10. Eu sou determinado.

11. Eu raramente penso sobre o objetivo das coisas.

12. Eu faço as coisas um dia de cada vez.

$1 \quad 2$

$$
4
$$

3. Eu posso enfrentar tempos difíceis porque já experimentei dificuldades antes.

14. Eu sou disciplinado.

15. Eu mantenho interesse nas coisas.

16. Eu normalmente posso achar motivo para rir.

17. Minha crença em mim

\section{4}

23

4

7

23

4

23

$$
4
$$

4

5
5

6
6

23

5


mesmo me leva a atravessar tempos difíceis.

18. Em uma emergência, eu sou uma pessoa em quem as pessoas podem contar.

19. Eu posso geralmente olhar uma situação de diversas maneiras.

20. Às vezes eu me obrigo a fazer coisas querendo ou não.

21. Minha vida tem sentido.

22. Eu não insisto em coisas as quais eu não posso fazer nada sobre elas.

23. Quando eu estou numa situação difícil, eu normalmente acho uma saída. 24. Eu tenho energia suficiente para fazer o que eu tenho que fazer.

25. Tudo bem se há pessoas que não gostam de mim.

$\begin{array}{lllllll}1 & 2 & 3 & 4 & 5 & 6 & 7 \\ 1 & 2 & 3 & 4 & 5 & 6 & 7 \\ 1 & 2 & 3 & 4 & 5 & 6 & 7 \\ 1 & 2 & 3 & 4 & 5 & 6 & 7 \\ 1 & 2 & 3 & 4 & 5 & 6 & 7 \\ 1 & 2 & 3 & 4 & 5 & 6 & 7 \\ & 2 & 3 & 4 & 5 & 6 & 7 \\ 1 & 2 & 3 & 4 & 5 & 6 & 7\end{array}$




\section{ANEXO 5- INSTRUMENTO DE AVALIAÇÃO DE QUALIDADE DE VIDA (WHOQOL-BREF)}

\section{Instruções:}

Este questionário é sobre como você se sente a respeito de sua qualidade de vida, saúde e outras áreas de sua vida. Por favor, responda a todas as questões. Se você não tem certeza sobre que resposta dar em uma questão, por favor, escolha entre as alternativas a que lhe parece mais apropriada. Esta, muitas vezes, poderá ser sua primeira escolha. Por favor, tenham em mente seus valores, aspirações, prazeres e preocupações. Nós estamos perguntando o que você acha de sua vida, tomando como referência as duas últimas semanas. Por exemplo, pensando nas últimas duas semanas, uma questão poderia ser:

Você deve circular o número que melhor corresponde ao quanto você recebe dos outros o apoio de que necessita nestas últimas duas semanas. Portanto, você deve circular o número 4 se você recebeu "muito" apoio como abaixo.

Você deve circular o número 1 se você não recebeu "nada" de apoio.

\begin{tabular}{|c|c|c|c|c|c|}
\hline \multirow{3}{*}{$\begin{array}{l}\text { Você recebe dos outros o apoio de que } \\
\text { necessita? }\end{array}$} & Nada & $\begin{array}{l}\text { Muito } \\
\text { pouco }\end{array}$ & Médio & Muito & Completamente \\
\hline & 1 & 2 & 3 & 4 & 5 \\
\hline & Nada & $\begin{array}{l}\text { Muito } \\
\text { pouco }\end{array}$ & Médio & Muito & Completamente \\
\hline $\begin{array}{l}\text { Você recebe dos outros o apoio de } \\
\text { que necessita }\end{array}$ & 1 & 2 & 3 & 4 & 5 \\
\hline
\end{tabular}

Por favor, leia cada questão, veja o que você acha e circule no número e lhe parece a melhor resposta.

$\begin{array}{llcccc}\text { Muito } & \text { Ruim } & \begin{array}{l}\text { Nem ruim } \\ \text { nem boa }\end{array} & \text { Boa } & \text { Muito boa } \\ 1 \text { Como você avaliaria sua qua- } & 1 & 2 & 3 & 4 & 5 \\ \text { lidade de vida? } & & & & \end{array}$

$\begin{array}{lllcccc} & \begin{array}{l}\text { Muito } \\ \text { insatis- } \\ \text { feito }\end{array} & \begin{array}{l}\text { Insatisfei- } \\ \text { to }\end{array} & \begin{array}{l}\text { Insatisfei- } \\ \text { to nem } \\ \text { satisfeito }\end{array} & \begin{array}{l}\text { Satis- } \\ \text { feito }\end{array} & \begin{array}{l}\text { Satisfeito } \\ \text { muito }\end{array} \\ 2 \text { Quão satisfeito (a) } & 1 & 2 & 3 & 4 & 5 \\ \text { você está com a sua } & & & & & & \\ \text { saúde? }\end{array}$

As questões seguintes são sobre o quanto você tem sentido algumas coisas nas últimas duas semanas.

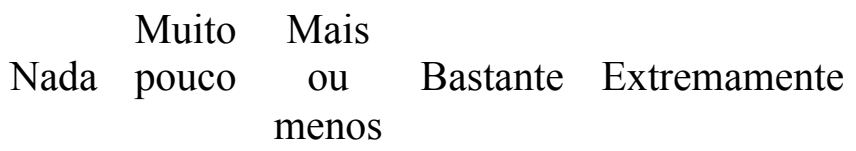

3 Em que medida você acha que sua dor (física) impede você de fazer o que você precisa? 4 algum tratamento médico para levar sua vida diária?

$\begin{array}{lllll}1 & 2 & 3 & 4 & 5 \\ 1 & 2 & 3 & 4 & 5\end{array}$




\begin{tabular}{|c|c|c|c|c|}
\hline $\begin{array}{l}\text { O quanto você aproveita a } \\
\text { vida? }\end{array}$ & 1 & 2 & 3 & 4 \\
\hline $\begin{array}{l}\text { Em que medida você acha } \\
\text { que a sua vida tem sentido? }\end{array}$ & 1 & 2 & 3 & 4 \\
\hline $\begin{array}{l}\text { O quanto você consegue se } \\
\text { concentrar? }\end{array}$ & 1 & 2 & 3 & 4 \\
\hline $\begin{array}{l}\text { Quão seguro (a) você se } \\
\text { sente em sua vida diária? }\end{array}$ & 1 & 2 & 3 & 4 \\
\hline $\begin{array}{l}\text { Quão saudável é o seu am- } \\
\text { biente físico (clima, barulho, } \\
\text { poluição, atrativos)? }\end{array}$ & 1 & 2 & 3 & 4 \\
\hline
\end{tabular}

As questões seguintes perguntam sobre quão completamente você tem sentido ou é capaz de fazer certas coisas nestas últimas duas semanas.

10 Você tem energia suficiente Mada
pouco para seu dia-a-dia? Você tem energia suficiente para seu diaa-dia?

11 Você é capaz de aceitar sua aparência física?

12 Você tem dinheiro suficiente para satisfazer suas necessidades?

13 Quão disponíveis para você estão às informações que precisa no seu dia-a-dia?

14 Em que medida você tem oportunidades de atividade de lazer?

15 Quão bem você é capaz de se locomover?

$\begin{array}{lllll}1 & 2 & 3 & 4 & 5 \\ 1 & 2 & 3 & 4 & 5 \\ 1 & 2 & 3 & 4 & 5 \\ 1 & 2 & 3 & 4 & 5 \\ 1 & 2 & 3 & 4 & 5 \\ 1 & 2 & 3 & 4 & 5\end{array}$

As questões seguintes perguntam sobre quão bem ou satisfeito você se sentiu a respeito de vários aspectos de sua vida nas últimas duas semanas.

\begin{tabular}{|c|c|c|c|c|c|c|}
\hline & & $\begin{array}{l}\text { Muito } \\
\text { Insatisfeito }\end{array}$ & $\begin{array}{l}\text { Insatisfei- } \\
\text { to }\end{array}$ & $\begin{array}{l}\text { Nem insatis- } \\
\text { feito nem } \\
\text { satisfeito }\end{array}$ & Satisfeito & $\begin{array}{c}\text { Muito } \\
\text { Satisfeito }\end{array}$ \\
\hline 16 & $\begin{array}{l}\text { Quão satisfeito (a) } \\
\text { você está com o seu } \\
\text { sono? }\end{array}$ & 1 & 2 & 3 & 4 & 5 \\
\hline 17 & $\begin{array}{l}\text { Quão satisfeito (a) } \\
\text { você está com sua } \\
\text { capacidade de de- } \\
\text { sempenhar as ativi- } \\
\text { dades do seu dia-a- } \\
\text { dia? }\end{array}$ & 1 & 2 & 3 & 4 & 5 \\
\hline
\end{tabular}


18 Quão satisfeito (a) você está com sua capacidade para trabalho?

19 Quão satisfeito (a) você está consigo mesmo?

20 Quão satisfeito (a) você está com suas relações pessoais (amigos, parentes, conhecidos, colegas)?

21 Quão satisfeito (a) você está com sua vida sexual?

Quão satisfeito (a)

22 você está com o apoio que você recebe de seus amigos?

23 Quão satisfeito (a) você está com as condições do local onde mora?

24 Quão satisfeito (a) você está com o seu acesso aos serviços de saúde?

25 Quão satisfeito (a) você está com o seu meio de transporte?

$$
1
$$

2

3

4

5

)

1

23

4

5

a)

2

3

4

5

-

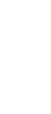

a)

as

$\begin{array}{lllll} & 2 & 3 & 4 & 5\end{array}$

$\begin{array}{lllll}1 & 2 & 3 & 4 & 5\end{array}$

As questões seguintes referem-se à com que frequência você sentiu ou experimentou certas coisas nas últimas semanas.

Nunca $\begin{gathered}\text { Algumas } \\ \text { vezes }\end{gathered} \quad$ Frequente $\begin{gathered}\text { Muito Sempre } \\ \text { frequente }\end{gathered}$

Com que frequência você tem sentimentos negati-

26 vos tais como mau hu-

$\begin{array}{lllll}1 & 2 & 3 & 4 & 5\end{array}$
mor, desespero, ansiedade, depressão?

Alguém lhe ajudou a preencher este questionário?. Quanto tempo você levou para preencher este questionário?.

Você tem algum comentário sobre o questionário?

OBRIGADO PELA COLABORAÇÃO 